\title{
Unfamiliar Oxidation States and Their Stabilization
}

\author{
by \\ Jacob Kleinberg \\ Associate Professor of Chemistry \\ University of Kansas
}

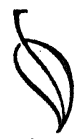

UNIVERSITY OF KANSAS PRESS, LAWRENCE - 1950 
Copyrtght, 1950, by the Untversity of Kansas Press

AIL RIGHTS RESERVED

PRINTED IN THE U.S.A. BY THE UNIVERSITY OF KANSAS PRESS LAWRENCE, RANSAS 
TO THE MEMORY OF MY MOTHER 


\section{Preface}

HE present work owes its origin to the author's early interest in the metallic characteristics of io1 dine, specifically as manifested in amine-stabilized coördination compounds in which this element is present in the unipositive state. After this rather restricted concern with a single element had broadened to include the preparation, characterization, and stabilization of compounds of the familiar elements in unfamiliar oxidation states, it occurred to the author that this subject might be of sufficient general interest to warrant treatment in monograph form.

Undoubtedly, some readers will deplore the absence of certain topics, equally worthy of discussion with those which have been included. However, the author feels that he need offer no apology for treating only those elements which he has found to be of greatest interest. His aim has been to make the treatment, so far as possible, both exhaustive and critical, and it is hoped that a thorough discussion of relatively few elements will be suggestive for the whole general field of unfamiliar oxidation states.

The author is greatly indebted to Professors John C. Bailar, Jr. and Arthur W. Davidson for their encouragement and advice during the preparation of the manuscript. In addition, both of these gentlemen read critically the finished product, and a great deal of whatever merit, scientific or literary, the monograph may possess, should be attributed to their contribution.

The author wishes also to express his thanks to Professor $\mathrm{H}$. A. Laitinen for valuable suggestions concerning the first draft of the manuscript, to the Graduate Research 
Committee of the University of Kansas for a grant to aid in the satisfactory completion of the writing, and to the Editor of the Journal of the American Chemical Society for permission to reproduce certain illustrations from that publication.

University of Kansas,

JACOB KLeinberg.

September 28, 1949. 


\section{Contents}

PAGE

I. INTRODUCTION

II. Low Oxidation States of the Elements of THE Aluminum Group - $\quad$ - $\quad$ - $\quad 16$

III. Oxygen: the Superoxides of the Alkali and Alraline Earth Metals - $\quad$ - $\quad$ - 25

IV. The Halogens $\quad$ - $\quad$ - $\quad$ - $\quad$ - $\quad$ - $\quad$ - 37

V. Copper and Silver $\quad$ - $\quad$ - $\quad$ - $\quad$ - 50

VI. Chromium and Manganese - $\quad$ - $\quad$ - 74

VII. Iron, Сobalt, AND NrCKel - - - - - 85

VIII. The "Rare-EARths" - - - $\quad$ - 101

IX. Miscerlaneous - - $\quad$ - $\quad$ - 115

REFERENCES - $\quad$ - $\quad$ - $\quad$ - $\quad$ - $\quad 121$

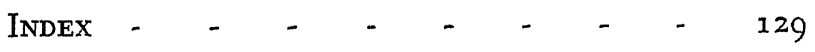




\section{I \\ Introduction}

$\mathrm{D}$ URING the last years of the nineteenth and the first quarter of the twentieth century, the spectacular achievements of organic chemistry served to divert attention from the study of inorganic compounds, a field which indeed began to be regarded by many as no longer likely to be fruitful. In recent years, however, because of our increased understanding of atomic structure and, perhaps, especially because of the dramatic advent of nuclear fission, the earlier trend has been reversed and we are witnessing a renaissance of interest in inorganic chemistry. The demands of the atomic-energy program have stimulated research into the properties of practically every element. An outstanding phase of recent investigations has been the preparation and characterization of unfamiliar, i.e., little-known, oxidation states of well-known elements.

There are many open questions in the chemistry of even the more familiar elements. A careful examination of the literature shows that, whereas the little-known oxidation states of many of these elements have been only superficially studied, there is a vast quantity of information exceedingly useful and potentially valuable to the inorganic chemist. This book has as its purpose the critical survey of the unfamiliar or little-known oxidation states of well-known elements. This survey is limited to cases where the groups bonded to the element in question have definite, generally accepted oxidation numbers in the compound; the carbonyls and nitrosyls are, therefore, 
excluded from consideration. Also, oxidation states existing only at high temperatures are not included.

It should be mentioned at the outset that the concept of oxidation state or oxidation number is often, particularly in the case of covalent compounds, a purely arbitrary one. For simple ions the oxidation state, it is true, does correspond to the number of unit electrical charges on the ion; in this instance, therefore, the terms oxidation state and valence are synonymous. The concept, however, frequently loses its objectivity in the case of covalent compounds. For example, in the extreme instance of the compounds of carbon, in which this element exhibits a constant covalence of four, application of the oxidation-state idea often leads to values for carbon which, particularly for the organic chemist, might be said to be almost entirely devoid of chemical significance. With metals, on the other hand, where constancy of covalence is relatively uncommon, the oxidation-state concept ordinarily possesses a true chemical meaning in the sense that conversion to well-defined lower or higher oxidation states involves reaction with definite quantities of substances which are generally recognized as reducing or oxidizing agents, respectively. This is illustrated by the following equation:

$$
\mathrm{MnO}_{4}^{-}+8 \mathrm{H}^{+}+5 \mathrm{e}^{-}={ }_{4} \mathrm{H}_{2} \mathrm{O}+\mathrm{Mn}^{+2} .
$$

Since, according to generally accepted convention, hydrogen is regarded as undergoing no change in oxidation state in the transition from hydrogen ion to water, it follows that manganese in the permanganate ion must exhibit an oxidation state of +7 , five equivalents of reducing agent being required to convert it to the manganese(II) ion. The following discussion attempts to limit 
the use of the oxidation-state concept to cases where in the terms just described, it is of true chemical significance.

\section{The Importance of the Study of Unfamiliar Oxidation States}

In addition to suggesting numerous problems worthy of research, acquaintance with the chemistry of unfamiliar oxidation states clarifies and extends many periodic relationships, and also adds greatly to our knowledge of factors which influence the stabilization of oxidation states in general. These points are expanded in some detail below.

An examination of the chemistry of the aluminum group (i.e., aluminum, gallium, indium, and thallium) emphasizes the fact that important periodic relationships have not yet been realized, perhaps because most of the work with these elements has been done either in the dry state or in water as a solvent. Uni-and tripositive states of thallium are well known and there is evidence for unipositive gallium and indium, ${ }^{1}$ while the existence of the dipositive state for these elements is open to question." The data from a few scattered experiments on the anodic oxidation of aluminum in various solvents ${ }^{3}$ may best be explained on the assumption that the metal goes into solution in an oxidation state lower than three. Striking proof that aluminum, gallium, and indium, when anodically oxidized in anhydrous acetic acid, enter solution in lower oxidation states is offered by some recent work. ${ }^{4}$ Much remains to be done with this group of elements, particularly in nonaqueous solvents.

Research on the unfamiliar oxidation states of the copper group has brought into much clearer focus the great similarity of these elements, particularly of copper 
and silver, in their higher states. Compounds containing the elements in each oxidation state from +1 to +3 for this group, with the exception of +2 gold, are now well known. Most of the known compounds of dipositive silver and of tripositive copper and silver are complex in nature.

The preparation of element 85 , astatine, by the bombardment of bismuth of mass 209 with 32 m.e.v. alpha particles, and the subsequent observations on its chemical properties, ${ }^{5}$ have brought to light some interesting relationships within the halogen family. The behavior of astatine, in many of its reactions, is that of a typical metal; for example, hydrogen sulfide precipitates element 85 quantitatively as sulfide in hydrochloric acid solution up to 6 normal. At first glance, this is extremely surprising, but it appears less so when it is realized that iodine, the element above 85 in the family, also possesses some metallic characteristics. Compounds in which unipositive iodine is stabilized by coördination with organic amines will be discussed in detail later. The behavior of astatine is also in line with the increased metallic character of the elements in a given group with increasing atomic number from carbon to lead, nitrogen to bismuth, and oxygen to polonium.

Investigations in the field of unfamiliar oxidation numbers have added considerably to our information concerning the general problem of the stabilization of oxidation or valence states. The term, stabilization of valence states, is used in the chemical literature in two ways: (1) stabilization with respect to oxidation or reduction or both, an effect which may be expressed in terms of changes in oxidation-reduction potentials, ${ }^{6}$ and (2) the preparation of the desired state of the element under conditions which 
permit either its isolation and study, or its examination in solution.

The following observations are pertinent:

(1) Higher oxidation states are frequently formed and stabilized in alkaline solution. This is not surprising in view of the increasing acid character of oxides with increasing oxidation state of the central atom. Numerous investigators have shown that the anodic oxidation of iron in concentrated alkali converts iron to the +6 ferrate state, ${ }^{7}$ and that increasing alkali concentration favors ferrate formation. Oxidation of copper(II) hydroxide in alkaline solution with sodium hydroperoxide, $\mathrm{Na} . \mathrm{OOH}$, apparently gives copper(III) oxide. ${ }^{8}$ Determination of the voltage-current curve for a silver anode in sodium hydroxide solution gives breaks corresponding to the formation of $\mathrm{Ag}_{2} \mathrm{O}$ and $\mathrm{AgO}{ }^{9}$

(2) Negative groups containing a central atom of high oxidation number have been found to stabilize high oxidation states. Complex molybdates of cobalt(IV) and nickel (IV) of the formulas $3 \mathrm{~K}_{2} \mathrm{O} . \mathrm{CoO}_{2} \cdot 9 \mathrm{MoO}_{3} \cdot 6 \frac{1}{2} \mathrm{H}_{2} \mathrm{O}$ and ${ }_{3} \mathrm{BaO} . \mathrm{NiO}_{2} .9 \mathrm{MoO}_{3} .12 \mathrm{H}_{2} \mathrm{O}$ have been characterized. ${ }^{10}$ The periodate and tellurate groups have been frequently used for this purpose. Tripositive copper and silver complexes containing these groups as stabilizers have been prepared. ${ }^{11}$ It is interesting in this connection to note that all of these compounds are obtained in an alkaline medium. It has been claimed that tetrapositive nickel has been made in the form of an alkali nickel periodate. ${ }^{12}$ Evidence has been presented which indicates that the dipositive silver formed when silver nitrate in nitric acid solution is treated with ozone, exists in the form of nitrate complexes. ${ }^{13}$ 
(3) Lower oxidation states have been stabilized by means of groups, or in solvents, which possess reducing properties. Complexes of dipositive chromium with hydrazine are extremely stable in air; in fact, some of the compounds are not oxidized even when suspended in water and stirred with air. The stability of these complex compounds has been attributed to the reducing properties of hydrazine. ${ }^{14}$ Undoubtedly, however, the stability of the hydrazine complexes is in part to be accounted for by their insolubility in water.

The importance of the role of the solvent is clearly demonstrated by the fact that it is possible to isolate and study complex cyanides of nickel $(\mathrm{O})$, nickel $(\mathrm{I}),{ }^{15}$ and palladium $(\mathrm{O})^{16}$ by the reduction in liquid ammonia of cyanides containing the metals in higher oxidation number. Aqueous solutions of the complex cyanide of nickel(I) have been obtained also, but they are rather unstable, partly because of the oxidizing action of water. No evidence, however, has been obtained for the more powerfully reducing nickel $(\mathrm{O})$ or for palladium $(\mathrm{O})$ in aqueous solution.

(4) The suggestion has been made that the complex cyanide ions, $\mathrm{Ni}(\mathrm{CN})_{4}^{-4}$ and $\mathrm{Ni}(\mathrm{CN})_{3}{ }^{-2}$, containing zero- and unipositive nickel respectively, resonate between double-bonded and single-bonded structures. ${ }^{17}$ Such resonance would contribute to the stability of these ions.

(5) Actual or near attainment of certain electronic configurations enhances the stability of many oxidation states. With regard to comparatively little-known states, this is exemplified in the case of the "anomalous" valences of the "rare-earths." It has been proposed that an $f$ subshell is most stable when it has 0,7 , or 14 electrons. ${ }^{18}$ 
This explains the stability of the $\mathrm{Ce}^{+4}, \mathrm{Eu}^{+2}, \mathrm{~Tb}^{+4}$, and $\mathrm{Yb}^{+2}$ ions. Tetrapositive cerium possesses no $4 f$ electrons. In the cases of dipositive europium and tetrapositive terbium, the ions have a half-completed 4 subshell, whereas +2 ytterbium has this subshell filled. The same hypothesis also provides a reasonable explanation for the existence of $\mathrm{Sm}^{+2}\left({ }_{4} \mathrm{f}^{6}\right)$ and its lesser stability as compared to dipositive europium. Similar considerations are pertinent to a discussion of +4 and +5 praseodymium.

They account also for the transition in preferred oxidation state from +6 for uranium to +3 for americium and curium. ${ }^{19}$ Apparently, there is an increase in the stability of the $5 f$ subshell as it approaches a half-filled condition. Curium, which probably has seven $5 f$ electrons, appears to exhibit an oxidation state of +3 only. Presumably, the half-completed subshell does not participate in chemical combination.

(6) The solubility of the substance of desired oxidation state frequently is a factor in its stabilization. The probability that the stability of the hydrazine complexes of dipositive chromium may be attributed in part to their insolubility has been mentioned. There are numerous other examples of the contribution of insolubility to stabilization, of which only a few will be given. The preparation of copper(III) oxide by oxidation of copper(II) hydroxide in strongly alkaline solution ${ }^{8}$ is undoubtedly favored by the insolubility of the product. The relationship of structure to the stability of dipositive europium has been discussed, but there is no question that the stability of europium(II) sulfate is further enhanced by its insolubility in water, the medium in which it is prepared.

(7) Both crystal structure and oxidation state in one compound may play important roles in promoting the 
formation of a certain oxidation state in a second compound. Although this phenomenon appears to be rather general, only two instances will be cited here.

Cerium(IV) oxide markedly catalyzes the formation of $\mathrm{PrO}_{2}$ when praseodymium (III) oxide is heated in high concentrations of pure oxygen. ${ }^{20}$ In fact, it has been claimed that the catalytic effect of small amounts of ceria has been responsible for the contradictory results obtained in the study of the higher oxides of praseodymium.

Attempts to precipitate low concentrations of manganese dioxide on $\gamma$-alumina, by heating a solution of manganese(II) nitrate on the latter, result in the conversion of the manganese to the sesquioxide only. In order to obtain conversion to manganese dioxide it is necessary to support the manganese on a high area rutile, $\mathrm{TiO}_{2}$. This phenomenon has been named valence inductivity. ${ }^{21}$

(8) Specific instances of stabilization of unfamiliar states by coördination have already been cited. There is, however, one phase of stabilization by coördination which is worthy of special emphasis. Molecules or ions capable of chelation, i.e., of occupying two or more coördinating positions and forming rings (preferably five- or six-membered rings), in general yield more stable compounds than coördinating groups occupying single positions. Numerous examples of the stabilizing effect of chelation will be offered in their appropriate places.

Of particular interest, at this point, is a report of recent work ${ }^{22}$ which has implications that may be of general utility in stabilizing low (and perhaps high) oxidation states. It was demonstrated that the oxidation state of cobalt in complexes with azo and azomethine dyes depends upon the nature of the dye molecule. The critical factors determining the oxidation state of the cobalt are 
the number of replaceable hydrogen atoms in the positions ortho to the azo or azomethine group and also the total number of positions available for coördination.

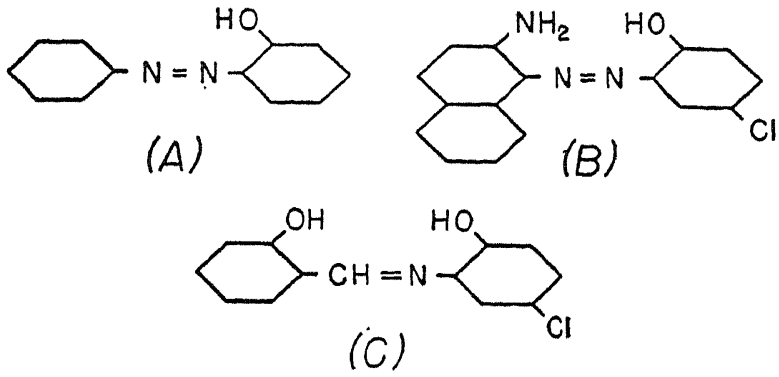

For example, the metal is found to be in the +3 state in the complex with dye $\mathrm{A}$, which contains one replaceable hydrogen; since there are only two coördination positions available for binding, three dye residues are necessary to give the cobalt a coördination number of six. On the other hand, dye $B$, which also possesses one replaceable hydrogen, fills three coördination positions, and only two molecules of dye are necessary for attainment of coördination number six; thus, +2 cobalt is stabilized. Dye $\mathrm{C}$, with two replaceable hydrogens, also stabilizes the +2 state. In this case, the complex contains only one dye residue, water molecules within the coördination sphere bringing the cobalt to its appropriate coördination number. It would be of extreme interest to determine how generally applicable are these ideas which have been so successfully applied to cobalt.

Methods for Characterizing Unfamiliar Statis

Unfamiliar oxidation states have been characterized principally by four types of evidence: (1) analytical data and chemical properties; $(2)$ isomorphism with compounds containing atoms of known oxidation state; (3) 
magnetic susceptibility measurements; and (4) X-ray studies. In some instances a combination of two or more of these has been necessary for the complete characterization of the oxidation state in question.

Analytical data, in conjunction with a study of the chemical properties of the substance, frequently give sufficient information for the determination of oxidation state. The necessity of a knowledge of the chemical properties of the substance in question is made apparent by the following illustration: a compound containing silver and oxygen in equal atomic proportions may be made by the oxidation of unipositive silver with persulfate in alkaline medium..$^{23}$ Analysis obviously indicates the formation of either silver(II) oxide or silver peroxide. The latter possibility, however, is eliminated by the fact that acidification of the compound gives no hydrogen peroxide.

Occasionally, it may be demonstrated that an atom possesses a specific oxidation state by proving that the compound in which it occurs is isomorphous with a known substance. Oxidation of a mixture of silver and cadmium salts with persulfate in the presence of pyridine yields mixed crystals of complexes with pyridine, proving that the silver and cadmium compounds are isomorphous and hence that the silver is dipositive. ${ }^{24} \mathrm{~A}$ particularly interesting illustration concerns the formation of ammonium cobalt(III) alum by the electrolytic oxidation of cobalt(II) sulfate in the presence of ammonium sulfate. ${ }^{25}$ Identification was made both by analysis and by the alumlike crystal structure of the material. In the absence of ammonium sulfate, no cobalt(III) compound is found.* The formation of this alum apparently involves the sta-

* Swann and Xanthakos (J. Am. Soc., 53, 400 [1931]) have been able to obtain cobalt(III) sulfate by the anodic oxidation of cobalt(II) sulfate in $10 \mathrm{~N}$ sulfuric acid. 
bilization of an unusual valence state by the attainment of a stable crystal lattice.

Magnetic susceptibility measurements very often give definite information concerning oxidation states and the nature of their chemical binding. Two instances in which such data have been utilized to prove structure are described below. A series of salts in which ethylenedibiguanide is coördinated to tripositive silver has been prepared. Tripositive silver and dipositive palladium have the same electronic configuration and the complexes of the former would be expected to be diamagnetic, as are those of the latter, provided the coördination bonds are of the planar, hybrid $d s p^{2}$ type. Magnetic measurements prove that this is the case. ${ }^{26}$ Such measurements have also proved that dipositive europium and tripositive gadolinium are isoelectronic, the magnetic susceptibilities of the two ions being nearly equal, and any other possibility being excluded by the low value obtained for $\Delta$, the molecular field constant in the Curie-Weiss law, $x_{m}=C / T+\Delta .^{27}$

The results of X-ray studies are often of prime importance for the positive characterization of compounds containing atoms in unfamiliar oxidation states. The problem of the determination of the correct structure of the superoxide ion is a case in point. Magnetic measurements on superoxides give values corresponding to the presence of one unpaired electron in the superoxide ion, and thereby indicating the structure :O:: .Q::- ${ }^{28}$ Powder photographs of potassium superoxide show that this substance possesses a face-centered lattice of the calcium carbide type. The structure is analogous to that of strontium and barium peroxides, thus confirming the existence of the $\mathrm{O}_{2}{ }^{-}$structure. ${ }^{29}$ Moreover, the value of $1.28 \pm 0.07 \AA$ for the distance between adjacent oxygen nuclẹi is in satis- 
factory agreement with that expected for a single bond plus a three-electron bond. ${ }^{30}$

General Methods for the Preparation of Unfamiliar Oxidation States of the Metals

Four general methods have been successfully used for the production of high oxidation states of well-known metals. They involve oxidation of lower states (1) with persulfate, (2) with ozone, (3) with fluorine, and (4) anodically.

The persulfate ion, frequently in alkaline solution, is one of the most widely used oxidizing agents. A few examples are cited. Treatment of cobalt(II) sulfate in ammoniacal solution with hydrogen peroxide and ammonium persulfate gives rise to a complex ion of the formula $\left[\left(\mathrm{NH}_{3}\right)_{5} \mathrm{CoO}_{2} \mathrm{Co}\left(\mathrm{NH}_{3}\right)_{5}\right]^{+5} .{ }^{31}$ Proof that this ion contains both tri- and tetrapositive cobalt will be considered in the section devoted to the unfamiliar oxidation states of iron, cobalt, and nickel. Oxidation of nickel(II) and cobalt(II) sulfates with ammonium persulfate in the presence of ammonium molybdate yields the previously mentioned complex molybdates of the corresponding tetrapositive ions. ${ }^{10}$ The use of the periodate and tellurate radicals for the stabilization of tripositive copper and silver has already been mentioned. ${ }^{11}$ Oxidation to the tripositive state in compounds containing these groups may be accomplished, in each case, by means of potassium persulfate in alkaline solution.

The anodic oxidation, under appropriate conditions, either of free metals or of ions in lower states, has served for the preparation of higher oxidation states. Reference has already been made to the formation of the ferrate ion, $\mathrm{FeO}_{4}^{-2}$, and of Ago, by the electrolytic oxidation of 
the respective metals in concentrated alkali." ${ }^{7} 9$ A method has been described for the preparation and isolation of cobalt(III) sulfate at the anode in an electrolyte consisting of the dipositive salt in $10 \mathrm{~N}$ sulfuric acid. ${ }^{32}$ A reaction which has been extensively investigated involves the electrolysis of a solution of silver nitrate in nitric acid. This reaction yields at an inert anode a black material to which several investigators have assigned the formula $\mathrm{Ag}_{7} \mathrm{NO}_{11}$. This substance unquestionably contains some silver in the tripositive form..$^{33}$ Other investigations which are concerned with the formation of higher oxidation states by anodic oxidation will be described in some detail in their appropriate places.

The potentialities of ozone and fluorine as oxidizing agents for the study of higher states have scarcely been tested. Ozone acts on a cold solution of a nickel(II) salt dissolved in sodium bicarbonate to give a red solution from which, it is claimed, nickel(IV) oxide may be obtained. ${ }^{34}$ This claim, which is not supported with quantitative data, deserves further study. The action of ozone on silver nitrate in concentrated nitric acid has been exhaustively studied by Noyes and co-workers, who have demonstrated that dipositive silver is formed in this reaction. ${ }^{35}$ Evidence is available which indicates that dry ozone may react with powdered silver to form silver(III) oxide. $^{36}$ Very few reactions involving direct oxidation by fluorine to give higher states have been described. When fluorine reacts with cobalt (II) chloride, at $150^{\circ} \mathrm{C}$. in a quartz vessel, the tripositive fluoride is formed..$^{37}$ The difluoride of silver is formed by the action of fluorine on silver and silver halides. ${ }^{38}$

Low oxidation states have been obtained either by the reduction of higher states or by the anodic oxidation 
of free metals in various solvents. The latter method has already been referred to in connection with the anodic dissolution of aluminum, gallium, and indium in oxidation states lower than three. ${ }^{3,4}$ In this respect it is noteworthy that no compounds containing these elements in low oxidation states have actually been isolated in this manner.

The reduction of higher oxidation states has been accomplished (1) by means of hydrogen at elevated temperatures, (2) cathodically, (3) by means of active metals in aqueous and nonaqueous media, and (4) by thermal decomposition. Representative illustrations are given below.

The reaction of hydrogen with chromium(III) chloride at elevated temperatures gives the corresponding dipositive salt. ${ }^{39}$ Similarly, reduction of the trihalides of samarium, europium, and ytterbium yields the dipositive compounds. ${ }^{40}$ Electrolytic reduction of tripositive europium and ytterbium is also effective for the formation of the dipositive materials. ${ }^{41}$

The use of active metals as agents for reduction appears to be of rather general applicability. A few interesting examples are described. The cyano complexes of $\operatorname{nickel}(\mathrm{O})$, $\operatorname{nickel}(\mathrm{I})$, and palladium $(\mathrm{O})$ have been mentioned. ${ }^{15,16}$ These compounds are obtained by the reduction, with potassium in liquid ammonia, of complex cyanides containing the respective elements in their dipositive states. Used in a Jones reductor, zinc has found some application in the production of low valence states; particularly intriguing is the reduction of the perrhenate ion to uninegative rhenium. ${ }^{42}$

The thermal decomposition of certain tripositive rare earth halides serves as a means of preparing the dihalides. 
The products of the thermal decomposition of the triiodide and bromide of samarium at $800-900^{\circ}$ in a high vacuum are the dihalides and the corresponding free halogens. ${ }^{43}$ Halides of dipositive ytterbium are prepared in a similar manner. ${ }^{44}$ 


\section{II}

\section{Low Oxidation States of the Elements of the Aluminum Group}

LTHOUGH the existence of multiple oxidation
states is a common phenomenon among transition
elements, it is usually regarded as somewhat anomalous among elements (at least among metals) in whose atoms the next to the outermost electronic shell has attained a stable configuration (i.e., "regular" elements). Thus no compounds are known in which an alkali metal exhibits an oxidation number other than +1 , or an alkaline earth metal an oxidation number other than +2 . Even within the ranks of the "regular" elements, however, the existence of compounds illustrating oxidation states lower than the one ordinarily regarded as typical may be very clearly illustrated by consideration of the aluminum group.

Outside of the alkali and alkaline earth groups, the metal best known for its constancy of oxidation number is aluminum. Nevertheless, since aluminum is a member of the same group as gallium, indium, and thallium, it might be supposed that the same factors which make it possible for the latter elements to assume more than one oxidation state may not be entirely inoperative in the case of aluminum. The well-known ability of thallium to form compounds in which it possesses an oxidation state of +1 as well as those in which it is in the +3 state is generally attributed to the difference in the ease of removal of $s$ and $p$ electrons in the same shell. Compounds 
in which gallium and indium apparently exhibit an oxidation number of $t_{1}$ or +2 , although less familiar than those of unipositive thallium, are not unknown. To state the matter more precisely, there seems little doubt that these elements may exist in the former state; the evidence for the latter is, however, open to question. There are to be found in the literature several references, not entirely unsupported by experimental evidence, to the probable existence of an oxidation state of aluminum lower than +3 , and additional data unmistakably pointing in this direction have recently been obtained in our own laboratory. The detailed consideration of unfamiliar oxidation states of well-known elements, then, may conveniently be started with a discussion of the aluminum group.

\section{Compounds of Gallium and Indium}

Halides whose empirical formulas correspond to the uni- and dipositive states have been made for gallium and indium. $\mathrm{GaCl}_{2}$ has been prepared by heating the trichloride in a tube at $175^{\circ}$ with an excess of gallium, and purified by sublimation in vacuo. ${ }^{1}$ The dichloride is a colorless, crystalline substance which melts at $170.5^{\circ}$ and slowly reacts with water to liberate hydrogen. Above $200^{\circ}$ it disproportionates into the metal and the trichloride. Vapor density measurements between $400^{\circ}$ and $470^{\circ}$ show that some $\mathrm{GaCl}_{2}$ "molecules" are present, but there is no indication of the presence of monochloride. ${ }^{1 \mathrm{c}} \mathrm{Re}$ duction of indium(III) fluoride with hydrogen at an elevated temperature yields the hygroscopic $\operatorname{InF}_{2}{ }^{2}{ }^{2}$ The action of dry hydrogen chloride on indium at its melting point has served for the preparation of $\mathrm{InCl}_{2}$. This substance decomposes in water to give the metal and the trihalide. Reduction of $\mathrm{InCl}_{2}$ by indium gives the mono- 
chloride, ${ }^{1 \mathrm{a}, 3}$ a light-sensitive substance which exists in two different modifications, one red and the other yellow. ${ }^{3}$ A phase study of the indium-iodine system shows the existence of a substance of the formula $\operatorname{InI}_{2}{ }^{4}$ (Fig. 1); decomposition prevents the isolation of this substance. The monoiodide may be prepared by the high temperature reaction of iodine with an excess of the metal in a carbon dioxide atmosphere. ${ }^{4}$ This substance liberates hydrogen from dilute acids.

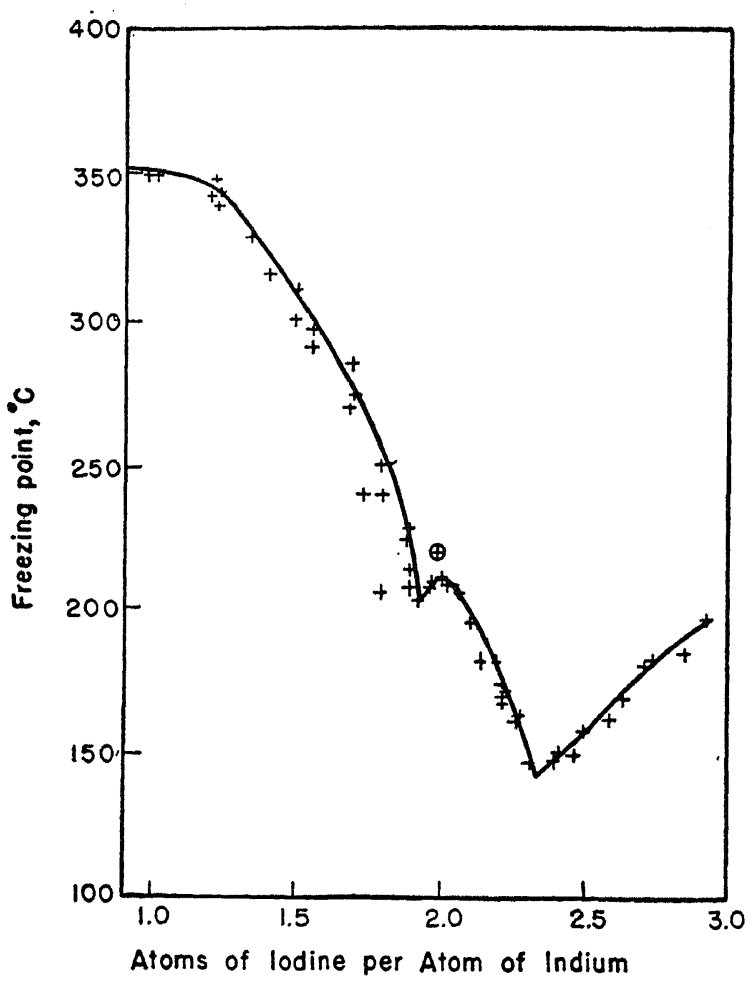

Frg. 1.-Phase Study of the Indium-Iodine System. 
The contention that the dichlorides of gallium and indium contain these elements in dipositive states appears to be of questionable validity. Magnetic susceptibility measurements on the dichloride of gallium and indium, ${ }^{5}$ and on the difluoride of the latter, ${ }^{2}$ show that they are diamagnetic, whereas true dihalides would have a paramagnetism corresponding to one unpaired electron. It has been suggested ${ }^{6}$ that the dihalides are actually autocomplexes of the formula $\mathrm{M}^{\mathrm{I}}\left[\mathrm{M}^{\mathrm{III}} \mathrm{X}_{4}\right]$. A structure of this type would account for the diamagnetism of the dihalides in the solid state.

Gallium(I) oxide has been made by heating together in a high vacuum the calculated quantities of the sesquioxide and the metal. ${ }^{7}$ The substance sublimes, beginning at $500^{\circ}$, as an amorphous dark-brown to black powder which is stable in dry air. The oxide possesses powerful reducing properties, converting dilute sulfuric acid to hydrogen sulfide. The heat of formation of the monoxide has been calculated to be $82 \pm 2 \mathrm{Kcal}$., and the heat of decomposition into metal and sesquioxide to be $37 \pm 2$ Kcal. ${ }^{8}$

Gallium(III) sulfide is reduced by hydrogen at $800^{\circ}$ to form $\mathrm{GaS}$. Decomposition of the latter substance, by heating in a high vacuum, gives the sulfide of tripositive gallium and the volatile grayish-black $\mathrm{Ga}_{2} \mathrm{~S}$. The latter may also be prepared in vacuo at $700-720^{\circ}$ from a mixture of the sesquisulfide and the calculated quantity of the metal. The existence of the various sulfides has been confirmed by means of characteristic X-ray diagrams. ${ }^{9}$ It has been claimed that the sulfide of unipositive indium may be made by treatment of the sesquisulfide with hydrogen at elevated temperatures. ${ }^{4}$ The same investigators say that InS may also be prepared by the action of hydrogen sulfide on indium. 


\section{The Anodic Oxidation of Aluminum, Gallium, AND INDIUM}

The data obtained from investigations of the anodic oxidation of aluminum in several solvents can be reasonably explained only on the basis that this element enters solution in an oxidation state less than 3 . The loss in weight of an aluminum anode in an electrolyte consisting of a solution of copper(II) nitrate in liquid ammonia is greater than that expected from Faraday's law, on the assumption that the aluminum goes into solution in the tripositive state. ${ }^{10}$ Similar experiments in aqueous solutions of sodium chloride give current efficiencies considerably greater than 100 per cent. ${ }^{11}$ Moreover, hydrogen in considerable quantities is evolved at the aluminum anode during the course of the electrolysis, and even for some time after its discontinuance. ${ }^{11 b}$ The hydrogen evidently arises from the reduction of water by an aluminum ion in a low oxidation state. Analogous results have been obtained in acetone solutions of lithium chloride. ${ }^{12}$ Here, again, hydrogen is liberated at the anode and a current efficiency of 133 per cent obtained. Somewhat similar observations have been made when anhydrous acetic acid is used as a solvent. ${ }^{13}$ In the absence of a bimetallic couple, aluminum is unattacked, even in the presence of oxygen, by glacial acetic acid which contains dissolved acetates (e. g., sodium or ammonium acetate). The anodic oxidation of aluminum in such solutions, in a carbon dioxidc atmosphere, in a cell provided with a fritted glass disk separating anode and cathode compartments (Fig. 2), indicates (according to calculations based on Faraday's law) that the metal leaving the electrode has an average oxidation number in the neighborhood of 2.5.* The alu-

* Oxidation numbers as low as 1.9 have recently been obtained (Mazzitelli, M.S. thesis, University of Kansas, 1949). 
minum ion, or ions, of low oxidation number has a marked reducing power, as indicated by the liberation of hydrogen in the solution.

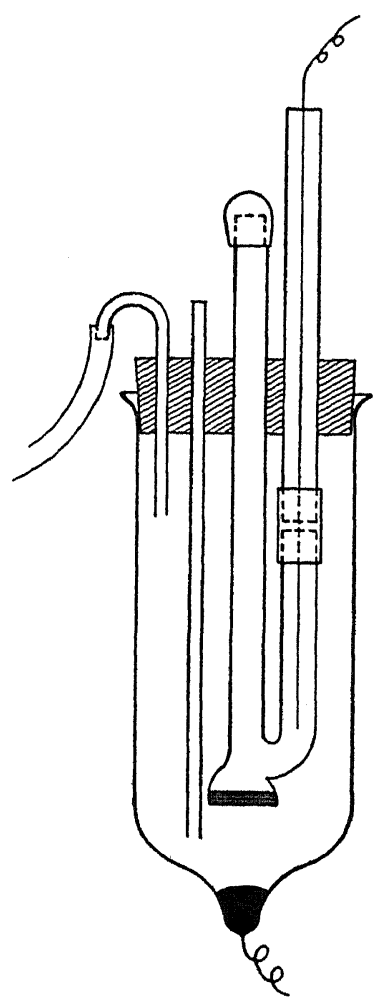

FIg. 2.-Cell for the Anodic Oxidation of the Aluminum Group Metals.

A noteworthy by-product of an investigation of the anodic oxidation of aluminum in various electrolytes in liquid-ammonia solution has been the observation that an appreciable concentration of metallic aluminum may exist in solution in this solvent; such a solution possesses 
the characteristic blue color associated with the coexistence of metal cations and ammoniated electrons. ${ }^{14}$ In every case in which aluminum iodide has been used as electrolyte, a deep blue color has appeared, on electrolysis, in the immediate vicinity of the cathode. This color is at first impermanent, disappearing upon diffusion into the body of the solution with the concurrent formation of a white precipitate, and being regenerated at the cathode. On prolonged electrolysis, however, the rate of disappearance gradually decreases and the entire solution eventually becomes blue. The most striking results were obtained in a solution containing 0.3 gram of aluminum iodide in 48 grams of ammonia, which was electrolyzed at $-33^{\circ}$ in an atmosphere of nitrogen between a bright platinum cathode and a chemically pure aluminum anode, at a cathode current density of about 0.01 ampere per sq. $\mathrm{cm}$.

Experiments analogous to those performed with aluminum have been carried out also with gallium and indium as anodes in anhydrous acetic acid solutions. The results of these experiments leave no doubt that both of these elements go into solution in oxidation states lower than $3 .{ }^{13}$ There is no question that in the case of gallium a singly charged $\mathrm{Ga}^{+}$ion is formed; the average oxidation number calculated is usually between 1 and 2. This ion possesses powerful reducing properties, converting hydrogen ion to free hydrogen especially at the fritted glass disk which separates anolyte from catholyte, and which may act as a catalyst for the reaction:

$$
\mathrm{Ga}^{+}+2 \mathrm{HC}_{2} \mathrm{H}_{3} \mathrm{O}_{2}=\mathrm{Ga}^{+3}+\mathrm{H}_{2}+2 \mathrm{C}_{2} \mathrm{H}_{3} \mathrm{O}_{2}^{-} \text {. }
$$

The unipositive gallium appears to be somewhat stabilized at low temperatures. Data for a typical experiment just described are given in Table I. 
TABLE I

Data for a Typical Anodic Oxidation of Gallium

\section{Conditions}

Atmophere: carbon dioxide

Electrolyte: 6.5 mole \% sodium acetate solution in anhydrous acetic acid

Area of electrode: 0.5 sq. $\mathrm{cm}$.

Current: $0.04 \mathrm{amp}$.

Temperature: $20^{\circ} \mathrm{C}$.

Time: 4 hours

Cathode: platinum

MEASUREMENTS ON ELECTROLYTIC CELL

Weight of gallium dissolved

Copper deposited in coulometer

Total volume of hydrogen found

$0.1898 \mathrm{~g}$.

$0.1323 \mathrm{~g}$.

(both at cathode and throughout solution)

Average oxidation number of gallium from coulometer data

Average oxidation number of gallium in electrolyte from iodine value

Difference in oxidation number

Hydrogen liberated at cathode (calculated from coulometric data)

Excess of hydrogen found by gas analysis (i.e., that liberated by reduction of acetic acid by gallium ion in lower oxidation state)

Change in average oxidation number corresponding to excess hydrogen liberated

Oxidation number change unaccounted for
70.1 cc. (S.T.P.)

1.53

2.32

$2.32-1.53=0.79$

46.6 cc. (S.T.P.)

23.5 cc. (S.T.P.)

0.77

$0.79-0.77=0.02$

The behavior of indium parallels that of gallium and aluminum in that current efficiencies (based on the assumption of oxidation to the tripositive ion) above 100 per cent are obtained, and the low oxidation state formed has sufficient reducing power to liberate hydrogen from the electrolyte. The mean oxidation number is in the neighborhood of 2.3. One important difference in be-

* The reducing power of the solution after electrolysis was determined by titration with iodine. 
havior is noted, however: the ion of low oxidation number rapidly disproportionates to give the free metal and tripositive indium. This property of indium of low oxidation number has been reported also by other investigators. $^{1 a}$ 


\section{III}

Oxygen: the Superoxides of the Alkali and Alkaline Earth Metals

MONG the "regular" elements of group IV, the duality of oxidation state which has sometimes 1 been attributed to the difference between $s$ and $p$ electrons in the same shell is so well known that neither the +2 nor the +4 state may be characterized as unfamiliar. The $-3,+3$, and +5 states of the "regular" elements of group V are also well known. Among the "regular" elements of group VI, the bewildering multiplicity of sulfur compounds has been competently discussed elsewhere The peroxides, also, are well known; there is, however, another group of oxygen compounds, to which attention has recently been directed because of their possible industrial significance, but for which no adequate systematic treatment is as yet available. These substances are the superoxides of the alkali and the alkaline earth metals. $\dagger$ The deep yellow superoxides contain the $\mathrm{O}_{2}^{-}$ ion; they may be considered to be salts of the weak unstablc acid $\mathrm{HO}_{2}$, which decomposes in the following manner: ${ }^{1}$

$$
2 \mathrm{HO}_{2}=\mathrm{H}_{2} \mathrm{O}_{2}+\mathrm{O}_{2} .
$$

* For an excellent presentation of the chemistry of inorganic sulfur compounds see Yost and Russell, Systematic Inorganic Chemistry, New York, 1944.

$\dagger$ Complexes presumably containing tripositive cobalt and the superoxide ion are described in the section dealing with the unfamiliar oxidation states of iron, cobalt, and nickel. 


\section{Preparation of Superoxides}

Apparently the most important factor with regard to the formation of superoxides by the burning of metals in oxygen is the size of the cation. Of the alkali metals, lithium gives chiefly the monoxide when burned in oxygen, and sodium the peroxide; only potassium, rubidium, and cesium form superoxides under these conditions. None of the alkaline earth metals yield superoxides on burning. It is probable that in the case of sodium, at least, the temperature of combustion is above the decomposition temperature of the superoxide.

The combustion of the metals in air or oxygen has served as one of the common methods for the preparation of the superoxides of potassium, rubidium, and cesium." It is interesting to note, however, that when rigorously dried oxygen is used, oxidation to the superoxides does not take place. These same oxides may be prepared in high purity by the rapid oxidation of the metals in liquid ammonia ${ }^{2 c, 3}$ at temperatures ranging from $-70^{\circ}$ to $-33^{\circ}$. The slow oxidation of the metals results in the formation of hydroxides and nitrites, ${ }^{2 c, 3 b}$ probably as a result of the following reactions:

$$
\begin{gathered}
2 \mathrm{~K}+\mathrm{O}_{2}=\mathrm{K}_{2} \mathrm{O}_{2} . \\
\mathrm{K}_{2} \mathrm{O}_{2}+2 \mathrm{~K}=2 \mathrm{~K}_{2} \mathrm{O} . \\
\mathrm{K}_{2} \mathrm{O}+\mathrm{NH}_{3}=\mathrm{KOH}+\mathrm{KNH}_{2} . \\
2 \mathrm{KNH}_{2}+3 / 2 \mathrm{O}_{2}=\mathrm{KOH}+\mathrm{KNO}_{2}+\mathrm{NH}_{3} .
\end{gathered}
$$

At temperatures above $-50^{\circ}$, even rapid oxidation yields a superoxide which is contaminated with hydroxide and nitrite.

It is of interest to note that rearrangement of potassium peroxide hydrates results in the formation of the superoxide. Thus $\mathrm{K}_{2} \mathrm{O}_{2} \cdot \mathrm{H}_{2} \mathrm{O}$ evolves no oxygen on stand- 
ing in vacuo for several days. Analysis of the final product shows that reaction has taken place according to the equation

$$
3\left(\mathrm{~K}_{2} \mathrm{O}_{2} \cdot \mathrm{H}_{2} \mathrm{O}\right)=2 \mathrm{KO}_{2}+{ }_{4} \mathrm{KOH}+\mathrm{H}_{2} \mathrm{O} .
$$

Rearrangement of the dihydrate proceeds similarly:

$$
3\left(\mathrm{~K}_{2} \mathrm{O}_{2} .2 \mathrm{H}_{2} \mathrm{O}\right)=2 \mathrm{KO}_{2}+4\left(\mathrm{KOH} . \mathrm{H}_{2} \mathrm{O}\right) .
$$

The data in the literature on the oxidation of sodium in liquid ammonia have been of a conflicting nature. The statement has been made ${ }^{3 a}$ that a substance of the formula $\mathrm{Na}_{2} \mathrm{O} . \mathrm{NH}_{3}$ is first formed and that this is further oxidized to $\mathrm{Na}_{2} \mathrm{O}_{3}$ when a solution of sodium in liquid ammonia at $-50^{\circ}$ is oxidized by a slow stream of oxygen. An investigation referred to above ${ }^{3 b}$ would, however, appear to cast considerable doubt on the interpretation of the evidence concerning the formation of these oxides. Analyses for the compound $\mathrm{Na}_{2} \mathrm{O} \cdot \mathrm{NH}_{3}$ would also correspond to a mixture of hydroxide and amide, substances which have been shown to be the first products of the slow oxidation of sodium in liquid ammonia. ${ }^{3 \mathbf{b}}$ Moreover, the claim for the existence of $\mathrm{Na}_{2} \mathrm{O}_{3}$ is based solely on an analysis for sodium, the oxygen content being calculated by difference. However, the amide in the mixture with hydroxide, formed as the first product in the slow oxidation of sodium in liquid ammonia, is further oxidized to nitrite. ${ }^{3 b}$ Consideration of the stoichiometry of these reactions ( see analogous equations for potassium as cited above) leads to the fact that the sodium content of the final mixture ( $3 \mathrm{NaOH}$ to $1 \mathrm{NaNO}_{2}$ ) is very nearly that which would be present in a substance of the formula $\mathrm{Na}_{2} \mathrm{O}_{3}$. It would appear, therefore, that the evidence for the formation of $\mathrm{Na}_{2} \mathrm{O}_{3}$ is quite unreliable. 
It has been stated that the highest oxide formed in the rapid oxidation of sodium in liquid ammonia at $-33^{\circ}$ is the peroxide. ${ }^{3 b}$ Proof for this declaration is based solely upon the volume of oxygen absorbed by the metal in solution. It has been recently shown ${ }^{4}$ that sodium in liquid ammonia absorbs, from oxygen which is being cycled rapidly through the solution at $-77^{\circ}$, a volume approaching that required for sodium superoxide. Moreover, after evaporation of the ammonia the remaining yellow and white mixture liberates, upon decomposition, a quantity of oxygen greater than that which can be accounted for solely on the basis of sodium peroxide.

A still more recent investigation ${ }^{5}$ has demonstrated that neither the gain in weight of sodium upon oxidation in liquid ammonia nor the volume of oxygen absorbed constitutes a reliable criterion for assigning a formula to the product; for even at $-77^{\circ}$ sodium undergoes some conversion to amide and subsequently to nitrite if, during

\section{TABLE II}

Rapid Oxidation of Sodium in Liquid Ammonia

(Vol. of $\mathrm{NH}_{3}-\mathrm{O}_{2}$ solution approximately $100 \mathrm{cc}$.)

\begin{tabular}{ccccc}
\hline $\begin{array}{c}\mathrm{Na}, \text { g. } \\
\text { (from } \\
\text { titration) }\end{array}$ & $\begin{array}{c}\text { Temp. of reaction } \\
\text { cell bath }\end{array}$ & $\begin{array}{c}\text { Vol. of oxygen } \\
\text { evolved from } \\
\text { prodt. on analy- } \\
\text { sis (S.T.P.) }\end{array}$ & $\begin{array}{c}\text { Vol. of } \\
\text { oxygen } \\
\text { calcd. } \\
\text { for NaO } \\
\text { cc. (STP) }\end{array}$ & $\begin{array}{c}\text { Atoms of } \\
\text { oxygen per } \\
\text { atom of Na } \\
\text { in prodt. }\end{array}$ \\
\hline 0.0591 & unthermostated & 34.0 & 43.0 & 1.68 \\
.0412 & $\#$ & 23.3 & 30.0 & 1.67 \\
.0126 & $\#$ & 7.2 & 9.2 & 1.67 \\
.0353 & $\#$ & 20.6 & 25.8 & 1.70 \\
.0424 & $"$ & 23.7 & 30.9 & 1.65 \\
.0492 & ca. $777^{\circ}$ & 27.8 & 35.9 & 1.67 \\
.0453 & $"$ & 25.7 & 33.0 & 1.67 \\
.0403 & $"$ & 22.9 & 29.5 & 1.67 \\
.0536 & $"$ & 31.4 & 39.1 & 1.70 \\
.0635 & $"$ & 36.2 & 46.3 & 1.67 \\
.0324 & $\#$ & 18.7 & 23.7 & 1.68 \\
\hline
\end{tabular}


the course of the oxidation, the blue color of the metal persists even for a short time. Amide formation may be avoided by the slow addition of a solution of the metal in liquid ammonia to another portion of ammonia through which oxygen is rapidly being passed. Under these conditions a product of apparently constant composition is formed whether the reaction is carried out at -33 or $-77^{\circ}$ (Table II).

The product is yellow with occasional traces of white. The empirical formula $\mathrm{NaO}_{1 \cdot 67}$ corresponds to a mixture of ${ }_{1} \mathrm{Na}_{2} \mathrm{O}_{2}$ with $4 \mathrm{Na}_{2} \mathrm{O}_{2}$. The high degree of paramagnetism of the substance provides additional evidence for the presence of sodium superoxide.

The reaction between sodium peroxide and oxygen in a stainless steel bomb at elevated temperatures results in the formation of sodium superoxide of greater than 90 per cent purity. ${ }^{6}$ Typical data for this reaction are summarized in Table III. The chemical properties of the prod-

\section{TABLE III}

Conversion of $\mathrm{Na}_{2} \mathrm{O}_{2}$ to $\mathrm{NaO}_{2}$

\begin{tabular}{ccccc}
\hline $\begin{array}{c}\text { Wt. of } \mathrm{Na}_{2} \mathrm{O}_{2} \\
\text { in g. }\end{array}$ & $\begin{array}{c}\text { Temp. }\left({ }^{\circ} \mathrm{C}\right) \\
\text { for } 100 \text { hrs. }\end{array}$ & $\begin{array}{c}\text { Initial press. } \\
\text { at elevated } \\
\text { temp. (atm.) }\end{array}$ & $\begin{array}{c}\text { Vol. of } \\
\text { oxygen } \\
\text { evolved } \\
\text { per g. } \\
\text { of pro- } \\
\text { duct (cc.) }\end{array}$ & $\begin{array}{c}\% \text { Conver- } \\
\text { sion to } \\
\mathrm{NaO}_{2}\end{array}$ \\
\hline 9.95 & $32^{\circ}$ & 137 & 140 & 0 \\
11.20 & 150 & 187 & 147 & 2 \\
11.22 & 200 & 205 & 161 & 11 \\
10.10 & 250 & 222 & 181 & 23 \\
11.15 & 300 & 238 & 215 & 44 \\
12.36 & 350 & 257 & 274 & 81 \\
10.35 & 400 & 280 & 286 & 89 \\
9.80 & 450 & 281 (small & 292 & 93 \\
11.23 & 490 & 298 & 291 & 92 \\
\hline
\end{tabular}


uct leave no doubt that it consists mainly of the superoxide. Treatment of the material with a carbon tetrachloride-glacial acetic acid mixture results in the vigorous evolution of oxygen, leaving a residue of peroxide. The data for magnetic measurements made on the products, and on other mixtures of sodium peroxide and superoxide, are shown below:

\section{TABLE IV}

Magnetic Susceptibility of $\mathrm{Na}_{2} \mathrm{O}_{2}-\mathrm{NaO}_{2}$ Mixtures

\begin{tabular}{|c|c|c|c|c|}
\hline $\begin{array}{l}\text { Vol. of oxygen } \\
\text { evolved per g. } \\
\text { of material (cc.) }\end{array}$ & $\begin{array}{c}\% \mathrm{NaO}_{2} \text { (calc'd } \\
\text { from oxygen } \\
\text { liberated) }\end{array}$ & $\begin{array}{c}x \mathrm{~g} \times 10^{\circ} \text { at } \\
20^{\circ} \mathrm{C} \text { (c.g.s. } \\
\text { units) }\end{array}$ & $\begin{array}{c}x \mathrm{~g} \times 10^{6} \\
\text { for pure } \\
\mathrm{NaO}_{2} \text { (calcd.) } \\
\text { (c.g.s. units) }\end{array}$ & $\begin{array}{c}\mu \text { calc'd } \\
\text { for pure } \\
\mathrm{NaO}_{2} \text { (Bohr } \\
\text { Magnetons) }\end{array}$ \\
\hline 142 & 0 & -0.23 & $\ldots$ & $\ldots . .$. \\
\hline 161 & 11 & +3.75 & 34.1 & 2.10 \\
\hline 202 & $3^{6}$ & 10.4 & 28.9 & 1.94 \\
\hline 225 & 50 & 16.9 & 33.8 & 2.10 \\
\hline 251 & 66 & 21.4 & 32.4 & 2.06 \\
\hline 286 & 88 & 29.5 & 33.5 & 2.09 \\
\hline 292 & 92 & 29.1 & 31.7 & 2.03 \\
\hline 291 & 90.5 & 28.8 & 31.7 & 2.03 \\
\hline
\end{tabular}

A plot (Fig. 3) of gram susceptibility of oxide mixture vs. weight per cent of sodium superoxide, as calculated from the volume of oxygen liberated on analysis, yields a straight line. This fact shows that the magnetic values for mixtures of sodium peroxide and superoxide follow the additivity rule. It is evident, therefore, that such mixtures may be analyzed with a fair degree of accuracy by merely measuring their susceptibilities; the maximum error in such analyses is \pm 3 per cent.

Extrapolation of the straight line of Fig. 3 to 100 per cent sodium superoxide gives for this substance a value of the gram susceptibility which corresponds to an effective moment $(\mu)$ of 2.07 Bohr magnetons. This figure 
is in excellent agreement with the moments of other superoxides, as reported in the literature.

Little is to be found in the literature on superoxides of the alkaline earth metals. Calcium superoxide, $\mathrm{Ca}\left(\mathrm{O}_{2}\right)_{2}$, has been prepared in about 8 per cent yield, as an admixture with calcium peroxide, by reaction at $100^{\circ}$ between hydrated calcium peroxide, $\mathrm{CaO}_{2} .8 \mathrm{H}_{2} \mathrm{O}$, and 30 per cent hydrogen peroxide. ${ }^{7}$ Barium superoxide has been similarly prepared in small yield. The smallness of the yields is presumably due to decomposition of some of the superoxide formed, by water from the hydrogen peroxide solution. Of the two superoxides, the calcium compound appears to be the more stable. It may be heated to $130^{\circ}$ without alteration in properties; when heated to $270-290^{\circ}$ it loses its yellow color, being converted first to the per-

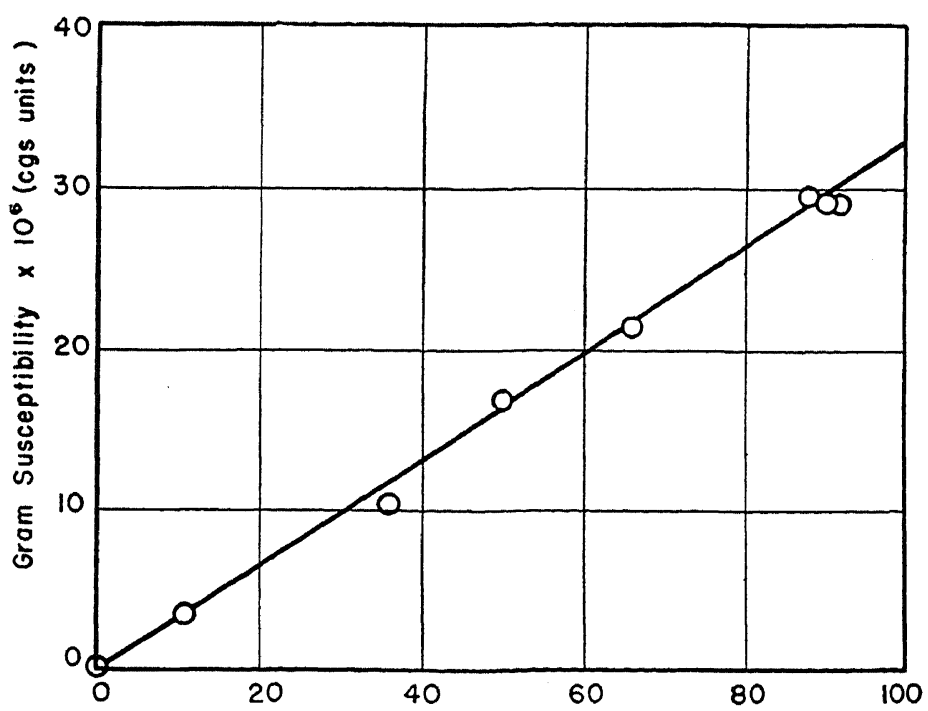

Weight percent $\mathrm{NaO}_{2}$ (Calculated from total $\mathrm{O}_{2}$ evolved)

Fig. 3.-Magnetic Susceptibilities of $\mathrm{Na}_{2} \mathrm{O}_{2}-\mathrm{NaO}_{2}$ Mixtures. 
oxide and then to the monoxide. Superoxides of the other members of the alkaline earth metal group have not been prepared.

\section{The Structure of the Superoxide Ion}

Until comparatively recently, the alkali metal superoxides have been considered to be tetroxides of the formula $\mathrm{M}_{2} \mathrm{O}_{4}$. The belief prevailed that these substances contained the $\mathrm{O}_{4}^{-2}$ anion and were analogous to the tetrasulfides. The discovery of the three-electron bond, ${ }^{8}$ however, soon led to the suggestion that these alkali metal oxides might contain an $\mathrm{O}_{2}^{-}$(superoxide) ion, with the structure

$$
\text { :O:::O: }:^{-}
$$

in which both an ordinary single (two-electron) bond and a three-electron bond between the two oxygen atoms are involved. The results of magnetic susceptibility measurements substantiate this suggestion. ${ }^{9}$ Potassium superoxide, $\mathrm{KO}_{2}$, is paramagnetic, having an effective moment at room temperature of 2.04 Bohr magnetons. This is close to the value 1.73 for the spin moment of one unpaired electron. It has been similarly shown that the structure of calcium superoxide, the preparation of which has already been described, is best represented by the formula $\mathrm{Ca}\left(\mathrm{O}_{2}\right)_{2} \cdot{ }^{10}$

Confirmation of the existence of the $\mathrm{O}_{2}{ }^{-}$ion is to be found in the results of X-ray investigations. Powder photographs of potassium superoxide have established that it possesses a tetragonal face-centered lattice of the calcium carbide type. ${ }^{11}$ This structure has also been con- 
firmed for rubidium and cesium superoxides. ${ }^{12 *}$ The elementary cell of potassium superoxide contains four potassium ions and eight superoxide ions. The distance between adjacent oxygen nuclei in the superoxide ion is $1.28 \pm 0.07 \AA$, a figure which is in good agreement with the value to be expected for a single bond plus a threeelectron bond. ${ }^{13}$

\section{Properties of the Superoxides}

The superoxides of the alkali and the alkaline earth metals are deep yellow in color. They darken at high temperatures, the molten compounds being black.

It has been previously stated that the alkali metal superoxides have a calcium carbide type of crystal structure. Their lattice constants are given in the following table. ${ }^{12}$

\section{TABLE V}

Lattice Constants of Alkali Metal Superoxides

\begin{tabular}{lll}
\hline & $a$ axis & $c$ axis \\
\hline $\mathrm{KO}_{2}$ & 5.70 & 6.75 \\
$\mathrm{RbO}_{2}$ & 6.00 & 7.03 \\
$\mathrm{CsO}_{2}$ & 6.28 & 7.27 \\
\hline
\end{tabular}

Other significant data are tabulated below:

\section{TABLE VI}

Magnetic Properties of Alkali Metal Superoxides ${ }^{12}$

\begin{tabular}{crrrrrr}
\hline & \multicolumn{3}{c}{$\chi \mathrm{g} \times 10^{\circ}$} & \multicolumn{3}{c}{$\mu$ eff. (Bohr Magnetons) } \\
\cline { 2 - 7 }${ }^{\circ} \mathrm{K}$ & $\mathrm{KO}_{2}$ & $\mathrm{RbO}_{2}$ & $\mathrm{CsO}_{2}$ & $\mathrm{KO}_{2}$ & $\mathrm{RbO}_{2}$ & $\mathrm{CsO}_{2}$ \\
\hline $90^{\circ}$ & 65.6 & 42.2 & 27.3 & 1.97 & 1.89 & 1.91 \\
$293^{\circ}$ & 22.6 & 13.0 & 9.3 & 1.84 & 1.89 & 1.89 \\
\hline
\end{tabular}

* The crystal structure of sodium superoxide has recently been determined from powder diffraction patterns. The diffraction lines correspond to a facecentered cubic lattice with $a^{\circ}=5.490 \pm 0.005 \AA$. In contrast to the situation with other superoxides, the orientations of the oxygen ions are disordered (Templeton, Abstracts of Papers, Atlantic City meeting of the American Chemical Society, Atlantic City, September 18-23, 1949, p. 79 P). 


\section{TABLE VII}

Other Properties of the Superoxides

\begin{tabular}{llcc}
\hline Property & $\mathrm{KO}_{2}$ & $\mathrm{RbO}_{2}$ & $\mathrm{CsO}_{2}$ \\
\hline $\begin{array}{l}\text { Density (g./cc.) } \\
\text { *Melting point, }{ }^{\circ} \mathrm{C}\end{array}$ & $\mathbf{2 . 1 4}$ & 3.06 & 3.80 \\
*Dissociation temper- & $80^{\circ}$ & $412^{\circ}$ & $432^{\circ}$ \\
$\begin{array}{l}\text { ature ( } \mathrm{p}=1 \text { atm.) } \\
\text { 6 }\end{array}$ & $\begin{array}{c}1150^{\circ} \\
\text { (unstable) }\end{array}$ & $\begin{array}{c}1265^{\circ} \\
\text { (unstable) }\end{array}$ \\
$\begin{array}{l}\triangle \mathrm{H}(\mathrm{Kcal}) \text { for } \\
\text { reaction }\end{array}$ & & \\
$2 \mathrm{M}+2 \mathrm{O}_{2}=2 \mathrm{MO}_{2}-133.7$ & -137.6 & -141 \\
\hline
\end{tabular}

The reactions of potassium superoxide with water have been investigated in some detail. ${ }^{3 c}$ At $0^{\circ}$ the compound reacts with liquid water according to the equation:

$$
2 \mathrm{KO}_{2}+\mathrm{aq} .=\mathrm{K}_{2} \mathrm{O}_{2} \text {.aq. }+\mathrm{O}_{2} \text {. }
$$

The aqueous solution of the peroxide decomposes at higher temperatures in the following manner:

$$
\mathrm{K}_{2} \mathrm{O}_{2} \text {.aq. }=\mathrm{KOH} \text {.aq. }+1 / 2 \mathrm{O}_{2} \text {. }
$$

Theoretically one should be able, by making use of these reactions, quantitatively to determine superoxide in an admixture with peroxide. In practice this is not usually feasible; almost invariably decomposition of peroxide occurs even at $0^{\circ}$ because of local heating upon dissolution. Treatment of the superoxide with water vapor results in the evolution of one atom of oxygen per mole of water added:

$$
2 \mathrm{KO}_{2}+{ }_{3} \mathrm{H}_{2} \mathrm{O}_{(\mathrm{v})}=2\left(\mathrm{KOH} \cdot \mathrm{H}_{2} \mathrm{O}\right)+3 / 2 \mathrm{O}_{2} \text {. }
$$

* These data are taken from an article by Tsentnershver and Blumenthal, Bull. intern. acad. polonaise, classe sci. math. nat., 1933A, pp. 499-522. There is some disagreement with the earlier values for the melting points of $\mathrm{RbO}_{2}$ and $\mathrm{CsO}_{2}$ (see ref. 2c). Similar values for the heats of formation of the superoxides are given by de Forcrand, Compt. rend., 158, 991 (1914). 
If the superoxide has been prepared in liquid ammonia, the water for the analysis is added to the ammonia solution. Under these conditions no oxygen is evolved until the liquid has been evaporated and the atmosphere of ammonia exhausted.

At temperatures above $300^{\circ}$, potassium superoxide dissociates reversibly into oxygen and what appears to be a solid solution of the peroxide and the superoxide. ${ }^{3 \mathrm{~b}} \mathrm{Be}-$ cause of this fact, the oxygen pressures do not represent true equilibrium pressures for the system, and the dissociation pressure of the superoxide cannot be determined.

\section{The "Sesquioxides" of the Alkali Metals}

Substances of the empirical formula $\mathrm{M}_{2} \mathrm{O}_{3}$ ( $\mathrm{M}=$ $\mathrm{K}, \mathrm{Rb}$, and $\mathrm{Cs}$ ) have been prepared. Reaction between stoichiometric quantities of nitrous oxide and molten potassium gives a buff-colored material, the analysis of which corresponds very closely to $\mathrm{K}_{2} \mathrm{O}_{3}{ }^{2 b}$ It has been stated also that this substance can be made by the oxidation of the metal in liquid ammonia, but this claim has been disputed. At room temperature and pressures below ten mm. of mercury, potassium peroxide combines with oxygen to give the "sesquioxide," $\mathrm{K}_{2} \mathrm{O}_{3}{ }^{3 c}$ Upon treatment with water vapor this material gives the hydrate $\mathrm{K}_{2} \mathrm{O}_{3} \cdot \mathrm{H}_{2} \mathrm{O}$, which is incapable of further oxygen absorption. This hydrate may be prepared also by the conversion of the peroxide in liquid ammonia to $\mathrm{K}_{2} \mathrm{O}_{3}$, followed by treatment with water. The chocolate-brown "sesquioxide" $\mathrm{Cs}_{2} \mathrm{O}_{3}$ has been obtained as a product intermediate between the peroxide and the superoxide in the rapid oxidation of cesium metal in liquid ammonia at -50 to $-70^{\circ}$; it is not obtained pure, however, but is con- 
taminated with traces of the nitrite and the nitrate..$^{2 \mathrm{c}}$ The thermal dissociation of rubidium superoxide at $55^{\circ}$ and low pressures gives the black "sesquioxide" $\mathrm{Rb}_{2} \mathrm{O}_{3}$, which decomposes at $600^{\circ}$ with the liberation of oxygen.. ${ }^{2 c}$

Consideration of the properties of these substances of empirical formula $\mathrm{M}_{2} \mathrm{O}_{3}$ leaves no doubt that they are not true sesquioxides, but are combinations of peroxide and superoxide. The study of the gradual thermal decomposition of potassium superoxide at low pressures ${ }^{14}$ proves that $\mathrm{K}_{2} \mathrm{O}_{3}$ is not an individual compound. The kinetic decomposition curve of $\mathrm{KO}_{2}$ (i.e., a plot of composition of the solid phase vs. time in minutes) at $360^{\circ}$ and a pressure of $0.01 \mathrm{~mm}$. of mercury has a smooth course, with no inflection at the point which corresponds to the composition $\mathrm{K}_{2} \mathrm{O}_{3}$. On the removal of oxygen from the superoxide the pressure remains constant until the composition of the peroxide is reached, where a sudden drop occurs.

An X-ray investigation of the "sesquioxides" of rubidium and cesium gives diffraction diagrams which are consistent with the formulas $\mathrm{Rb}_{4} \mathrm{O}_{6}$ and $\mathrm{Cs}_{4} \mathrm{O}_{6} .{ }^{15}$ Both are face-centered cubic crystals with cube edges of 9.30 and $9.86 \AA$, respectively. The magnetic susceptibilities of these substances are consistent with the hypothesis of a proportion of two moles of superoxide to one of peroxide. The rubidium-oxygen distances are 3.54 and $2.95 \AA$, and the cesium-oxygen distances, 3.74 and $3.12 \AA$. 


\section{IV \\ The Halogens}

T FIRST GLANCE it might appear that a group of
elements so long known and so intensively studied
as the halogens would require no further discussion. Certainly no further examination is necessary of those phases of the chemistry of the halogens which deal with the -1 state in the halide ions and the various positive oxidation states in oxyhalogen compounds, intcrhalogens, and halogen halogenoids.

Other compounds are known, however, in which the halogens, particularly iodine, appear to play the role of a metal. It is with these substances that this discussion will be chiefly concerned. The fact that iodine exhibits some metallic properties becomes less surprising in view of the recent discovery that astatine, the element below it in its periodic group, shows many metallic characteristics.

In addition to a survey of the metallic properties of the halogens, the evidence for the existence of the perchlorate radical, containing chlorine in the +8 state, will be described.

CoÖRdination Compounds of Unipositive Iodine

\section{AND BROMINE}

The reaction between equivalent quantities of iodine and the silver salt of any one of a number of monocarboxylic acids in petroleum ether, ether, or benzene, at moderate temperatures, gives a complex intermediate containing unipositive iodine: ${ }^{1}$

$$
{ }_{2} \mathrm{RCOOAg}+\mathrm{I}_{2} \stackrel{\text { solvent }}{=}(\mathrm{RCOO})_{2} \mathrm{AgI}+\mathrm{AgI} .
$$


The formation of this complex appears to be a general phenomenon when iodine and a silver salt of a substituted benzoic acid react in a chloroform medium. ${ }^{2}$

The exact structure of the complex is unknown; the following formulations are possible:

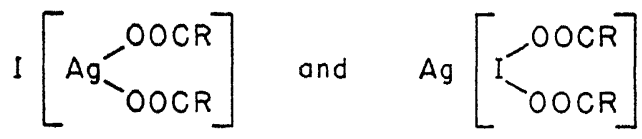

The thermal decomposition of this compound proceeds according to equation:

$$
(\mathrm{RCOO})_{2} \mathrm{AgI}=\mathrm{RCOOR}+\mathrm{CO}_{2}+\mathrm{AgI} .
$$

Hydrolysis gives the free parent acid, the unipositive iodine undergoing autoöxidation-reduction. $3(\mathrm{RCOO}){ }_{2} \mathrm{AgI}+{ }_{3} \mathrm{H}_{2} \mathrm{O}=6 \mathrm{RCOOH}+2 \mathrm{AgI}+\mathrm{AgIO}_{3}$.

The suggestion that the very unstable compound hypoiodous acid may have the properties of a weak base, $\mathrm{IOH}_{2}{ }^{3}$ has been substantiated ${ }^{4}$ by the preparation of a number of its salts, which have been stabilized by coördination with organic amines.* These compounds are generally prepared by the treatment of the silver salt of the necessary acid with the calculated quantity of iodine and a slight excess of amine in some nonaqueous solvent such as chloroform. Reaction occurs immediately according to the equation below:

$$
\mathrm{AgNO}_{3}+2 \mathrm{py}+\mathrm{I}_{2}=\left(\mathrm{Ipv}_{2}\right) \mathrm{NO}_{3}+\mathrm{AgI} \cdot \dagger
$$

After removal of the silver iodide by filtration, the complex is usually thrown down by ether or petroleum ether.

* Carlsohn, UUber eine Neue Klasse von Verbindungen des Positiv Einwertigen Iods, Verlag Hirzel, Leipzig, 1932. Unless otherwise noted, the material on coördination compounds of unipositive iodine has been taken from this source.

$\nmid \mathrm{Py}=$ pyridine. 
In the preparation of pyridine complexes, when the desired compound is insoluble in the solvent used as reaction medium, the mercurous salt of the acid is utilized in place of the silver salt.

$$
\begin{aligned}
& \mathrm{Hg}_{2}(\mathrm{OOCR})_{2}+6 \mathrm{py}+3 \mathrm{I}_{2}= \\
& 2 \mathrm{I}(\mathrm{py})-\mathrm{OOCR}+2 \mathrm{HgI}_{2} \cdot 2 \mathrm{py} .
\end{aligned}
$$

The mercuric iodide complex is readily soluble in organic solvents, and is, therefore, easily separated from the iodine compound.

In the preparation of unipositive iodine complexes by the treatment of the silver salt of an organic acid with iodine in the presence of $\alpha$ - or $\beta$-picoline in a chloroform medium, the formation of the free organic acid is a competing reaction. ${ }^{2}$ In cases where low yields of the positive iodine complex are obtained, high recovery of the free acid is possible, even under rigorously anhydrous conditions. The source of the hydrogen for free acid formation has not yet been determined.

An investigation of the pyridine-coördinated iodine(I) complexes of ring-substituted benzoic acids has demonstrated that the nature of the substituent is of primary importance in determining the tendency toward complex formation. ${ }^{5}$ The presence on the benzene nucleus of highly electron-withdrawing groups, such as the $-\mathrm{NO}_{2}$ group, appears to favor the formation of the positive iodine complex. Acids containing substituents which are weakly electron-releasing, such as the halogens and $-\mathrm{CH}_{3}$, form complexes readily when the substituents are located para to the carboxyl group, only under special conditions and in low yields when they are in the meta position, and not at all or with difficulty when the substituents are ortho to the carboxyl group. Acids containing groups which are 
strongly electron-releasing, such as the $\mathrm{NH}_{2}$ and the - $\mathrm{OH}$ groups, yield no iodine complexes, but appear to undergo ring substitution by iodine. When the yield of positive iodine complex is low, the formation of free acid is again noted. ${ }^{2}$

Most of the unipositive iodine complexes which have so far been prepared have contained pyridine as the coördinating agent. ${ }^{4,5}$ The properties of these compounds have been extensively studied. The iodine(I) perchlorate contains two molecules of pyridine, whereas the nitrate occurs with either one or two molecules of pyridine, and the complexes of weak acids have one molecule of pyridine per atom of iodine. The compounds are all either colorless or very pale yellow.

The chemical reactions of these salts conclusively show that the iodine is indeed unipositive. When they are dissolved in sodium hydroxide solution containing potassium iodide and the solution is acidified, iodine is liberated in every case:

$$
\mathrm{I}^{+}+\mathrm{I}^{-}=\mathrm{I}_{2} \text {. }
$$

This reaction may be utilized for the determination of iodine in the complex. With potassium chloride and potassium bromide, metathesis takes place, with the formation of ICl.py and IBr.py respectively.

The solubility in water, or in organic media, of the unipositive iodine complexes appears to decrease with increasing melting point of the compound. They are hydrolyzed in water in accordance with the following equations:

$$
\begin{gathered}
\mathrm{I}(\text { py })_{2} \cdot \mathrm{NO}_{3}+\mathrm{H}_{2} \mathrm{O}=\mathrm{I}(\text { py }) \cdot \mathrm{OH}+\text { pyH. } \mathrm{NO}_{3} . \\
5 \mathrm{I}(\text { py }) \cdot \mathrm{OH}=2 \mathrm{I}_{2}+\text { pyHIO } \\
3
\end{gathered}
$$


The treatment of dipyridine iodine(I) nitrate, $\mathrm{I}(\mathrm{py})_{2} . \mathrm{NO}_{3}$, with an equivalent quantity of sodium hydroxide results in the formation of the base $\mathrm{I}(\mathrm{py})_{2} . \mathrm{OH}$, which immediately goes over to the orange-colored anhydride

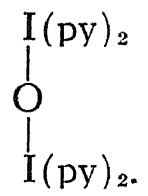

This substance; on being dried in a vacuum, loses two molecules of pyridine to give

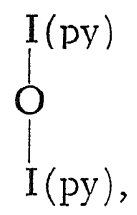

which then disproportionates in the following manner:

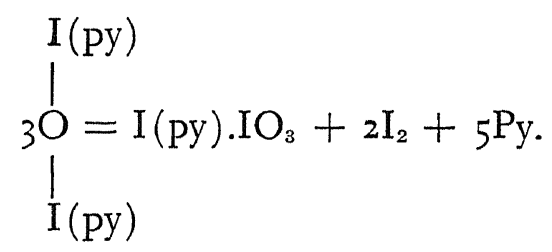

In pyridine solution the unipositive iodine in the nitrate complex is slowly reduced to the elementary state, the free iodine formed combining with the pyridine.

Electrolysis of dipyridine iodine(I) nitrate in anhydrous chloroform yields iodine at the cathode while the solution around the anode remains colorless. This fact offers additional proof that the iodine is the positive constituent of the salt.

On the basis of the decomposition potentials of the interhalogen compounds, $\mathrm{ICl}, \mathrm{IBr}$, and $\mathrm{ICl}_{3}$, and of elec- 
trode potential data for the iodine electrode against solutions of the above substances, it has been shown that the $\mathrm{I}^{+}$ion should be placed among the noble metals in the electromotive series. ${ }^{6}$ This has been substantiated in a qualitative way by the reactions of metals with dipyridine iodine (I) nitrate. When zinc, magnesium, iron, copper, silver, mercury, gold, or platinum is treated with a chloroform solution of the complex, each replaces the iodine. It would be unjustifiable, however, to state on this basis that iodine is more noble than silver, since the preparation of dipyridine iodine $(\mathrm{I})$ nitrate depends upon the replacement of silver by iodine. In the case of silver, at least, the reaction can evidently go in either direction. In each case the displaced element is removed from the reaction in the form of insoluble silver iodide; perhaps this fact accounts for the apparent reversibility.

On the assumption of a coördination number of two for unipositive iodine, the following types of structures have been postulated for the salts:

$$
\begin{gathered}
{\left[\mathrm{I}(\mathrm{py})_{2}\right] \mathrm{X} \text { and }[\mathrm{IpyX}]} \\
(\mathrm{X}=\text { uninegative acid radical }) .
\end{gathered}
$$

In an attempt to verify these structures, conductance measurements have been carried out on acetone and methanol solutions. Salts of type $\left[\mathrm{I}(\mathrm{py})_{2}\right] \mathrm{X}$ would be expected to be good conductors, whereas those of type [IpyX] should not conduct the electric current. Moreover, salts of the latter type should revert in the presence of pyridine to the form $\left[\mathrm{I}(\mathrm{Py})_{2}\right] \mathrm{X}$ according to the equation

$$
[\mathrm{IpyX}]+\mathrm{py}=\left[\mathrm{I}(\mathrm{py})_{2}\right] \mathrm{X}
$$

and thus should become good conductors. The results of 


\section{TABLE VIII}

Equivalent Conductance of Unipositive Iodine Complexes in Acetone at $20^{\circ}$

\begin{tabular}{|c|c|c|}
\hline Dilution (liters /equiv.) & Salt & $\begin{array}{l}\text { Equivalent conduc- } \\
\text { tance }\left(\mathrm{ohm}^{-1} \mathrm{~cm}^{2}{ }^{2} \text { ) }\right.\end{array}$ \\
\hline$V=100$ & $\begin{array}{l}\mathrm{I}(\mathrm{py})_{2} \cdot \mathrm{NO}_{3} \\
\text { Ipy. } \mathrm{NO}_{3} \\
\text { Ipy.OOC. } \mathrm{CH}_{3} \\
\text { Ipy.OOC.C. } \mathrm{H}_{5}\end{array}$ & $\begin{array}{l}41.6 \\
13 \\
0.06 \\
0.06\end{array}$ \\
\hline$V=200$ & $\begin{array}{l}\text { Ipy.OOC.CH} \\
\text { Ipy.OOC. } \mathrm{CH}_{2}\end{array}$ & 1.7 \\
\hline
\end{tabular}

the conductance experiments are given in Tables VIII and IX.

From Table VIII it is apparent that although the equivalent conductance of Ipy. $\mathrm{NO}_{3}$ in acetone is small in comparison with that of $\mathrm{I}(\mathrm{py})_{2} \cdot \mathrm{NO}_{3}$, it is nevertheless appreciable. No explanation is offered for this phenomenon, other than the possibility that the conductance may be due to some decomposition product of the complex. It is entirely possible that acetone may to some extent enter the coördination sphere, forming a coördinate covalent bond with the iodine by means of a free pair of electrons on the carbonyl oxygen. Such a reaction would drive the nitrate ion out of the coördination sphere and thus make the compound a conductor. The data of Table IX lend credence to this hypothesis. Monopyridine iodine (I) nitrate conducts the current in methanol equally well whether or not pyridine is present, whereas the conductivity of the benzoate is enormously increased by the addition of pyridine. It should be borne in mind that the nitrate ion, being an extremely electronegative unit, would exhibit a lesser tendency than the benzoate ion to maintain a coördination bond. In the case of the nitrate com- 
plex, then, methanol may well coórdinate through a free pair of electrons on the oxygen atom. Although the conductance studies do not provide conclusive evidence, it appears likely that unipositive iodine has a coördination number of two in its complexes.

\section{TABLE IX}

Equivalent Conductance of Unipositive Iodine Complexes in Methanol at $20^{\circ}$

\begin{tabular}{clc}
\hline Dilution (liters/equiv.) & Salt & $\begin{array}{c}\text { Equivalent conduc- } \\
\left.\text { tance (ohm } \mathrm{cm}^{-2}\right)\end{array}$ \\
\hline $\mathrm{V}=100$ & Ipy. $\mathrm{NO}_{3}$ & $55 \cdot 3$ \\
& Ipy. $\mathrm{NO}_{3}+$ about two moles & \\
& of pyridine & 55 \\
& Ipy.OOC. $\mathrm{C}_{6} \mathrm{H}_{5}$ & 2 \\
& Ipy.OOC. $\mathrm{C}_{6} \mathrm{H}_{5}+$ about & \\
& 2 moles of pyridine & $\mathbf{1 5 . 2}$ \\
\hline
\end{tabular}

Mention has already been made of the $\alpha$ - and $\beta$-picoline coördinated positive iodine complexes of organic acids. ${ }^{2}$ Other salts in which methyl-substituted pyridines have been coördinated to unipositive iodine are the following: $\left[\mathrm{I}(\beta \text {-picoline })_{2}\right] \mathrm{NO}_{3},\left[\mathrm{I}(2,6 \text {-lutidine })_{2}\right] \mathrm{NO}_{3}$, $\left[\mathrm{I}(2,4 \text {-lutidine })_{2}\right] \mathrm{NO}_{3}$ and $\left[\mathrm{I}(2,4,6 \text {-collidine })_{3}{ }_{1 / 2}\right] \mathrm{NO}_{3}{ }^{7}$

The unipositive bromine complexes $\left[\mathrm{Br}(\mathrm{py})_{2}\right]_{\mathrm{NO}_{3}}{ }^{8,9}$ and $\left[\mathrm{Br}(\mathrm{py})_{2}\right] \mathrm{ClO}_{4}{ }^{9}$ have been prepared also, by methods similar to those used for the preparation of the corresponding iodine salts. The procedure used in the analysis of these compounds proves that the bromine is unipositive. A sample of the complex is treated with potassium iodide dissolved in sodium hydroxide solution; the solution is then acidified with sulfuric acid, and the liberated iodine is titrated with sodium thiosulfate solution. One atom of bromine liberates two of iodine:

$$
\mathrm{Br}^{+}+2 \mathrm{I}^{-}=\mathrm{Br}^{-}+\mathrm{I}_{2} \text {. }
$$




\section{TRIPOSITIVE IODINE}

There is considerable evidence that iodine may play a metallic role even in its tripositive state. Ozonized oxygen converts iodine to a compound having the formula $\mathrm{I}_{4} \mathrm{O}_{9} .{ }^{10}$ This substance is considered to be the normal iodate of tripositive iodine, $\mathrm{I}\left(\mathrm{IO}_{3}\right)_{3}$. The basic iodate, $\mathrm{IO}\left(\mathrm{IO}_{3}\right)$, results from the action of hot concentrated sulfuric acid on iodic acid, followed by treatment of the product with water. ${ }^{10}$ The oxidation of iodine by perchloric acid, or by ozone and perchloric acid, results in the formation of an iodine perchlorate, the composition of which may be represented by the formula $\mathrm{I}\left(\mathrm{ClO}_{+}\right)_{3}$. $2 \mathrm{H}_{2} \mathrm{O}^{11}$

Fuming nitric acid, in the presence of acetic anhydride, oxidizes iodine to the normal triacetate, $\mathrm{I}\left(\mathrm{OOCCH}_{3}\right)_{3} \cdot{ }^{12}$ This reaction has been utilized for the preparation of a whole series of compounds of tripositive iodine. ${ }^{11}$ The results are summarized in Table X.

These compounds are quite sensitive to moisture and unstable toward high temperatures. They are hydrolyzed in the following manner:

$$
{ }_{5} \mathrm{IPO}_{4}+{ }_{9} \mathrm{H}_{2} \mathrm{O}=\mathrm{I}_{2}+{ }_{3} \mathrm{HIO}_{3}+{ }_{5} \mathrm{H}_{3} \mathrm{PO}_{4} .
$$

Electrolytic studies demonstrate conclusively that the iodine in the compounds just described is in the triposi-

\section{TABLE $X$}

Some Compounds of Tripositive Iodine

\begin{tabular}{|c|c|}
\hline Com & Method of Preparation \\
\hline 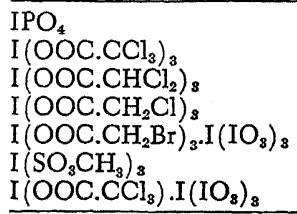 & $\begin{array}{l}\mathrm{I}_{2}+\mathrm{H}_{3} \mathrm{PO}_{4}+\left(\mathrm{CH}_{3} \mathrm{CO}\right)_{2} \mathrm{O}+\text { concentrated } \mathrm{HNO}_{3} \\
\mathrm{I}_{2}+\mathrm{CCl}_{3} \mathrm{COOH}+\left(\mathrm{CH}_{3} \mathrm{CO}\right)_{2} \mathrm{O}+\text { fuming } \mathrm{HNO}_{3} \\
\mathrm{I}_{2}+\mathrm{CHCl}_{2} \mathrm{COOH}+\left(\mathrm{CH}_{3} \mathrm{CO}\right)_{2} \mathrm{O} \text { +fuming } \mathrm{HNO}_{3} \\
\mathrm{I}_{2}+\mathrm{CH}_{2} \mathrm{ClCOOH}+\left(\mathrm{CH}_{3} \mathrm{CO}\right)_{2} \mathrm{O}+\text { fuming } \mathrm{HNO}_{3} \\
\mathrm{I}_{2}+\mathrm{CH}_{2} \mathrm{BrCOOH}_{3}\left(\mathrm{CH}_{3} \mathrm{CO}\right)_{2} \mathrm{O}+\text { fuming } \mathrm{HNO}_{3} \\
\mathrm{I}\left(\mathrm{OOCH}_{3}\right)_{8}+\mathrm{CH}_{3} \mathrm{SO}_{3} \mathrm{H} \\
\mathrm{I}_{2}+\mathrm{CCl}_{3} \mathrm{COOH}+\mathrm{O}_{8}\end{array}$ \\
\hline
\end{tabular}


tive state. ${ }^{11}$ When a saturated solution of iodine triacetate in acetic anhydride is electrolyzed, the quantity of silver iodide formed on a silvered platinum gauze cathode is in complete agreement with Faraday's law, on the assumption that the iodine is present as a tripositive cation.

\section{The Chemical Characteristics of Astatine, ELEMENT $85^{13}$}

Astatine, element 85 , was first prepared in quantities large enough for chemical study by the bombardment of bismuth with $32 \mathrm{mev}$. $a$-particles. The reaction involved, and the nuclear properties of the isotope of astatine formed, are shown below.

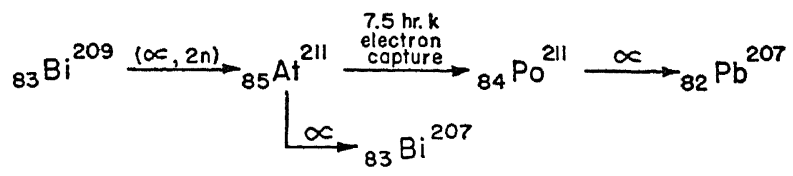

The properties of this short-lived element have been studied by tracer techniques with the aid of carriers. The chemical reactions of astatine are found, in general, to be more closely related to those of polonium, the element to its left in the periodic classification, than to those of iodine, its nearest neighbor in the same group. The results of these investigations may be summarized as follows:

(1) Hydrochloric acid does not precipitate astatine from a solution $0.25 \mathrm{~N}$ in nitric acid, lead and thallium being used as carriers.

(2) Astatine is not precipitated quantitatively from ammonium sulfide solution, silver and mercury being used as carriers. However, it is precipitated quantitatively by hydrogen sulfide from acid solutions up to $6 \mathrm{~N}$ in hydrochloric acid, bismuth, mercury, silver and antimony being 
used as carriers. The sulfide precipitate so obtained is not completely soluble in ammonium sulfide.

(3) Ammonia water or concentrated alkali precipitates element 85 , although not quantitatively. The apparent precipitation may possibly be due to adsorption by the carriers, which are mercury, iron, and others.

(4) Fractional hydrolysis of bismuth nitrate, containing 85 , by dilution with water, results in enrichment of the first fractions in 85 .

(5) Reducing agents such as sulfur dioxide, zinc, or stannous chloride, in hydrochloric or sulfuric acid solution, quantitatively precipitate free astatine.

(6) Silver nitrate does not precipitate astatine from a dilute nitric acid solution, potassium iodide being used as carrier.

(7) Recovery of astatine by distillation from a dilute nitric acid solution is poor and irregular. Iodine from a potassium iodide carrier is, however, practically completely recovered.

(8) Extraction of 85 with carbon tetrachloride, iodine serving as carrier, gives a poor but definite yield.

(9) Astatine is deposited on a copper plate from a $0.025 \mathrm{~N}$ nitric acid solution containing bismuth and mercury.

A recent report gives some information concerning the oxidation states of astatine. ${ }^{14}$ A negatively charged ion similar to the iodide ion is obtained on strong reduction, and has been identified by co-precipitation with silver iodide. At least two positive oxidation states may be obtained by the oxidation of astatine in aqueous solution with strong oxidizing agents. Astatine oxidized by cold bromine carries poorly on silver iodate, whereas hypochlorous acid produces an oxidation state which carries 
completely on silver iodate. Migration experiments show that the astatine exists in anionic complexes.

The physiological behavior of astatine is similar to that of iodine. Astatine is concentrated in the thyroids of nor$\mathrm{mal}$ and thyro-toxic guinea pigs, and excreted in a manner similar to iodine. ${ }^{15}$

\section{+8 Chllorine: The Percilorate Radical}

In spite of a report denying the existence of this radical, ${ }^{16}$ a critical examination of the literature ${ }^{17}$ indicates that the reaction between equivalent quantities of sil$\operatorname{ver}(\mathrm{I})$ perchlorate and iodine in an anhydrous ether medium results in large part in the formation of the free perchlorate radical, $\left(\mathrm{CIO}_{+}\right)_{\mathrm{x}}$, according to the equation

$$
\mathrm{XAgClO}_{4}+\mathrm{X} / 2 \mathrm{I}_{2}=\mathrm{XAgI}+\left(\mathrm{ClO}_{4}\right)_{x} \text {. }
$$

The reaction between silver perchlorate and iodine was carried out in the following manner. Iodine was added in small portions to a suspension of the silver salt in ether, and the mixture was shaken at intervals until the iodine color disappeared. No more than one equivalent of iodine was taken up by the silver perchlorate. About 10-1 5 per cent of the iodine used did not go directly into the formation of silver iodide, but rather into an exceedingly unstable iodine compound. The ethereal solution resulting from the reaction was shown to contain (1) $\alpha$-iodoether and perchloric acid formed by iodination of the solvent, (2) the perchlorate ether, $\mathrm{CH}_{3} \mathrm{CH}\left(\mathrm{ClO}_{4}\right)$. $\mathrm{OCH}_{2} \mathrm{CH}_{3}$, from reaction between the iodoether and silver perchlorate, and (3) a large quantity of a substance possessing considerable oxidizing power. The properties of the latter material which prove it to be the perchlorate radical are herewith summarized. 
It is instantly hydrolyzed by water with the formation of perchloric acid. Reaction with metals such as iron, copper, zinc, and magnesium yields perchlorates without hydrogen evolution, in contrast to the case when dilute perchloric acid in absolute ether is used. Treatment with magnesium iodide in absolute ether results in the liberation of iodine, by titration of which the quantity of perchlorate radical present may be determined. The most striking demonstration of the presence of the perchlorate radical, however, is to be found in the instantaneous combination with the free radical triphenylmethyl to form triphenylmethyl perchlorate, $\left(\mathrm{C}_{6} \mathrm{H}_{5}\right)_{3} \mathrm{CClO}_{4}$. This reaction is carried out in the complete absence of triphenylmethyl chloride (or the corresponding carbinol) and silver perchlorate, since these substances are also capable of yielding the perchlorate with triphenylmethyl. Moreover, in controls run with ethereal solutions of perchloric acid, formation of the perchlorate salt was slight, polymerization of the triphenylmethyl being the main reaction. 


\section{$\mathrm{V}$}

\section{Copper and Silver*}

HE existence of multiple oxidation states is a characteristic property of the transition elements. In

1 every case, however, there are a few states which, because of the readiness with which they are assumed, have come to be regarded as the normal oxidation states for these elements. In almost every instance, one of these states corresponds to the position of the element in the classical short form of the periodic tables. Indeed, it seems likely that our preoccupation with this system of classification has delayed the study of oxidation states which might until recently have appeared to be anomalous.

In the so-called group IB of the old system (copper, silver, and gold), for example, although the existence of dipositive copper and tripositive gold could hardly be ignored in view of the abundance of the familiar copper(II) and gold(III) compounds, nevertheless these states have been regarded as exceptional rather than typical. In recent years, however, abundant information has been accumulated with regard to di- and tripositive silver, as well as tripositive copper. In the present chapter these oxidation states will be considered, together with unipositive copper, which has been somewhat obscured by the greater stability of most of the common dipositive compounds. Such treatment will not only provide numerous illustrations of the factors which stabilize oxidation

\footnotetext{
*For an excellent brief review of the oxidation states of silver, see Bailar, J. Chem. Education, 21, 523 (1944).
} 
states less readily assumed than the familiar ones, but will also make it possible to bring out many more significant periodic relationships within the group than have previously been appreciated.

\section{Unipositrve COPPER}

The only simple salts of unipositive copper which are stable are those which are difficultly soluble in water. Indeed, copper(II) ion in aqueous solution, in the presence of certain of the anions (e. g., cyanide, iodide, thiocyanate, and xanthate) which form insoluble salts with cuprous ion, passes spontaneously into the latter state. Those simple copper(I) salts (e.g., the sulfate and fluoride) which disproportionate readily in aqueous medium into copper(II) ion and metallic copper, or those which like the nitrate and perchlorate, are too readily subject to internal oxidation-reduction to be capable of existence, are or would be predominantly ionic in character. On the other hand, the stable copper(I) salts, both simple and complex, have been considered to be those in which the copper possesses a considerable degree of covalent character. This hypothesis is borne out in the case of the simple cuprous halides, which become increasingly stable with increasing covalent character of the bond between copper and the halogen, ${ }^{1}$ from fluorine to iodine. Considerable additional evidence that the chief factor determining the stability of the cuprous state is the degree of covalent character of the bonds between the copper ions and neighboring ions or molecules may be derived from a study of the equilibrium

$$
{ }_{2} \mathrm{Cu}^{+}=\mathrm{Cu}+\mathrm{Cu}^{+2}{ }^{2}
$$

The effect on this equilibrium of two solvents in which the electrostatic interaction between the ions and 


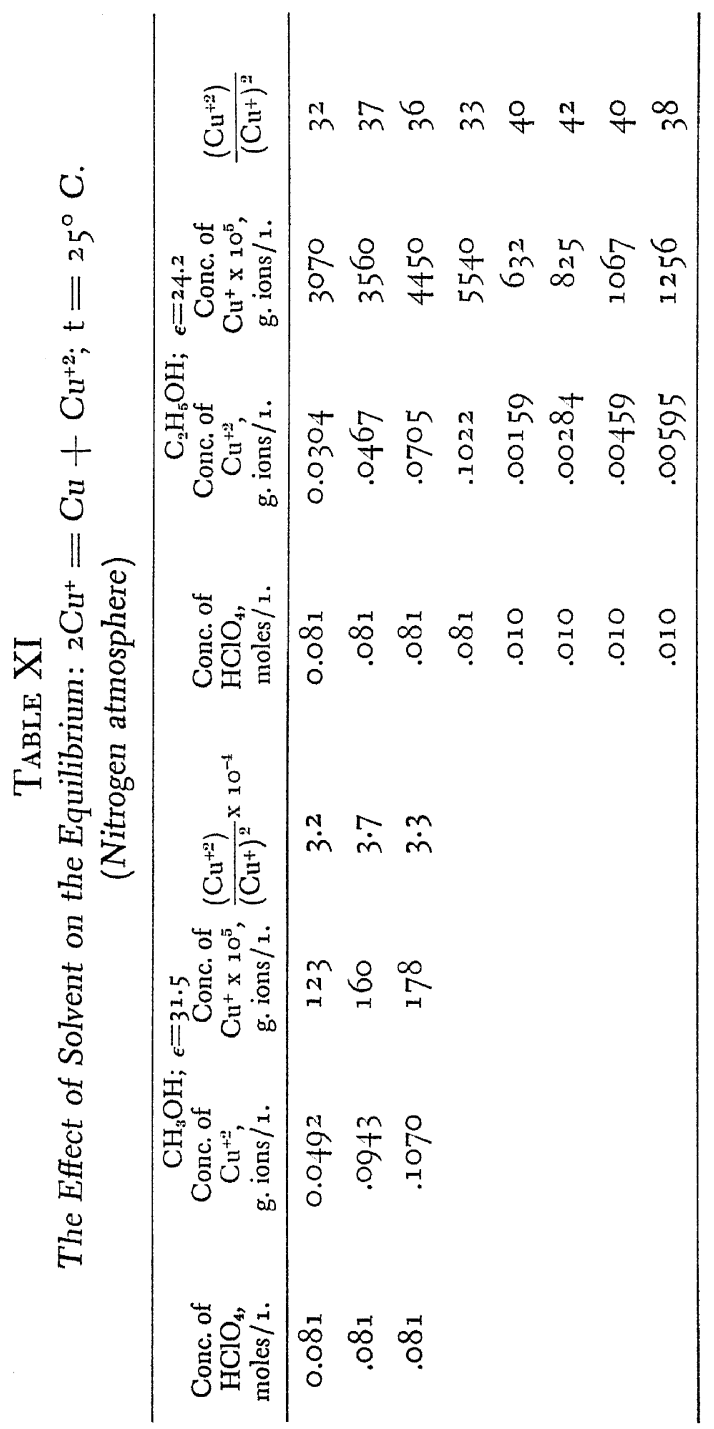


solvent molecules differs from that in water has been determined. Equilibration of copper(II) perchlorate with metallic copper in anhydrous methanol and ethanol as solvents gave the result shown in Table XI. These data show that with decrease in dielectric constant of the solvent there is a displacement of the equilibrium in such a direction as to favor the cuprous state. It may be concluded, therefore, that the shift in equilibrium in this direction parallels the decrease in electrostatic interaction between the ions and solvent molecules.

Experiments similar to that just described were performed in aqueous medium in the presence of various coördinating agents (e. g., chloride ion, ammonia,* methylamine, pyridine, ethylenediamine and tri- and pentamethylenediamines). In every instance, except with ethylenediamine and trimethylenediamine, the presence of coördinating agent markedly shifts the equilibrium in the direction of cuprous ion. All the coördinating groups mentioned form rather stable complexes with copper ions in water, and are probably more readily polarizable than the water molecule. Thus the formation of the complex is undoubtedly accompanied by an increase in the covalent character of the binding of the copper ion. The anomalous behavior of ethylenediamine and trimethylenediamine, both of which markedly favor the cupric state, is explained by the ability of these substances to form extremely stable chelates with cupric ion.

Although the experiments just described appear to prove beyond doubt that the chief factor influencing the stability of cuprous ion is the degree of covalence of its binding, this concept is not of general applicability to the

* It has been called to the author's attention that $\mathrm{CuNO}_{3} .2 \mathrm{NH}_{3}$ may be prepared by the reduction of copper(II) nitrate with copper in liquid ammonia. (Sec Sloan, J. Am. Chem. Soc., 32, 972 [1910]). 
oxidation states of other elements. ${ }^{3}$ Hydration, for example, does not always favor the higher state of oxidation, nor does the formation of purely covalent complexes invariably stabilize the lower state.

Many cuprous complexes of considerable stability are known. Among the substances which have been used to stabilize unipositive copper are aceto- and succinonitrile, thiourea and ethylenethiourea, thiosulfate and cyanide ions, and phosphine and arsine.

While it is impossible to prepare copper(I) nitrate, a complex of this substance with acetonitrile is readily obtained. ${ }^{4}$ Treatment of a dilute solution of silver nitrate in acetonitrile with finely divided copper yields a colorless solution from which, by removal of excess solvent under reduced pressure, crystals of $\mathrm{CuNO}_{3} \cdot 4 \mathrm{CH}_{3} \mathrm{CN}$ may be obtained. Dilute solutions of this complex in acetonitrile can be kept in contact with air for many hours without any evidence of oxidation; the crystalline material, however, is readily oxidized in air. Removal of the acetonitrile of solvation results in the formation of cupric nitrate and free copper. By reduction of the appropriate anhydrous cupric halides with the powdered metal in acetonitrile, compounds of the composition $\mathrm{CuCl} . \mathrm{CH}_{3} \mathrm{CN}$ and $\mathrm{CuBr} \cdot \mathrm{CH}_{3} \mathrm{CN}$ may be obtained. Solutions of these complexes in acetonitrile are not quite so stable as the corresponding nitrate solution. With succinonitrile, a nitrate complex of the formula $\mathrm{CuNO}_{3} .2 \mathrm{C}_{2} \mathrm{H}_{4}(\mathrm{CN})_{2}$ may be obtained by a method somewhat analogous to that used for the preparation of the corresponding acetonitrile compound. The succinonitrile complex is quite stable in air. It is readily soluble in water, from which hydrous copper(I) oxide is slowly precipitated. 
The existence of the following series of copper(I) complexes with thiourca (tu) has been demonstrated: ${ }^{5}$

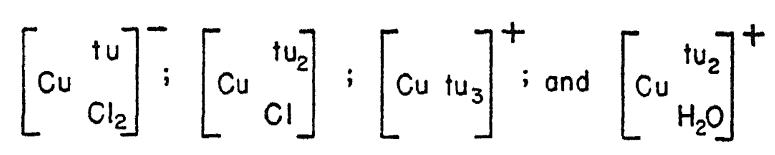

The parent member of the series, trithioureacopper(I) chloride, $\left[\mathrm{Cu} \mathrm{tu}_{3}\right] \mathrm{Cl}$, is readily obtained by the addition of freshly prepared copper(I) chloride to a hot aqueous solution of thiourea. The unipositive state is stabilized by coördination with thiourea to so great an extent that the parent complex is formed even when copper(II) chloride is used as starting material. ${ }^{6}$ Reaction between a dilute solution of trithioureacopper (I) chloride and potassium nitrate solution results in the precipitation of $\left[\mathrm{Cu} \mathrm{tu} \mathrm{H}_{2} \mathrm{O}\right] \mathrm{NO}_{3}$; a polymeric nitrate complex is formed when concentrated solutions are used. ${ }^{5}$ Treatment of $\left[\mathrm{Cu} \mathrm{tu}{ }_{3}\right] \mathrm{Cl}$ with dilute hydrochloric acid or a saturated solution of potassium chloride yields the insoluble $\left[\mathrm{Cu} \mathrm{tu}{ }_{2} \mathrm{Cl}\right]$. By reaction first with water and then with concentrated hydrochloric acid, ${ }^{5}$ the latter substance is converted to a complex which apparently contains $[\mathrm{Cu} \mathrm{tuCl}]^{-}$ion.

The cuprous state is stabilized also by coördination

with ethylenethiourca (ctu),

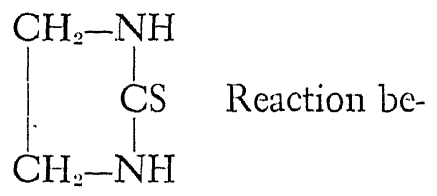

tween an excess of this substance and hot aqueous copper(II) nitrate solution results in the reduction of the latter to the +1 state. Concentration of the resulting solution yields the exceedingly stable salt $\left[\mathrm{Cu} \mathrm{etu}_{4}\right] \mathrm{NO}_{3}$, which is neutral to litmus in aqueous medium. ${ }^{\top}$ When a 
smaller proportion of ethylenethiourea is used, there is formed a hydrated binuclear complex which loses threefourths of its combined water at $110^{\circ}$. The last reaction is reversed upon exposure of the partly dehydrated substance to the atmosphere:

$$
\begin{gathered}
{\left[\mathrm{Cu}_{2} \mathrm{etu}_{5} \mathrm{H}_{2} \mathrm{O}\right]\left(\mathrm{NO}_{3}\right)_{2}+{ }_{3} \mathrm{H}_{2} \mathrm{O}=} \\
{\left[\mathrm{Cu}_{2} \mathrm{etu}_{5} \mathrm{H}_{2} \mathrm{O}\right]\left(\mathrm{NO}_{3}\right)_{2} \cdot 3 \mathrm{H}_{2} \mathrm{O}}
\end{gathered}
$$

The combining ratio of ethylenethiourea to unipositive copper appears to be dependent upon the nature of the anion, as shown by the compositions of the sulfate, acetate, and halide salts:

$[\mathrm{Cu} \mathrm{etu}]_{2} \mathrm{SO}_{4} ;\left[\mathrm{Cu} \mathrm{etu}{ }_{3}\right] \mathrm{C}_{2} \mathrm{H}_{3} \mathrm{O}_{2}$; and $\left[\mathrm{Cu} \mathrm{etu}{ }_{2}\right] \mathrm{X}$.

The first two substances are made by reaction of the complexing agent with the corresponding copper(II) compounds, whereas the halides are formed by direct combination with the simple copper(I) salts.

It has been long known that unipositive copper forms stable complexes with thiosulfate ion. A study of the reaction between copper(II) and thiosulfate ions by potentiometric and concentration-cell methods ${ }^{8}$ has led to the following conclusions. In moderately concentrated solutions (up to 1 molar), thiosulfate ion reacts with copper(II) ion according to the equation:

$$
{ }_{2} \mathrm{Cu}^{+2}+{ }_{2} \mathrm{~S}_{2} \mathrm{O}_{3}{ }^{-2}={ }_{2} \mathrm{Cu}^{+}+\mathrm{S}_{4} \mathrm{O}_{6}{ }^{-2} .
$$

In more concentrated solutions ( 3 to 6 molar) the mechanism becomes more complicated, other sulfur compounds, such as sulfites and sulfates, possibly being formed. A second stage, in either case, proceeds with the formation of cuprous complexes:

$$
\mathrm{n} \mathrm{Cu}+\mathrm{m} \mathrm{S}_{2} \mathrm{O}_{3}^{-2}=\left[\mathrm{Cu}_{\mathrm{n}}\left(\mathrm{S}_{2} \mathrm{O}_{3}\right)_{\mathrm{n}}\right]^{(2 \mathrm{~m}-\mathrm{n})}-\text {. }
$$


The complexes obtained, the compositions of which depend upon the nature of the thiosulfate used (i.e., sodium, potassium, or ammonium), may be classified into the types:

\section{$\mathrm{M}\left[\mathrm{CuS}_{2} \mathrm{O}_{3}\right] ; \mathrm{M}_{4}\left[\mathrm{Cu}_{2}\left(\mathrm{~S}_{2} \mathrm{O}_{3}\right)_{3}\right]$; and $\mathrm{M}_{5}\left[\mathrm{Cu}\left(\mathrm{S}_{2} \mathrm{O}_{3}\right)_{3}\right]$.}

The great tendency for the copper (I) ion to form stable complexes with the cyanide ion is illustrated by the fact that metallic copper will dissolve with the evolution of hydrogen in hydrocyanic acid, weak as it is, to give hydrogen tricyanocuprate $(\mathrm{I}), \mathrm{H}_{2} \mathrm{Cu}(\mathrm{CN})_{3} .{ }^{9}$ The copper $(\mathrm{I})$ cyanide complexes which have been the subject of many investigations may be grouped into the following types: ${ }^{10}$ ( $\mathrm{M}=$ alkali metal).

\section{$\mathrm{MCu}_{2}(\mathrm{CN}): ; \mathrm{M}_{2} \mathrm{Cu}_{3}(\mathrm{CN})_{\pi ;} ; \mathrm{MCu}(\mathrm{CN})_{2} ; \mathrm{M}_{2} \mathrm{Cu}(\mathrm{CN})_{3}$; and $\mathrm{M}_{3} \mathrm{Cu}(\mathrm{CN})_{4}$.}

It appears significant that the most stable of these complexes are those in which the copper reaches its maximum coördination number of four. For example, concentrated solutions of potassium tetracyanocuprate(I) are unaffected by hydrogen sulfide, whereas salts of the other types, upon treatment with this reagent, give a precipitate of copper sulfide. X-ray determination of the structure of potassium tetracyanocuprate(I) shows the four cyanide groups to be disposed tetrahedrally around the metal atom; this is in contrast to tetracovalent cupric complexes, which possess a planar structure. ${ }^{11}$ Interesting cyanide complexes containing both uni- and dipositive copper have been described. In these compounds the cupric ion is stabilized by chelation with ethylenediamine, and the cuprous ion by coördination with cyanide ion. ${ }^{12}$

Certain alkyl-substituted phosphines or arsines combinc with equimolecular quantities of copper (I) iodide, 
dissolved in potassium iodide solution, to give non-ionic compounds of the empirical formulas $\mathrm{R}_{3} \mathrm{P} . \mathrm{Cul}$ and $\mathrm{R}_{3}$ As.CuI. ${ }^{13}$ Molecular weight determinations and $\mathrm{X}$-ray analyses demonstrate conclusively, however, that the actual molecule in each instance is a polymer of four of the simple units shown above. In this manner, each copper atom attains its maximum coördination number of four, and the molecule its relatively high degree of stability.

Monomolecular non-ionic complexes in which the copper atom has a coördination number of four may be made from the polymers described above by treatment with $a, \alpha$-dipyridyl. ${ }^{13}$ When acetone solutions of iodo(tri-n-butylphosphine) copper(I) tetramer and four molecular equivalents of $\alpha, \alpha$-dipyridyl, are brought together a deep red mixture is formed, from which are deposited dark orange crystals of monoiodo ( $\alpha, \alpha$-dipyridyl ) (tri-n-butylphosphine) copper(I):

\section{[Bu $\mathrm{Bu}_{3}$ P.Cul.dipy].}

Molecular weight determinations prove this compound to be monomolecular. The stability of the complex is in great part attributable to the effect of the chelated $\boldsymbol{\alpha}$, a-dipyridyl group.

The monomolecular complex is readily soluble in most organic solvents. When such solutions are boiled, n-butylphosphine is evolved and a decp red substance is precipitated. ${ }^{13}$ The precipitate is identical with a connpound which is obtained by reduction of an ammoniacal solution of copper(II) sulfate with hydrazine, followed by treatment with dipyridyl and potassium iodide solution. ${ }^{14}$ On the assumption that the coördination number of the copper remains unchanged during the formation 
of the red complex from the phosphine derivative, the following formula ${ }^{13}$ has been assigned to the former compound:

$\left[\operatorname{dipy} \cdot \mathrm{Cu}^{-\mathrm{I}}-\mathrm{Cu} \cdot \operatorname{dipy}\right]$

TRIPOSITIVE COPPER

The results of early attempts to prepare compounds containing copper in an oxidation state higher than +2 are somewhat contradictory. About the only positive information to be gained from these studies is the fact that the oxidation of dipositive copper can be accomplished by means of halogens in an alkaline medium. ${ }^{15}$ The first proof of the existence of tripositive copper is provided by the results of an investigation of the electrolytic oxidation of a copper anode in concentrated sodium hydroxide solution. ${ }^{16}$ The material formed at the anode possesses powerful oxidizing properties, converting ammonia to the nitrite ion. The most favorable conditions for the oxidation of the anodic copper are (1), a well-cooled electrolyte of 12-14 $\mathrm{N}$ sodium hydroxide, and (2), a current density greater than 0.1 ampere per square centimeter of anode. Under these conditions a large amount of an olive-brown paste is obtained, which is shown by analysis to be an oxide of tripositive copper, contaminated with a small quantity of copper(II) oxide. That the copper comes off the anode in the tripositive form is confirmed by calculations involving the anodic loss of weight and Faraday's law.

Pure copper sesquioxide, $\mathrm{Cu}_{2} \mathrm{O}_{3}$, has been made by reaction between sodium hydroperoxide, $\mathrm{NaOOH}$, and cuprite ion, $\mathrm{CuO}_{2}{ }^{-2}$, in concentrated sodium hydroxide 
solution. ${ }^{17}$ The cuprite is prepared by the dissolution of freshly precipitated copper(II) hydroxide in 34 per cent sodium hydroxide solution. The tripositive oxide separates as a red precipitate, the yield, on the basis of the quantity of sodium cuprite used, being $80-90$ per cent. Characterization of the oxide is based upon elemental analysis and the determination of its oxidizing power.

That $\mathrm{Cu}_{2} \mathrm{O}_{3}$ is a true oxide, and not a peroxide, is shown by the fact that on acidification with sulfuric acid it gives no hydrogen peroxide. It is a powerful oxidizing agent, reacting with oxalic acid to give carbon dioxide and water, and liberating chlorine from concentrated hydrochloric acid. Thermally, $\mathrm{Cu}_{2} \mathrm{O}_{3}$ is rather stable; it begins to decompose at $100^{\circ}$, and at $400^{\circ}$ is completely converted to copper(II) oxide. Warm concentrated sulfuric acid dissolves $\mathrm{Cu}_{2} \mathrm{O}_{3}$ with the evolution of oxygen and the reduction of the copper to the dipositive state. The oxide dissolves appreciably in ammonia water, and slightly in concentrated sodium hydroxide solution.

Compounds containing tripositive copper as part of an anionic complex have been prepared also; the anion contains in addition either the tellurate or the periodate group. These groups, in which the respective central atoms are in their highest attainable oxidation states, appear to stabilize the tripositive copper. The tellurate complexes have been produced by two methods: (1) the anodic oxidation of copper in an electrolyte consisting of a strongly alkaline solution of potassium tellurate, ${ }^{18,19 a}$ and (2) the oxidation of dipositive copper in a strongly alkaline tellurate medium by potassium persulfate. ${ }^{18,19}$ No substance of fixed composition can be obtained from solutions in which potassium hydroxide is the alkaline medium; only hydrolysis products are isolated. ${ }^{19}$ However, 
treatment of such solutions with sodium ion permits the isolation of pure compounds, ${ }^{19 b}$ the compositions of which have been shown by analysis to be $\mathrm{Na}_{5} \mathrm{H}_{4}\left[\mathrm{Cu}\left(\mathrm{TeO}_{6}\right)_{2}\right]$. $18 \mathrm{H}_{2} \mathrm{O}$ and $\mathrm{Na}_{7} \mathrm{H}_{2}\left[\mathrm{Cu}\left(\mathrm{TeO}_{6}\right)_{2}\right] .12 \mathrm{H}_{2} \mathrm{O}$. The first compound, which is maroon in color, may be converted to the second, a dark chestnut red substance, by recrystallization from water. The compounds are diamagnetic, a fact which indicates planar $d s p^{2}$ binding in the complex anion.

The anodic oxidation of strongly alkaline solutions of dipositive copper in the presence of an excess of periodate ion gives complexes similar to those obtained with tellurate. ${ }^{20}$ The compounds which have been isolated, $\mathrm{K}_{7}\left[\mathrm{Cu}\left(\mathrm{IO}_{6}\right)_{2}\right] \cdot 7 \mathrm{H}_{2} \mathrm{O}$ and $\mathrm{Na}_{7}\left[\mathrm{Cu}\left(\mathrm{IO}_{6}\right)_{2}\right] \cdot 12 \mathrm{H}_{2} \mathrm{O}$, are, like the complex tellurates, diamagnetic.

\section{Dipositive Silver}

The electrolytic oxidation of silver nitrate solutions gives a black substance the formula of which approximates $\mathrm{Ag}_{7} \mathrm{O}_{8} \mathrm{NO}_{3}$. (This compound will be discussed in detail later.) Treatment of this oxynitrate with boiling water gives the black silver(II) oxide. ${ }^{21}$ This oxide may be obtained also by the oxidation of silver nitrate with potassium persulfate in an alkaline medium. ${ }^{22} \mathrm{AgO}$ is a true dipositive oxide, since acidification yields no hydrogen peroxide. It may be heated to $100^{\circ}$ without change; at higher temperatures it decomposes into silver and oxygen. AgO dissolves in dilute sulfuric acid with the evolution of oxygen; in concentrated nitric and sulfuric acids, however, it gives solutions of strong oxidizing power. ${ }^{21 b}$ Equilibration with dilute nitric acid changes the dipositive oxide to the black oxynitrate complex $\mathrm{Ag}_{7} \mathrm{O}_{8} \mathrm{NO}_{3} .{ }^{21 d}$ 
The voltage-current curve for a silver anode in sodium hydroxide solution shows that the silver is quantitatively oxidized first to $\mathrm{Ag}_{2} \mathrm{O}$ and then to $\mathrm{AgO}$ (Fig. 4). No evidence is obtained for an oxide of silver corresponding to an oxidation state greater than $+2 .{ }^{23}$ Measurement of the potential for the cell $\mathrm{Pt}, \mathrm{H}_{2}, \mathrm{I} \mathrm{N}, \mathrm{NaOH}, \mathrm{AgO}_{(\mathrm{s})}$, $\mathrm{Ag}_{2} \mathrm{O}_{(\mathrm{s})}, \mathrm{Pt}$ gives a value of 1.40 volts, which is practically independent of the hydroxyl ion concentration.

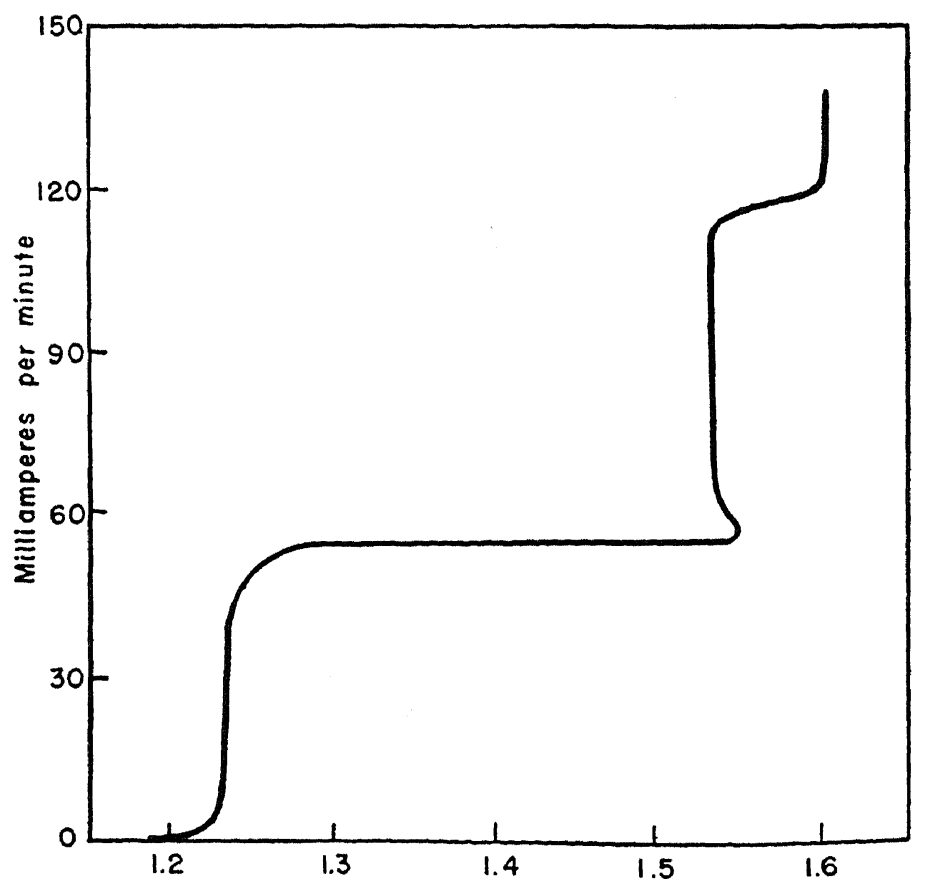

Voltage against Hydrogen Electrode in the Same Solution.

Fig. 4.-Oxidation of Silver in $1 \mathrm{~N} \mathrm{NaOH}$. 
Calculated thermodynamic constants ${ }^{210}$ for AgO have the values:

$$
\begin{gathered}
\Delta \mathrm{F}^{\circ}{ }_{298}=3.40 \mathrm{Kcal} ; \quad \Delta \mathrm{F}^{\circ}{ }_{273}=2.88 \mathrm{Kcal} ; \\
\Delta \mathrm{H}^{\circ}=-2.73 \mathrm{Kcal} .
\end{gathered}
$$

Silver(II) fluoride has been prepared by reaction between fluorine and silver or silver salts at temperatures below $450^{\circ} .{ }^{24}$ It is a dark brown substance, stable up to temperatures a little below $450^{\circ}$. Above this temperature it is completely decomposed into silver(I) fluoride and elementary fluorine. It reacts with water, with the liberation of oxygen and ozone. It is a powerful oxidizing agent, converting ethanol to acetaldehyde, low oxidation states of manganese to permanganate, and tripositive chromium to chromate. $\mathrm{AgF}_{2}$ reacts violently with many metals and nonmetals, and by reaction with sulfur dioxide and carbon monoxide forms $\mathrm{SO}_{2} \mathrm{~F}_{2}$ and $\mathrm{COF}_{2}$ respectively. It is a sufficiently powerful fluorinating agent to convert carbon tetrachloride to the tetrafluoride. $\mathrm{AgF}_{2}$ is strongly paramagnetic, but the value found for its molar susceptibility, $440 \times 10^{-6}$ gauss $/ \mathrm{cm}^{-1}$ at $20^{\circ}$, is far below the theoretical for one unpaired electron. ${ }^{24 \mathrm{~b}, 25}$

The reaction between silver(I) salts and ozone in nitric acid solution has been studied in great detail. ${ }^{26}$ In concentrated acid solution, at least, unipositive silver is converted to the dipositive state by ozone. The reaction does not go to completion, but results in the establishment of a steady state, ${ }^{26 a}$ because of the reduction of the dipositive silver by water with the evolution of oxygen. The initial rate of oxidation at $0^{\circ}$ of the unipositive silver is found to be proportional to the $\mathrm{Ag}(\mathrm{I})$ and ozone concentrations. This fact is accounted for in terms of a mechanism involving the formation of an intermediate ion 
containing tripositive silver, which may be formulated as follows:

$$
\begin{gathered}
\mathrm{Ag}^{+}+\mathrm{O}_{3}=\mathrm{AgO}^{+}+\mathrm{O}_{2} \text { (slow). } \\
\mathrm{AgO}^{+}+\mathrm{Ag}^{+}+2 \mathrm{H}^{+}=2 \mathrm{Ag}^{+2}+\mathrm{H}_{2} \mathrm{O} \text { (rapid). }
\end{gathered}
$$

The initial rate is only slightly affected by the acid concentration, or by the ionic strength of the solution.

Proof that the silver is actually oxidized to the dipositive state was furnished by three independent methods, only one of which will be discussed here, namely, the determination of the oxidation state by means of magnetic susceptibility measurements. ${ }^{26 \mathrm{~b}}$ The change in paramagnetic susceptibility resulting from the partial oxidation of a solution of unipositive silver was used to calculate the magnetic moment of the oxidized form, on the assumption that it is either $\mathrm{Ag}$ (II) or $\mathrm{Ag}$ (III). On the assumption that all the oxidized silver is in the dipositive state a moment of 1.98 Bohr magnetons is obtained, and for tripositive silver, a moment of 2.81 magnetons. The value of 1.98 magnetons corresponds with that to be expected for $\mathrm{Ag}(\mathrm{II})$ from its structural similarity with dipositive copper, and also from the known susceptibilities of complex salts of dipositive silver (to be discussed later). On the other hand, the value obtained on the assumption that the silver is present as $\mathrm{Ag}$ (III) is wholly inconsistent with the diamagnetism of the isoelectronic dipositive palladium (Janes, J. Am. Chem. Soc., 57, 471 [1935]), and also with the known diamagnetism of tripositive silver in complex compounds. To account for the fact that basic salts of tripositive silver are precipitated on dilution of aqueous solutions containing $\mathrm{Ag}$ (II), the equilibrium

$$
2 \mathrm{Ag}^{+2}+\mathrm{H}_{2} \mathrm{O}=\mathrm{Ag}^{+}+\mathrm{AgO}^{+}+2 \mathrm{H}^{+}
$$

is postulated. 
The kinetics of the reduction of dipositive silver by water has been investigated in various concentrations of nitric acid. ${ }^{2 a, c}$ The rate of reduction for the over-all reaction

$$
{ }_{4} \mathrm{Ag}^{+2}+{ }_{2} \mathrm{H}_{2} \mathrm{O} \longrightarrow \rightarrow{ }_{4} \mathrm{Ag}^{+}+{ }_{4} \mathrm{H}^{+}+\mathrm{O}_{2}
$$

is aclequately represented by the rate equation

$$
\frac{-\mathrm{d}\left(\mathrm{Ag}^{+2}\right)}{\mathrm{dt}}=\mathrm{k}_{1} \frac{\left(\mathrm{Ag}^{+2}\right)^{2}}{\left(\mathrm{Ag}^{+}\right)}+\mathrm{k}_{2} \frac{\left(\mathrm{Ag}^{+2}\right)^{4}}{\left(\mathrm{Ag}^{+}\right)} \text {. }
$$

$\mathrm{E}^{\circ}$, the formal oxidation potential (i.e., for a halfcell containing equal molarities of uni- and dipositive silver) has been measured for the reaction $\mathrm{Ag}(\mathrm{I})=\mathrm{Ag}(\mathrm{II})$ $+\mathrm{e}^{-}$in various concentrations of nitric and perchloric acids. ${ }^{27,21 a}$ The potential at $25^{\circ}$ in $4 \mathrm{M}$ perchloric acid is found to be -1.9998 volts; in $4 \mathrm{M}$ nitric acid, -1.9287 volts. Thermodynamic data have been calculated ${ }^{21 d}$ for the reactions:

$$
\begin{gathered}
\mathrm{Ag}(\mathrm{II})\left(4 \mathrm{MHNO}_{3}\right)+1 / 2 \mathrm{H}_{2}(\mathrm{I} \text { atm })= \\
\left.\mathrm{Ag}(\mathrm{I})\left(4 \mathrm{M} \mathrm{HNO}_{3}\right)+\mathrm{H}^{+} \text {(act. I M }\right)
\end{gathered}
$$

and

$$
\text { (b) } \begin{array}{r}
\mathrm{Ag}(\mathrm{II})\left(4 \mathrm{M} \mathrm{HClO}_{4}\right)+1 / 2 \mathrm{H}_{2}(\text { 1atm })= \\
\mathrm{Ag}(\mathrm{I})\left(4 \mathrm{M} \mathrm{HClO}_{4}\right)+\mathrm{H}^{+} \text {(acct. 1M) }
\end{array}
$$

For reaction (a), $\Delta \mathrm{F}^{\circ}=-44.49 \mathrm{Kcal} ., \Delta \mathrm{H}^{\circ}=-41.0 \mathrm{Kcal}$; for (b) $\Delta \mathrm{F}^{\circ}=-46.13 \mathrm{Kcal} ., \Delta \mathrm{H}^{\circ}=-41.1 \mathrm{Kcal}$.

Of interest is the hypothesis that $\mathrm{Ag}$ (II), as well as the higher oxidation states of other elements, is decomposed by water with the evolution of oxygen because of the tendency to form hydrogen peroxide. ${ }^{26 c, 27}$ On the basis of this hypothesis such reactions will take place 
only if their oxidation potentials approach or exceed the potential for the reaction

$$
\mathrm{H}_{2} \mathrm{O}_{2}+2 \mathrm{H}^{+}+2 \mathrm{e}^{-}=2 \mathrm{H}_{2} \mathrm{O}(1),
$$

which is 1.77 volts.

There is little doubt that dipositive silver in nitric acid solution exists principally in the form of nitrate complexes. The evidence may be summarized as follows. ${ }^{21 \mathrm{~d}}$

1. Solutions of $\mathrm{Ag}$ (II) in nitric acid are black to brown in color, whereas in perchloric acid solutions, of concentrations 60 per cent and below, they are pink.

2. The oxidation potential for the reaction $\mathrm{Ag}(\mathrm{I})=$ $\mathrm{Ag}$ (II) $+\mathrm{e}^{-}$is considerably different in $4 \mathrm{M}$ nitric acid than in perchloric acid of the same concentration.

3. The solubility of the complex oxynitrate, of approximate formula $\mathrm{Ag}_{7} \mathrm{O}_{8} \mathrm{NO}_{3}$, increases at constant $\mathrm{pH}$ with increasing nitrate ion concentration. *

4. Transference experiments show that, in the dark brown solutions formed by the dissolution of $\mathrm{Ag}_{7} \mathrm{O}_{8} \mathrm{NO}_{3}$ in concentrated nitric acid, some silver goes to the anode. ${ }^{28}$

The complex compounds of dipositive silver are highly colored crystalline substances, many of which are readily obtained and extremely stable in air. All of the compounds which have been prepared contain groups possessing at least one nitrogen atom capable of acting as a donor in the formation of a coördinate covalent bond.

Treatment of silver nitrate in pyridine with potassium persulfate results in the formation of orangeyellow needles of tetrapyridinesilver(II) persulfate, $\left[\mathrm{Ag}(\mathrm{py})_{4}\right] \mathrm{S}_{2} \mathrm{O}_{8}{ }^{29}$ The dipositive character of the silver is

* The dissolution in nitric acid of $\mathrm{Ag}_{8} \mathrm{O}_{8} \mathrm{NO}_{3}$, which contains some tripositive silver, gives solutions containing $\mathrm{Ag}$ (II) (ref. 21d). 
cstablished by the fact that the compound is isomorphous with the corresponding $\mathrm{Cu}$ (II) ${ }^{295}$ and $\mathrm{Cd}(\mathrm{II})^{30}$ complexes. The complex persulfate is unaffected by light. Tetrapyridinesilver(II) nitrate $\left[\mathrm{Ag}(\mathrm{py})_{4}\right]\left(\mathrm{NO}_{3}\right)_{2}$ may be prepared by the electrolytic oxidation of silver nitrate in a concentrated solution of pyridine in water. ${ }^{31}$ The complex is isolated in small yield from the anode liquor as orange-red needles. The compound gives the usual reactions associated with dipositive silver; it oxidizes dipositive manganese to permanganate and ammonia to nitrogen, is decolorized by hydrogen peroxide, and is converted to $\mathrm{AgO}$ by sodium hydroxide.

Studies on the preparation of complex compounds

with $\alpha, a$-dipyridyl

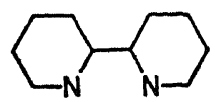

as the coördinating

agent, indicate that dipositive silver may have a coördination number of either four or six. ${ }^{32}$ By means of the persulfate oxidation of unipositive silver, two general types of ions, $\left[\mathrm{Ag}(\text { dipy })_{2}\right]^{+2}$ and $\left[\mathrm{Ag}(\operatorname{dipy})_{3}\right]^{+2}$, have been prepared. A binuclear complex ion of the composition $\left[\mathrm{Ag}_{2}\left(\text { dipy }_{5}\right]^{++4}\right.$ has been isolated also. The $\left[\mathrm{Ag}(\text { dipy })_{2}\right]^{+2}$ ion may also be obtained electrolytically. ${ }^{33}$

Complex salts with orthophenanthroline containing the ion

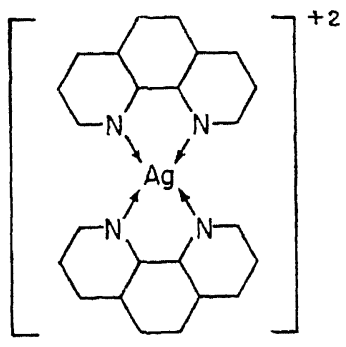


are brown, stable substances, ${ }^{34}$ which do not decompose even in strongly acid solution in the cold. The stability of these compounds is doubtless enhanced by ring formation in the complex ion. The complexes are isomorphous with the analogous dipositive copper and cadmium salts.

A series of salts of the probable configurations

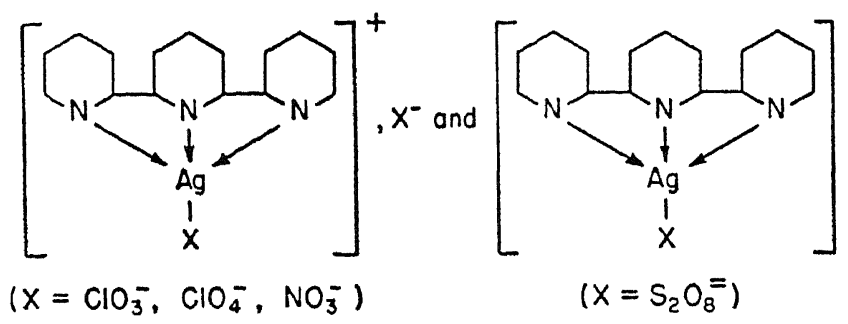

have been prepared from the tridentate amine tripyridyl..$^{35}$ They are regarded as planar in configuration, in keeping with the known structure of other four-coördinated dipositive silver complexes.

Picolinic acid ${ }^{36}$ and quinolinic acid,<smiles>O=C(O)C1CCCNC1C(=O)O</smiles>

form red crystalline compounds with dipositive silver:

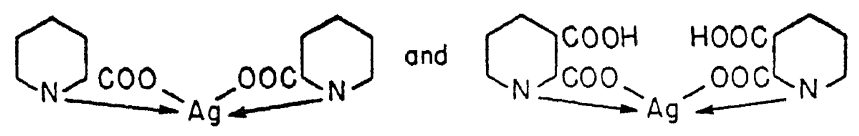

$\mathrm{X}$-ray analysis shows the picolinic acid complex to be planar and isomorphous with the corresponding dipositive copper salt.

The statement has been made that a deep green dipositive silver complex of the constitution 


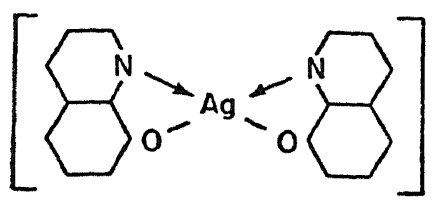

is precipitated when hot solutions of silver(I) acetate and 8-hydroxyquinoline are mixed. ${ }^{38}$ Two independent investigations, however, have failed to verify this; ${ }^{39}$ in fact, the deep green complex possesses magnetic properties corresponding to $\mathrm{Ag}(\mathrm{I})$ rather than to $\mathrm{Ag}$ (II).

Several investigations have been made of the magnetic properties of dipositive silver complexes. ${ }^{40}$ All such compounds, as is to be expected, are paramagnetic, having in general a moment corresponding closely to that required for one unpaired electron. In the dipyridyl series, however, compounds in which the dipositive silver has a coordination number of six give a distinctly higher value for the magnetic moment.

\section{Triposittve Silver}

The electrolysis of silver(I) nitrate in nitric acid solution gives, at an inert anode, a black crystalline substance which has been exhaustively investigated. ${ }^{21,41}$ The same substance may be obtained by the equilibration of $\mathrm{AgO}$ with dilute nitric acid, ${ }^{21 d}$ and by the action of fluorine on an aqueous solution of silver(I) nitrate. ${ }^{42}$ The composition of this black material approximates the formula $\mathrm{Ag}_{7} \mathrm{O}_{8} \mathrm{NO}_{3},{ }^{41 a, b}$ though a more precise investigation gives $\mathrm{AgO}_{1.148}\left(\mathrm{NO}_{3}\right)_{0.153}$ as the empirical formula. ${ }^{21 d}$

The average oxidation number of silver in the black oxynitrate is $2.448 .^{21 \mathrm{~d}}$ The compound contains no peroxy oxygen. ${ }^{41 \mathrm{c}}$ It is a powerful oxidizing agent, converting oxalic acid to carbon dioxide, and ammonia to nitro- 
gen. ${ }^{41 a}$ Boiling water reacts with the oxynitrate to give $\mathrm{AgO}$, silver(I) nitrate, and oxygen. ${ }^{21}$ Examination of single crystals and powders of the oxynitrate by X-ray diffraction shows that it has a face-centered cubic structure with a cubc edgc of $9.870 \AA . .^{43}$

The electrolytic reduction of argentic oxynitrate at constant current in I $\mathrm{N}$ sodium hydroxide solution offers additional evidence that the substance contains some tripositive silver. ${ }^{23}$ Three definite potentials are observed, one of 1.57 volts, a second of 1.41 volts, and a third of 1.17 volts. The second and third potentials correspond to known values for the $\mathrm{AgO}, \mathrm{Ag}_{2} \mathrm{O}$ and $\mathrm{Ag}_{2} \mathrm{O}, \mathrm{Ag}$ stages, respectively; the value of 1.57 volts must, therefore, correspond to the reduction of a higher oxidation state than +2 , probably +3 .

Evidence has been obtained for the formation of $\mathrm{Ag}_{2} \mathrm{O}_{3}$ by the action of dry ozone on powdered silver, ${ }^{44}$ in which a bluish-black substance, possessing powerful oxidizing properties, is obtained. In $1 \mathrm{~N}$ potassium hydroxide solution it gives a potential of 1.57 volts, which shortly drops to 1.43 volts. The first value agrees with that obtained previously 33 for the reduction of silver of oxidation number greater than two.

It has been demonstrated that the marked catalytic effect of $\mathrm{Ag}^{+}$ion in certain oxidations by persulfate ion is attributable to the formation of the unstable $\mathrm{Ag}^{+3}$ ion. ${ }^{45}$ The rates of oxidation of $\mathrm{Cr}^{+3}$ to $\mathrm{Cr}_{2} \mathrm{O}_{7}{ }^{-2}, \mathrm{VO}^{+2}$ to $\mathrm{VO}_{3}^{-}$, $\mathrm{Mn}^{+2}$ to $\mathrm{MnO}_{2}$, and $\mathrm{N}_{2} \mathrm{H}_{4}$ to $\mathrm{N}_{2}$ are directly proportional to the concentrations of $\mathrm{S}_{2} \mathrm{O}_{8}{ }^{-2}$ and $\mathrm{Ag}^{+}$ions, but are independent of the concentration of the reducing agent. The reaction mechanism, which appears to be essentially the same in each case, is believed to consist of a slow oxidation of $\mathrm{Ag}^{+}$to $\mathrm{Ag}^{+3}$ by persulfatc ion, followed by a 
rapid reaction between $\mathrm{Ag}^{+3}$ and reducing agent with the regencration of $\mathrm{Ag}^{+}$. This may be illustrated as follows in the case of the oxidation of $\mathrm{Cr}^{+3}$ to $\mathrm{Cr}_{2} \mathrm{O}_{7}^{-2}$ :

$$
\begin{gathered}
\mathrm{Ag}^{+}+\mathrm{S}_{2} \mathrm{O}_{5}^{-2}=\mathrm{Ag}^{+3}+{ }_{2} \mathrm{SO}_{4}^{-2} \text { (slow) } \\
3 \mathrm{Ag}^{+3}+2 \mathrm{Cr}^{+3}+7 \mathrm{H}_{2} \mathrm{O}=\mathrm{Cr}_{2} \mathrm{O}_{7}^{-2}+3 \mathrm{Ag}^{+}+14 \mathrm{H}^{+} \text {(rapid). }
\end{gathered}
$$

If silver (I) nitrate is permitted to react with persulfate ion in the absence of other reducing agents, an unstable black precipitate is formed which, on rapid analysis, may be shown to contain two oxidizing equivalents for each atom of silver. ${ }^{45 a, 46}$ The substance obtaincd is believed to be either an impure form of $\mathrm{Ag}_{2} \mathrm{O}_{3}$ or a basic sulfate of tripositive silver ${ }^{45 a}$ the reactions of the compound are those of a weakly basic oxidc. During the course of precipitation the acidity of the solution incrcases. The precipitate is fairly soluble in concentrated sulfuric, nitric, or perchloric acid, giving a deep brown color. The solubility increases rapidly with the concentration of the acid; dilution of the acid solution results in reprecipitation of the black substance. The acid solutions show no test for hydrogen peroxide. The substance, suspended in dilute acid, shows the usual reactions of a very strong oxidizing agent. On standing, the oxidizing power decreases until a value is reached which, if the original substance is considered to be $\mathrm{Ag}_{2} \mathrm{O}_{3}$, corresponds to the formula $\mathrm{Ag}_{2} \mathrm{O}_{3} .2 \mathrm{AgO} .^{46}$

An unstable oxide or basic salt of tripositive silver is precipitated during the electrolytic oxidation of silver(I) perchlorate in perchloric acid solution. This substancc appears also to be formed on the surface of $\mathrm{AgO}$ on treatment with perchloric acid. ${ }^{21 a}$

The stability of tripositive silver may be increased considerably by coördination with other ions or molecules. Periodate and tellurate complexes, analogous to those 
obtained for tripositive copper, have been prepared..$^{19,20,47}$ The electrolytic oxidation of telluric acid at a silver anode is said to yield a compound of the formula $5 \mathrm{Ag}_{2} \mathrm{O}_{3} \cdot \mathrm{Ag}_{2} \mathrm{O}$. ${ }_{9} \mathrm{TeO}_{3}$; no analyses are given, however. ${ }^{19 a}$ Compounds which have been isolated and analyzed are

$$
\begin{gathered}
\mathrm{HK}_{6}\left[\dot{\mathrm{Ag}}\left(\mathrm{IO}_{6}\right)_{2}\right] \cdot 10 \mathrm{H}_{2} \mathrm{O}, \mathrm{HK}_{6}\left[\mathrm{Ag}\left(\mathrm{IO}_{6}\right)_{2}\right] \cdot \mathrm{KOH} \cdot 8 \mathrm{H}_{2} \mathrm{O}, \\
\mathrm{KNa}_{6}\left[\mathrm{Ag}\left(\mathrm{IO}_{6}\right)_{2}\right] \cdot \mathrm{NaOH} \cdot \mathrm{H}_{2} \mathrm{O}, \\
\mathrm{Na}_{6} \mathrm{H}_{3}\left[\mathrm{Ag}\left(\mathrm{TeO}_{6}\right)_{2}\right] \cdot 18 \mathrm{H}_{2} \mathrm{O} \text {, and } \\
\mathrm{Na}_{7} \mathrm{H}_{2}\left[\mathrm{Ag}\left(\mathrm{TeO}_{6}\right)_{2}\right] \cdot 14 \mathrm{H}_{2} \mathrm{O} .
\end{gathered}
$$

These substances which are yellow to orange in color, are obtained by the persulfate oxidation of $\mathrm{Ag}(\mathrm{I})$ in a strongly alkaline periodate or tellurate medium; all are diamagnetic. ${ }^{19 \mathrm{~b},} 20$

Four-coördinated salts of tripositive silver with ethylenedibiguanide have been prepared, ${ }^{48}$ which probably have the constitution

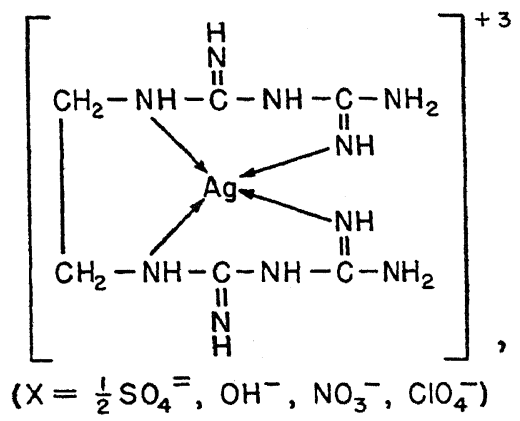

$3 x^{-}$

Oxidation to the tripositive state is accomplished with potassium persulfate. These compounds are deep red to violet-red in color, and are stable at ordinary temperatures. The nitrate can be recrystallized from dilute nitric acid. The compounds liberate two equivalents of iodine from acidified potassium iodide solution per atom of sil- 
ver. Their molecular conductance at infinite dilution corresponds to that of other salts of the composition $\mathbf{M X}_{3}$. The complexes are diamagnetic, a fact which indicates that the bonds are of the planar $d s p^{2}$ type.

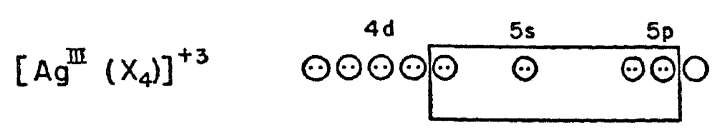

In this respect tripositive silver resembles tripositive gold. 


\section{VI}

\section{Chromium and Manganese}

MONG the remaining transition elements whose
oxidation states are very numerous and varied,
there are five elements which stand out as being atomic numbers 24 through 29; namely, chromium, manganese, iron, cobalt, and nickel.

Chromium and manganese occupy an almost unique position because of the common employment of compounds of these elements in their highest oxidation states as oxidizing agents. When these compounds are so used in acid solution, the reduction products are $\mathrm{Cr}^{+3}$ and $\mathrm{Mn}^{+2}$ ions respectively; and these states too, as well as most of the intermediate states of manganese, have been extensively studied. In each case, however, a still lower oxidation state is attainable through drastic reduction. It is these lower states, as well as the intermediate +5 state of manganese, which are comparatively unfamiliar and which will constitute the subject of the present chapter.

\section{Simple and Double Chromium(II) Salts}

The only simple chromium(II) salts which have been investigated in any great detail are the chloride and the acetate. The former has been prepared in a variety of ways. Reduction of anhydrous chromium(III) chloride by hydrogen at high temperatures gives the corresponding anhydrous dipositive salt. ${ }^{1}$ Aqueous solutions of this substance and of other dipositive chromium salts, may be made by 
the cathodic reduction of solutions of the appropriate chromium(III) compounds, ${ }^{2}$ as well as by reduction with zinc and hydrochloric acid. ${ }^{3}$ For example, chromium(II) sulfate has been prepared electrolytically in the following manner. The cell consisted of a pure lead cathode immersed in a catholyte consisting of a solution of chromium(III) sulfate in $2 \mathrm{~N}$ sulfuric acid, which was separated by means of a porous disk from an anolyte of the same acid. After electrolysis for 16 hours at a current density of 0.0135 ampere per square centimeter, $\mathrm{CrSO}_{4 .} .5 \mathrm{H}_{2} \mathrm{O}$ of 98.5 per cent purity was precipitated by the addition of alcohol to the cathodic solution. Anhydrous chromium(II) acetate may be obtained from a cencentrated solution of the chloride by metathesis with sodium acetate. ${ }^{4}$ Because of the ease with which it may be obtained in pure condition, chromium(II) acetate is used as the starting material for the preparation of many of the other dipositive compounds. Treatment of chromium (II) acetate with concentrated hydrochloric acid, provided the temperature is kept low, ${ }^{4 \mathrm{~b}, 5}$ results in the formation of the bright blue $\mathrm{CrCl}_{2.4} \mathrm{H}_{2} \mathrm{O}$. The blue tetrahydrate changes, above $3^{\circ}$, to an isomeric green modification, and at $51^{\circ}$ the green form loses water, yielding the pale blue trihydrate..$^{\text {a }}$

Several salts containing dipositive chromium in combination with organic anions are known. ${ }^{2 a}$ The addition of powdered sodium formate to an electrolytically reduced chloride solution, which is kept under petroleum ether to prevent oxidation, yields $\mathrm{Cr}(\mathrm{OOCH})_{2} \cdot 2 \mathrm{H}_{2} \mathrm{O}$ as a fine red powder. This substance is readily oxidized in air. If ammonium formate is used as the precipitating agent, a very unstable double salt of the composition $\mathrm{NH}_{4} \mathrm{OOCH}$. $\mathrm{Cr}(\mathrm{OOCH})_{2}$ is formed. Chromium(II) glycollate dihydrate may be formed in a manner similar to that used 
for the preparation of the formate. A simple malonate dihydrate and a double salt of the formula $\mathrm{Na}_{2}\left(\mathrm{C}_{3} \mathrm{H}_{2} \mathrm{O}_{4}\right)$. $\mathrm{Cr}\left(\mathrm{C}_{3} \mathrm{H}_{2} \mathrm{O}_{4}\right) \cdot 4 \mathrm{H}_{2} \mathrm{O}$ have also been reported.

An interesting compound is the blue double sulfate $\mathrm{K}_{2} \mathrm{SO}_{4}$. $\mathrm{CrSO}_{4} \cdot 6 \mathrm{H}_{2} \mathrm{O}$. This crystallizes slowly from a mixture of solutions of chromium(II) chloride and potassium sulfate to which alcohol has been added. The rhombic crystals are isomorphous with those of $\mathrm{K}_{2} \mathrm{SO}_{4} \cdot \mathrm{FeSO}_{4}$. $6 \mathrm{H}_{2} \mathrm{O} .^{4 \mathrm{a}}$

The simple chromium(II) ion is a potent reducing agent, being readily oxidized in air and even capable, under some conditions, of liberating hydrogen from aqueous solutions. Certain metals and their salts catalyze the latter reaction. One investigator has claimed that neutral and acidic chromium(II) chloride solutions are not oxidized spontaneously in the absence of air, even on boiling. ${ }^{*}$ However, the addition of catalysts, such as platinum, palladium, gold and copper salts, and arsenic(III) and antimony (III) sulfides, accelerates the reaction. ${ }^{6}$ The platinum group metals and their salts similarly catalyze the oxidation of chromium(II) salts in alkaline solution. ${ }^{7}$ The velocity of oxidation in ammoniacal solutions is greater than in acid solutions, and increases with increasing concentration of ammonia. In these solutions the reaction is autocatalytic, being catalyzed by the tripositive chromium formed. ${ }^{2 b}$

Numerous other instances of the action of dipositive chromium as a powerful reducing agent have been reported. These reductions are herewith summarized briefly: nitric oxide to ammonia; ${ }^{8}$ acetylene to ethylene; ${ }^{9}$ fumaric to succinic acid; cinnamic to phenylpropionic acid; ben-

* Asmanov (ref. 2b) has stated that difositive chromium in hydrochloric acid solution is oxidized with the liberation of hydrogen. 
zaldoxime to benzylamine; ${ }^{10}$ hydrocyanic acid to methylamine; chloroacetic to acetic acid; oxalic to glycollic acid; thiocyanic acid to methylamine; hydrazoic acid to ammonia and nitrogen. ${ }^{?}$

\section{Complex Compounds of Dipositrue Chromium}

Considerable work has been carried out on the ammine complexes of dipositive chromium. A variety of studies have been made on the complexes of chromium(II) chloride and ammonia. ${ }^{11}$ The most comprehensive of these investigations ${ }^{11 c}$ has involved a phase study of the system $\mathrm{CrCl}_{2}-\mathrm{NH}_{3}$. The results of this study are shown diagrammatically in Fig. 5. This shows the existence of four ammoniates; significant data concerning these complexes are tabulated below.

\section{TABLe XII}

Data Concerning Ammoniates of $\mathrm{CrCl}_{2}$

\begin{tabular}{cccl}
\hline Ammine & $\begin{array}{c}\text { Analysis, moles } \mathrm{NH}_{3} \\
\text { per mole } \mathrm{CrCl}_{2}\end{array}$ & $\begin{array}{c}\text { Dissociation } \\
\text { pressure, cm. }\end{array}$ & \multicolumn{1}{c}{ Color } \\
\hline $\mathrm{CrCl}_{2} \cdot 6 \mathrm{NH}_{3}$ & 6.01 & 23.25 & dark blue \\
$\mathrm{CrCl}_{2} \cdot 5 \mathrm{NH}_{3}$ & 4.95 & 3.5 & violet \\
$\mathrm{CrCl}_{2} \cdot 3 \mathrm{NH}_{3}$ & 3.03 & 0.85 & light blue \\
$\mathrm{CrCl}_{2} \cdot 2 \mathrm{NH}_{3}$ & 2.00 & practically & zero \\
& & zage green & \\
\hline
\end{tabular}

The diammine described above undergoes an interesting reaction with chlorine at elevated temperatures. Reaction begins at $250^{\circ}$, when a reddish-violet hygroscopic substance which is unstable in air is formed; at $275^{\circ}$ the color of the substance changes to deep purple, and ammonium chloride is evolved. At a still higher temperature complete reaction takes place, with the formation of anhydrous chromium(II) chloride, ammonium chloride and nitrogen. The reaction involves the direct 
oxidation of ammonia, the chromous ion being unaffected. The triammine behaves similarly.

Other complexes of ammonia with dipositive chromium have been described. Violet chromium(II) formate $\mathrm{Cr}(\mathrm{OOCH})_{2 .} 1 / 2 \mathrm{H}_{2} \mathrm{O}$, which may be prepared from a solution of the red dihydrate previously described, ${ }^{2, a}$ absorbs after dehydration under nitrogen at $170^{\circ}$, four moles of ammonia to give the tetrammoniate. ${ }^{6}$ When dry ammonia is passed into a suspension of anhydrous chromium (II) acetate in benzene, an ammoniate of the formula $\left[\mathrm{Cr}\left(\mathrm{C}_{2} \mathrm{H}_{3} \mathrm{O}_{2}\right)\right]_{2} \cdot \mathrm{NH}_{3}$ is formed; this substance is readily oxidized by air. ${ }^{12}$

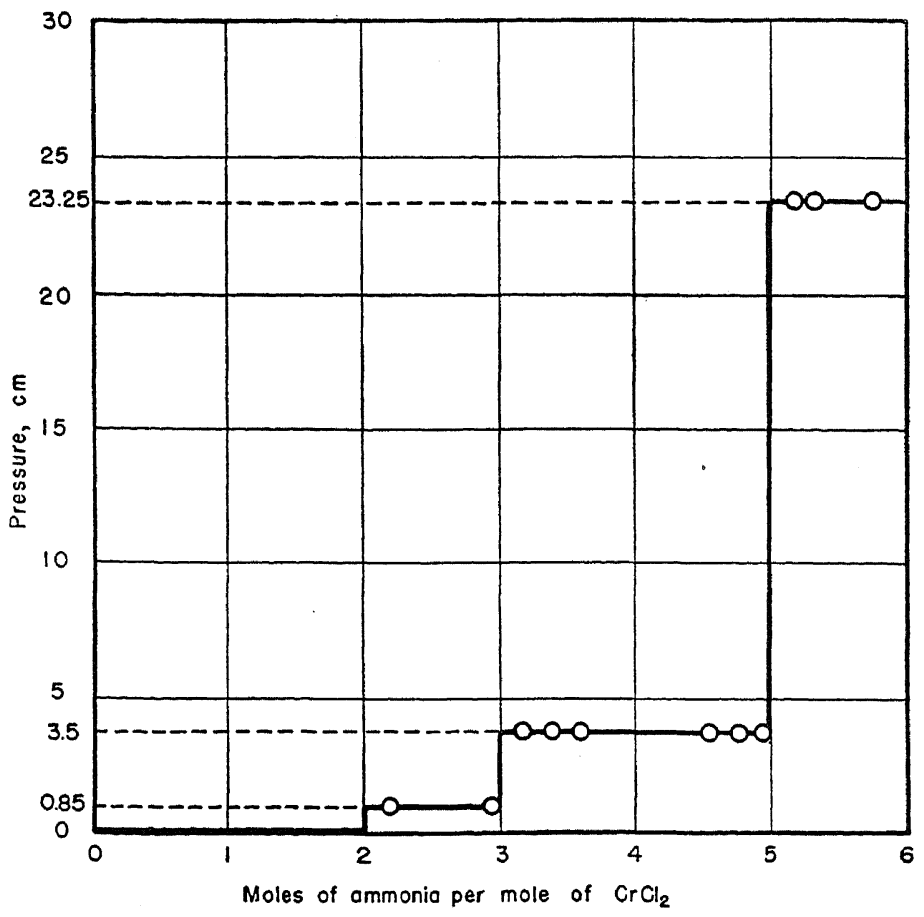

Frg. 5.-System Chromous Chloride-Ammonia at $35.5^{\circ}$. 
Whereas most complexes of dipositive chromium are more or less unstable in water and air, those containing hydrazine as the complexing agent are unusually stable toward atmospheric oxidation. ${ }^{13}$ The inertness of these compounds toward such oxidation may be attributed in great part to the stabilizing influence of the reducing properties of hydrazine. The complexes thus far made are all relatively insoluble in water, and are therefore prepared by precipitation from solutions of chromium(II) acetate. The dihydrazino complexes of the chloride, bromide, and iodide of dipositive chromium, and the compound $\mathrm{CrSO}_{4} .2 \mathrm{~N}_{2} \mathrm{H}_{4} \cdot \mathrm{H}_{2} \mathrm{SO}_{4}$, have been made in this manner. When these compounds are dissolved in acids or in aqueous ammonia, the dipositive chromium is readily oxidized in air.

Chromium(II) ammines containing bases with nitrogen in the ring have been rather extensively investigated. Compounds reported with pyridine as the complexing agent are:

$$
\begin{gathered}
\mathrm{Cr}(\mathrm{OOCH})_{2} \cdot \mathrm{C}_{5} \mathrm{H}_{5} \mathrm{~N}^{6}{ }^{6}\left[\mathrm{Cr}\left(\mathrm{C}_{2} \mathrm{H}_{3} \mathrm{O}_{2}\right)_{2}\right]_{2} \cdot \mathrm{C}_{5} \mathrm{H}_{5} \mathrm{~N},{ }^{12 *} \\
\mathrm{Cr}\left(\mathrm{C}_{2} \mathrm{H}_{3} \mathrm{O}_{2}\right)_{2} \cdot \mathrm{C}_{5} \mathrm{H}_{5} \mathrm{~N}_{5}^{14} \mathrm{CrCl}_{2} \cdot \mathrm{C}_{5} \mathrm{H}_{5} \mathrm{~N} .2 \mathrm{H}_{2} \mathrm{O}^{6} \text { and } \\
\mathrm{CrCl}_{2} \cdot \mathrm{C}_{5} \mathrm{C}_{5} \mathrm{~N}^{111,15}
\end{gathered}
$$

On record are the $a, \alpha$-dipyridyl complex of chromium(II) bromide, $\left[\mathrm{Cr}\left(\mathrm{C}_{10} \mathrm{H}_{8} \mathrm{~N}_{2}\right)_{3}\right] \mathrm{Br}_{2} \cdot 6 \mathrm{H}_{2} \mathrm{O}$, and the complexes with hexamethylenetetramine,

$$
\mathrm{Cr}(\mathrm{SCN})_{2.2}\left(\mathrm{C}_{6} \mathrm{H}_{12} \mathrm{~N}_{4} \cdot \mathrm{HSCN}\right) \text {, }
$$

and $\mathrm{CrCl}_{2} .2 \mathrm{HCl} . \mathrm{C}_{6} \mathrm{H}_{12} \mathrm{~N}_{4} \cdot 4 \mathrm{H}_{2} \mathrm{O} .{ }^{16}$ A red solution, presumably containing a complex, is formed on the addition of o-phenanthroline to a solution of chromium(II) ace-

* Hume and Stonex were able to obtain only traces of a product when they followed the directions given for making this compound. 
tate. ${ }^{17}$ This solution undergoes a sharp and reversible change to reddish-violet with oxidizing agents in acid solution. From the behavior of the oxidized compound with ferrous ion it is shown that the potential of the redox system described approximates that of the $\mathrm{Fe}^{+2}-\mathrm{Fe}^{+3}$ system. Measurement of the potential of the $\mathrm{Cr}^{+2}-\mathrm{Cr}^{+3}$ system in the presence of o-phenanthroline indicates that this reagent markedly stabilizes dipositive chromium toward oxidation. The chromiun complexes formed are of little value as indicators, since the color intensity is not high and color contrast at the end-point not sufficiently great.

The following observations concerning the stability of chromium(II) ammines have been made. ${ }^{15}$ Ammines containing ethylenediamine, 1,2-propylenediamine, or 2,3-butylenediamine cannot be isolated from aqueous solution because of the rapid oxidation of the chromium to the tripositive state by the water. However, when the dipositive chromium is coördinated with dipyridyl, pyridine, or quinoline, it is stable toward water, and in the case of the dipyridyl is somewhat stabilized also against atmospheric oxidation.

A few complex compounds of miscellaneous classifcation have also been described. A dark-blue cyanide of the formula $\mathrm{K}_{4} \mathrm{Cr}(\mathrm{CN})_{6} \cdot 6 \mathrm{H}_{2} \mathrm{O}$ is isolated upon treatment of chromium(II) acetate with an excess of potassium cyanide in a hydrogen atmosphere. ${ }^{18} \mathrm{~A}$ dark-blue substance approximating the formula $\mathrm{Na}_{3} \mathrm{Cr}(\mathrm{CNS})_{5}$. ${ }_{11} \mathrm{H}_{2} \mathrm{O}$ is obtained when chromium(II) acetate is added to a cold solution of sodium thiocyanate, ${ }^{19}$ this complex thiocyanate is unusually sensitive to air and moisture. Alkali metal salts of anthranilic acid give an orange precipitate of the normal inner complex salt. ${ }^{14}$ Orange-yel- 
low chromium (II) 8-hydroxyquinolate is quantitatively precipitated upon the addition of a solution of chromium(II) chloride to an excess of 5 per cent 8-hydroxyquinoline in $2 \mathrm{M}$ acetic acid, ${ }^{14}$ the compound appears to be unaffected by air. Since analyses of this substance do not correspond with any simple formula, no formula is suggested.

The Magnitic Properties of Dipositive Chromium Compounds

The magnetic behavior of solid chromium(II) sulfate hexahydrate and of anhydrous chromium(II) chloride has been studied over the range from 54 to $400^{\circ} \mathrm{K} .{ }^{20}$ The sulfate obeys the Curie-Weiss Law and possesses a paramagnetic moment of 4.82 Bohr magnetons, corresponding to the four unpaired 3 d electrons of the dipositive chromium ion. The chloride on the other hand, shows abnormal behavior, although at high temperatures it exhibits a moment similar to that obtained for the sulfate.

In an effort to determine the nature of the binding in the complexes, the magnetic susceptibilities of dilute solutions of chromium(II) chloride and its unstable com-

\section{TABLE XIII}

Paramagnetic Susceptibilities of Dipositive Chromium in Various Compounds

\begin{tabular}{|c|c|c|c|}
\hline Compound & Molarity of $\mathrm{Cr}$ & $\begin{array}{l}\text { Molarity of other } \\
\text { constituent }\end{array}$ & $\begin{array}{c}\mu \text { obsd. } \\
\text { (Bohr magnetons) }\end{array}$ \\
\hline \multicolumn{4}{|l|}{ Chromium(II) } \\
\hline & $0.135^{8}$ & & 5.00 \\
\hline Ammonia comples & $\mathrm{ex} .0281$ & $8.3^{8}$ & 4.90 \\
\hline \multicolumn{4}{|l|}{ Ethylenediamine } \\
\hline \multicolumn{4}{|l|}{ Thiocyanate } \\
\hline complex & .0680 & 2.50 & 4.90 \\
\hline Cyanide complex & .0442 & 0.664 & 3.15 \\
\hline
\end{tabular}


plexes with cyanide, * thiocyanate, ammonia, and ethylenediamine have been measured. ${ }^{14}$

It is apparent that, in every case but that of the cyanide complex, the binding between the dipositive chromium and the complexing agent is ionic in nature. The cyanide complex involves octahedral bond formation $\left(d^{2} s p^{3}\right)$, with the result that two of the four unpaired electrons of the dipositive chromium are paired and the magnetic moment lowered; this is illustrated below.

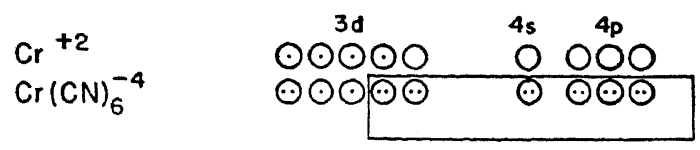

Unipositive Manganese

The reduction in an atmosphere of hydrogen of an alkaline solution of hexacyanomanganate(II) ion, $\mathrm{Mn}(\mathrm{CN})_{e}{ }^{-4}$, by granulated aluminum or by Devarda's alloy results in the formation of an intensely yellow solution containing a complex cyanide of unipositive manganese. $^{21 a}$ Conversion to the unipositive state to the extent of as much as 80 per cent is obtained. The unipositive manganese is a powerful reducing agent. In air it is oxidized to hexacyanomanganate(III) ion, $\mathrm{Mn}(\mathrm{CN})_{6}{ }^{-3}$; it bleaches indigo and methylene blue, and converts dipositive lead or cadmium to the elementary state.

Filtration of the yellow solution of the unipositive manganese into an alkaline solution containing sodium cyanide and sodium acetate yields a white precipitate which analyzes as $\mathrm{Na}_{5} \mathrm{Mn}(\mathrm{CN})_{6} .{ }^{21 \mathrm{~b}}$ The corresponding potassium compound may be obtained in a similar man-

* In acid solution below $\mathrm{pH}_{5}$ or 6 the cyanide complex is exceedingly unstable. If the solutions are neutralized to these $\mathrm{pH}$ values, however, the complex is quite stable. 
ner. The same investigators present cvidence, of a not completely conclusive nature, that the ion $\mathrm{Mn}(\mathrm{CN})_{3}{ }^{-2}$ may also exist.

The potassium complex cyanide of unipositive manganese may be isolated as a white salt by the cathodic reduction of potassium hexacyanomanganate(II) in the absence of air. ${ }^{22}$ With a $0.05 \mathrm{M}$ solution of the dipositive complex, and a current density of 0.065 ampere per s.q. $\mathrm{cm}$. of cathode $(\mathrm{Pt})$ surface, yields corresponding to a current efficiency of 15 per cent are obtained. Although the results of analysis of the whitc compound prepared under conditions described above approximate those calculated for the formula $\mathrm{K}_{3} \mathrm{Mn}(\mathrm{CN})_{4}$, other investigators have reported that the electrolytic reduction of potassium hexacyanomanganate(II) givcs a whitc double salt of the constitution $\mathrm{K}_{2}\left[\mathrm{Mn}(\mathrm{CN})_{3}\right] \cdot \mathrm{K}_{4}\left[\mathrm{Mn}(\mathrm{CN})_{6}\right]_{.}{ }^{23}$ It should be stated, however, that the analyses reported correspond no more than approximatcly with the composition for the compound.

Attempts to determine by magnetic measurcments the constitution of the potassium cyanide complex of manganese(I) which was prepared by reduction of the hexacyanomanganate(II) ion with aluminum powder in alkaline medium, have not proved very successful. ${ }^{24} \mathrm{Al}$ though the material gave a minimum value of $1.04 \mathrm{Bohr}$ magnetons for the molar susceptibility, ${ }^{24 \mathrm{~b}}$ the tentative formula assigned to it was $\mathrm{K}_{5} \mathrm{Mn}(\mathrm{CN})_{6}$, which corresponds to a diamagnetic compound. It was suggested that the magnetic value obtained indicates the presence of a small residual paramagnetism. It must be pointed out, however, that chemical analysis of the material studied suggests the likelihood of contamination with some higher oxidation state of manganese. 


\section{Pentapositive Manganese}

The reaction of manganese dioxide with an excess of potassium carbonate at a temperature above $700^{\circ}$ is said to lead to the formation of potassium manganate $(\mathrm{V})$ $\mathrm{K}_{3} \mathrm{MnO}_{4}{ }^{25}$ The introduction of manganese dioxide and sodium peroxide into a sodium nitrite melt at approximately $500^{\circ}$ produces an intense blue coloration. Crystallization of this material from concentrated sodium hycroxide solution gives sodium manganate(V) decahydrate, $\mathrm{Na}_{3} \mathrm{MnO}_{4} .10 \mathrm{H}_{2} \mathrm{O}$, as bright blue prisms. ${ }^{26}$ When a solution of the pentapositive manganese compound in concentrated potassium hydroxide solution is heated, disproportionation into manganate(VI) ion and manganese dioxide occurs. Sodium manganate $(V)$ may be prepared also by the reduction of the manganate(VI) or permanganate with sodium sulfite in cold, strongly alkaline solution.

It has recently been demonstrated that pentapositive manganese can be detected polarographically in strongly alkaline solutions. ${ }^{27}$ The first step in the reduction of $0.001 \mathrm{M}$ potassium permanganate in $0.1 \mathrm{M}$ sodium hydroxide solution is accompanied by a diffusion current corresponding to a one-electron change; second and third steps similarly involve one-electron changes. The fourth and final step proceeds with the deposition of manganese dioxide at the platinum electrode. Indirect evidence has indicated that pentapositive manganese in $0.1 \mathrm{M}$ sodium hydroxide solution persists no longer than a few minutes. 


\section{VII \\ Iron, Cobalt, and Nickel}

B ECAUSE of their close resemblance to each other, the elements making up the family of triads, namely iron, cobalt, nickel, and the platinum metals, were assigned to a separate group in the Mendeléeff periodic classification. Although these elements do possess many similarities, the chemical differences are sufficiently pronounced to warrant the study of the best-known triad, consisting of iron, cobalt, and nickel, as a unit, separate from the platinum metals.

A review of the literature on iron, cobalt, and nickcl shows that comparativcly little is known concerning any of the oxidation states of these elements other than the familiar ones. Iron exhibits, in addition to the usual +2 and +3 states, the unfamiliar oxidation states of +4 and +6 , as exemplified by the perferrite, $\mathrm{FeO}_{3}{ }^{-2}$, and the ferrate, $\mathrm{FeO}_{4}{ }^{-2}$, anions. The most stable oxiclation state of nickel is +2 , and for cobalt +2 in simple compounds and +3 in most complex compounds. Additional, less stable, states for cobalt are +3 (in simple compounds) and +4 ; and for nickel, $0,+1,+3$, and +4 . Although, theoretically, a maximum oxidation state of +8 is attainable in this group (and indeed is observed with ruthenium and osmium), no acceptable evidence exists for this state in the case of any of the triad under discussion.

\section{TETrapositive IroN}

The known perferrites, $\mathrm{SrFeO}_{3}$ and $\mathrm{BaFeO}_{3}$, have been made only by the interaction of solids at high tempera- 
tures. Strontium perferrite is obtained by hating a mixture of ferric and strontium nitrates in a current of air at temperatures not above $600^{\circ}$; barium perferrite is formed when ferric and barium hydroxides are heated at $400^{\circ}$ in a stream of oxygen. ${ }^{1}$ It is interesting that analyses of the solids formed never correspond exactly to the stoichiometric formulas for perferrites, there being always a deficiency of oxygen. It would appear, therefore, that the formulas assigned above to the perferrites are idealized.

This supposition is borne out by studics on the solid phase reaction between barium carbonate and ferric oxide. $^{2}$ The first step in the reaction appears to be the formation of ferrite, which is followed by atmospheric oxidation of the iron. The most favorable temperature for this oxidation lies between 835 and $880^{\circ} .{ }^{2 a}$ At temperatures about $700^{\circ}$ for all mixtures containing 50 to 97 per cent of barium carbonate, a compound of idealized formula $\mathrm{BaFeO}_{3}$ is present in the products. The range of mixtures giving rise to this compound narrows considerably with increasing temperature of reaction. By heating mixtures containing $7^{2}$ per cent barium carbonate at $80^{\circ}$, barium perferrite may be obtained substantially free from barium carbonate, ferric oxide, and barium oxide. X-ray evidence indicates that the perferrite has a perovskitelike structure. The composition of this compound is best represented by the formula $\mathrm{Ba}_{8} \mathrm{Fe}_{8} \mathrm{O}_{21}$, the lattice being defiicient in oxygen. ${ }^{2 \mathrm{~b}}$

Barium perferritc is an efficient catalyst for the oxidation of carbon monoxide. ${ }^{2 c}$ This fact has been explained in terms of the deficiency in oxygen in the crystal lattice. The formula for the compound, as has been stated, corresponds approximately to $\mathrm{Ba}_{5} \mathrm{Fe}_{s} \mathrm{O}_{21}$, although the 
structure calls for the formula $\mathrm{BaFeO}_{3}$. More oxygen ions, therefore, are readily accommodated in the crystal without fundamental change in lattice; and upon accommodation of more oxygen in the crystal, oxidation of the carbon monoxide at the surface can readily occur.

The perferrites are rather stable in alkaline media, but when acidified evolve oxygen, the iron being reduced to the tripositive state. Strontium perferrite decomposes slowly above $65^{\circ}$ with the liberation of oxygen. ${ }^{1}$ Barium perferrite is stable to at least $880^{\circ} .^{2 a}$

It has been suggested that the ferryl ion, $\mathrm{FeO}^{+2}$ is an intermediate in several chemical reactions. Among the reactions mentioned are the catalytic decomposition of hydrogen peroxide by ferric ion, the reduction of ferric ion by stannous tin, and the oxidation of ferrous ion by iodine. $^{3}$

\section{The Ferrates}

Sodium and potassium ferrates have been prepared in a variety of ways. The reaction of iron powder with fused potassium nitrate gives only a small yield of potassium ferrate. ${ }^{4}$ Better yields of alkali metal ferrates are obtained by passing chlorine into a suspension of ferric hydroxide in concentrated alkaline solution. ${ }^{5,4 b}$ The product isolated, however, is always contaminated with ferric hydroxide and with the alkali used. ${ }^{4 b}$ A solution of sodium ferrate may be made by fusion of ferric oxide and sodium peroxide, and cxtraction of the resulting mixture with ice-water. ${ }^{5 b}$

Several investigators have studied the anodic oxidation of iron in alkaline solution as a source of ferrate solutions. ${ }^{6}$ The results of the most comprehensive investigation dealing with the formation of sodium ferrate solutions $^{6 e}$ are hercwith summarized. Increasing tempera- 
tures up to $50^{\circ}$, and high alkali concentration, favor ferrate formation; with increasing current density the yield goes through a maximum. The current yield of sodium ferrate is increased considerably by occasional cathodic polarization of the anode to keep it from becoming passive. To avoid cathodic reduction of the ferrate formed, anode and cathode compartments must be separated by a diaphragm. At high temperatures the anodic dissolution of iron in concentrated sodium hydroxide solution takes place in two stages: ( 1 ) the formation at $70^{\circ}$ of dipositive iron; and (2) its oxidation to ferrate.

Calcium, ${ }^{4 b}$ strontium, and barium ${ }^{7,4 b}$ ferrates are made from solutions of alkali metal ferrates by metathetical reactions. Barium ferrate has served also as a source of other heavy metal ferrates. ${ }^{4 b}$

The soluble ferrates give deep red solutions which, as has already been pointed out, are stabilized by high hydroxyl ion concentration. ${ }^{6}$ In acid solution, ferrate ion is a powerful oxidizing agent. ${ }^{4 b, 5 b}$ If a non-oxidizable acid is present, oxygen is liberated from solution. When ferrate ion undergoes reduction, ferric ion is formed. At high temperatures, ferrate solutions decompose with the liberation of oxygen and the precipitation of hydrous ferric oxide. ${ }^{6}$ Thermal decomposition of solid ferrates gives as ultimate products oxygen, ferric oxide, and the appropriate metal oxide. ${ }^{4 b}$ The decomposition of barium ferrate has been studied in some detail; the important stages in its breakdown are shown below:

$$
\mathrm{BaFeO}_{4} \stackrel{123^{\circ}}{\longrightarrow} \mathrm{BaFeO}_{3} \stackrel{144^{\circ}}{\longrightarrow}>\mathrm{BaO}+\mathrm{Fe}_{2} \mathrm{O}_{3} \text {. }
$$

The Zero Oxidation State of Nickel

The reduction of potassium tetracyanonickelate(II) by an excess of potassium in liquid ammonia gives a bulky 
yellow precipitate which turns copper colored when freed of ammonia. ${ }^{8}$ From the reaction ratio $\mathrm{K}: \mathrm{K}_{2}\left[\mathrm{Ni}(\mathrm{CN})_{4}\right]$, and from analysis, the empirical formula of the product is found to be $\mathrm{K}_{4}\left[\mathrm{Ni}(\mathrm{CN})_{4}\right]$; hence the oxidation state of the nickel is zero. This substance, potassium tetracyanonickelate $(\mathrm{O})$, is extremely unstable in air, turning black on exposure. It dissolves in water with the formation of a deep red basic solution, and the simultaneous evolution of hydrogen. The red solution possesses all the properties characteristic of unipositive nickel.

The following resonance structures have been postulated for the $\mathrm{Ni}(\mathrm{CN})_{4}{ }^{-4}$ ion, which is isoclectronic with nickel tetracarbonyl, $\mathrm{Ni}(\mathrm{CO})_{4} .{ }^{9}$ *

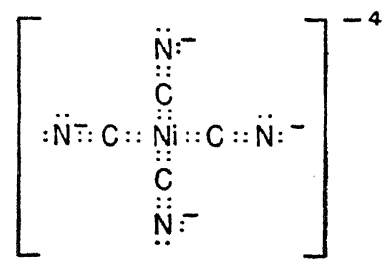

(A)

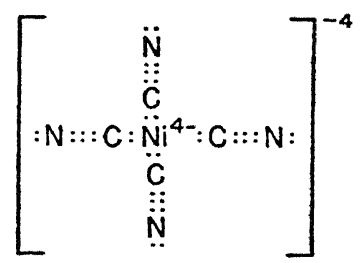

(B)

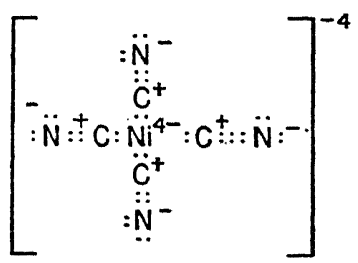

(c)

* It has recently been demonstrated that the postulated structural analogy between $\mathrm{K}_{4} \mathrm{Ni}(\mathrm{CN})_{4}$ and nickel tetracarbonyl is real. Reactions in which potassium cyanide displaces carbon monoxide from nickel carbonyl or in which carbon monoxide displaces potassium cyanide from $\mathrm{K}_{k} \mathrm{Ni}(\mathrm{CN})_{4}$ have been carried out in methyl cyanide as solvent. The products formed always corresponded to tetracoördination of nickel in a zero oxidation state (Burg and Dayton, $\mathrm{Ab}$ stracts, of Papers, San Francisco meeting of the American Chemical Society, March 27-April I, 1949, p. 28-0). 


\section{UNIPOSITIVE NICKEL}

The reduction of aqueous solutions of potassium tetracyanonickelate(II), $\mathrm{K}_{2}\left[\mathrm{Ni}(\mathrm{CN})_{4}\right]$, by various agents in a hydrogen atmosphere yields a deep red solution with powerful reducing properties, being capable of liberating hydrogen from water. ${ }^{10}$

Reduction of the tetracyanonickelate(II) by tin or zinc and sodium hydroxide, hydroxylamine, stannous chloride in alkaline solution, sodium or potassium amalgam, or the electric current, has yielded this red solution containing nickel in a low oxidation state. Oxidation of the red solution by air or other reagents gives the original dipositive nickel complex. Isolation of a deep red substance from the reduced solution may be accomplished by precipitation with alcohol in the absence of air; analysis of this material gives results corresponding to the empirical formula $\mathrm{K}_{2}\left[\mathrm{Ni}(\mathrm{CN})_{3}\right] .^{10 \mathrm{~d}, 8}$ This cyanide complex of unipositive nickel may also be conveniently obtained in the pure condition by the action of sodium or potassium on a solution of the tetracyanonickelate(II) in liquid ammonia. ${ }^{8}$

Acidification of aqueous solutions of $\mathrm{K}_{2}\left[\mathrm{Ni}(\mathrm{CN})_{3}\right]$ results in the precipitation of orange-red $\mathrm{NiCN}$, which dissolves in potassium cyanide solution with the formation of the original complex. ${ }^{10 d}$ Solutions of the unipositive nickel complex rapidly absorb carbon monoxide, becoming pale orange. The quantity of carbon monoxide absorbed corresponds to the formation of $\mathrm{K}_{2}\left[\mathrm{Ni}(\mathrm{CN})_{3} \mathrm{CO}\right] .{ }^{11}$ Nitric oxide is similarly absorbed, but the products of reaction have not been identified.11a Aqueous solutions of $\mathrm{K}_{2}\left[\mathrm{Ni}(\mathrm{CN})_{3}\right]$ are rather stable in the absence of an excess of cyanide; this ion, however, appears to catalyze the oxidation of unipositive nickel 
by water. ${ }^{10 e, 11 a}$ It is claimed that the presence of cyanide ion tends to give the nickel in the complex ion a greater coördination number than is compatible with an oxidation state of $+1 .{ }^{11 a}$

The effect of the presence of cyanide ion is further substantiated by measurements of the electromotive force of the cell $\mathrm{Pt}, \mathrm{Ni}^{+}, \mathrm{Ni}^{+2}, \mathrm{KCN} / \mathrm{Hg}_{2} \mathrm{Cl}_{2}, \mathrm{Hg}$. The electromotive force rises sharply when excess cyanide ion is present. ${ }^{12}$ The influence of the concentration ratio of the uni- and dipositive complexes on the oxidation potential for the reaction $\mathrm{Ni}^{+}=\mathrm{Ni}^{+2}+\mathrm{e}^{-}$in a cyanide medium is shown in Table XIV. ${ }^{13}$

\section{TABLE XIV \\ Oxidation Potentials*}

System: Pt, $\mathrm{K}_{2}\left[\mathrm{Ni}(\mathrm{CN})_{3}\right], \mathrm{K}_{2}\left[\mathrm{Ni}(\mathrm{CN})_{4}\right] / /$ normal $\mathrm{Hg}_{2} \mathrm{Cl}_{2}, \mathrm{Hg}$ Conditions: Measurements made in a $0.5 \mathrm{~N}$ potassium hydroxide solution which originally contained about 0.1 mole of $\mathrm{K}_{2}\left[\mathrm{Ni}(\mathrm{CN})_{4}\right]$ per liter; $\mathrm{t}=+2^{\circ}$; hydrogen atmosphere over cell.

\begin{tabular}{lll}
\hline $\mathrm{K}_{\mathrm{i}}\left[\mathrm{Ni}(\mathrm{CN})_{3}\right]$ & $\mathrm{K}_{2}\left[\mathrm{Ni}(\mathrm{CN})_{4}\right]$ & $\mathrm{K}_{\mathrm{h}}$ \\
\hline $0.068 \mathrm{~mole} / \mathrm{l}$. & $0.038 \mathrm{~mole} / 1$. & 0.889 \\
.045 & .051 & .857 \\
.038 & .068 & .840 \\
.033 & .073 & .828 \\
\hline
\end{tabular}

Two resonance structures have been suggested for the $\left[\mathrm{Ni}(\mathrm{CN})_{3}\right]^{-2}$ ion. $^{9}$

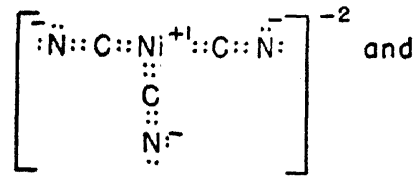

(A)

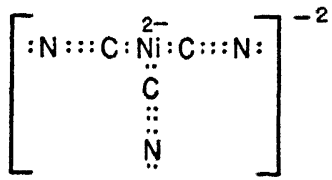

(B)

* The Latimer convention (Latimer, The Oxidation States of the Elements and their Potentials in Aqueous Solutions, New York, 1938) is used throughout for the expression of values for oxidation potentials. 
However, solutions of the unipositive nickel cyanide complex are diamagnetic, ${ }^{10 \mathrm{f}, \mathrm{g}}$ and it is highly probable that ion exists as a dimer involving a metal to metal bond.

\section{Unipositive Cobalt}

It has been stated that the electrolytic reduction of aqueous solutions of potassium hexacyanocobaltiate(III) produces a deep-brown solution of the unipositive cobalt complex $K_{x}\left[\mathrm{Co}(\mathrm{CN})_{y}\right] .{ }^{13}$ Attempts to isolate the complex compound have been unsuccessful.*

\section{Tripositive Cobalt and Nickel}

Whereas in simplet compounds and in certain ionic complexes the +2 state of cobalt is by far more stable than the +3 state, the situation is reversed with regard to the covalent complex compounds. The following explanation has been offered for this reversal. ${ }^{14}$ The structures of dipositive and tripositive cobalt in simple ions and in covalent octahedral complexes, only those orbitals available for binding being shown, are as pictured below:

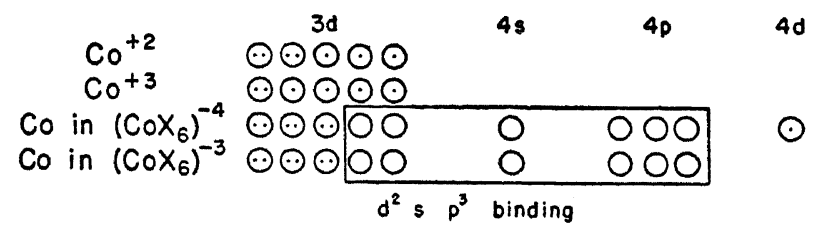

It is apparent that the covalent octahedral complexes of dipositive cobalt have an unpaired electron in an unstable $4 d$ orbital, while the electrons in the tripositive

* The existence of unipositive cobalt has recently been confirmed polarographically (Hume and Kolthoff, J. Am. Chem. Soc. 71, 867 [1949]). The reduction of the $\left[\mathrm{Co}\left(\mathrm{H}_{2} \mathrm{O}\right)(\mathrm{CN})_{5}\right]^{-3}$ and $\left[\mathrm{Co}\left(\mathrm{H}_{2} \mathrm{O}\right)(\mathrm{CN})_{5}\right]^{-2}$ ions at the dropping mercury electrode involve two- and one-electron processes, respectively.

t It is to be understood that the simple cobalt ions are aquated in water solution. The water is probably held to the cobalt by ion-dipole bonds. 
complexes are all paired. The latter fact presumably accounts for the stability of the tripositive complexes. It is noteworthy that all of the known complexes of tripositive cobalt are covalent in character with the exception of the $\left(\mathrm{CoF}_{6}\right)^{-3}$ ion, where the binding is essentially ionic.* With regard to tripositive cobalt, therefore, the present discussion will be limited to the relatively unfamiliar simple compounds.

The electrolytic oxidation of cobalt(II) or of nickel (II) acetates in anhydrous acetic acid presumably gives the triacetate; ${ }^{15}$ the results of these experiments, however, are inconsistent. The similar oxidation of solutions of the dichlorides of cobalt and nickel in ethanol which contains hydrogen chloride, yields products which possess oxidizing properties, and which presumably consist in part of the trihalides. ${ }^{16}$ The oxidation at a platinum anode of cobalt(II) sulfate dissolved in $10 \mathrm{~N}$ sulfuric acid gives the salt of the tripositive ion, which is a useful oxidizing agent in certain organic reactions. ${ }^{17}$ The conditions most favorable for the formation of this substance are (1) a temperature of less than $10^{\circ}$; (2) a current density between 0.01 and 0.02 ampere per square centimeter; and ( 3 ) a current not to exceed 5 amperes for 500 cubic centimeters of the anolyte, which is a saturated solution of $\mathrm{CoSO}_{4}$. The cobaltic sulfate precipitates as greenish blue crystals. If the cobaltous sulfate is electrolytically oxidized in the presence of ammonium sulfate, dark-blue crystals of the alum, $\left(\mathrm{NH}_{4}\right)_{2} \mathrm{SO}_{4} \cdot \mathrm{Co}_{2}\left(\mathrm{SO}_{4}\right)_{3} .24 \mathrm{H}_{2} \mathrm{O}$, are obtained. ${ }^{18}$

Reaction at $150^{\circ}$ in a quartz vessel between cobalt(II) chloride and elementary fluorine gives the light brown trifluoride, $\mathrm{CoF}_{3}$. The same substance is obtained

* See Pauling, The Nature of the Chemical Bond, p. 117. 
as an admixture with cobalt(II) fluoride when powdered cobalt is heated with fluorine at $500^{\circ} .{ }^{19}$ The trifluoride has a heat of formation estimated at about $240 \mathrm{Kcal}$. It is insoluble in the usual organic solvents. It is a powerful oxidizing agent, liberating oxygen from water. At temperatures between 600 and $700^{\circ}, \mathrm{CoF}_{3}$ volatilizes with decomposition into cobalt(II) fluoride and fluorine. Its use as a fluorinating agent has been suggested.

There is good evidence for the existence of cobalt (III) oxide. Cobalt(II) hydroxide suspended in potassium hydroxide solutions absorbs oxygen; the rate of absorption increases with increasing alkali concentration, and the amount absorbed approaches that corresponding to the formation of $\mathrm{Co}_{2} \mathrm{O}_{3} . \mathrm{XH}_{2} \mathrm{O}$ as the upper limit (Table XV). ${ }^{20}$

\section{TABLE XV}

The Absorption of Oxygen by Cobalt(II) Hydroxide

\begin{tabular}{crrrr}
\hline $\begin{array}{c}\text { Millimoles of } \mathrm{KOH} \\
\text { (constant vol. of } 25 \mathrm{cc} \text { ) }\end{array}$ & 12 & \multicolumn{2}{c}{$\begin{array}{c}20 \\
\text { Quantity of oxygen absorbed }(\mathrm{mg}) ; \\
\text { Time (min.) }\end{array}$} & $\begin{array}{c}55.4 \\
\left.\text { (40 mg. corresponds to } \mathrm{Co}_{2} \mathrm{O}_{3} . \mathrm{XH}_{2} \mathrm{O}\right)\end{array}$ \\
\hline 5 & 7.6 & 6.4 & 4.4 & 4.0 \\
25 & 9.2 & 11.6 & 11.8 & 17.6 \\
50 & 12.4 & 18.0 & 27.0 & 38.0 \\
75 & 16.0 & 25.2 & 38.8 & 40.0 \\
\hline
\end{tabular}

Electromotive force measurements have been made of a system comprising as one half-cell a gold electrode inmersed in a solution of di- and tripositive cobalt nitrates in 1 to $4 \mathrm{M}$ nitric acid, and as the other half-cell a hydrogen electrode in 1 or $2 \mathrm{M}$ perchloric acid. ${ }^{21}$ The oxidation potential for the reaction $\mathrm{Co}^{+2}=\mathrm{Co}^{+3}+\mathrm{e}^{-}$has values at $0^{\circ}$ ranging from -1.800 volts in $1 \mathrm{M}$ nitric acid to -1.816 volts in $4 \mathrm{M}$ acid, and values at $25^{\circ}$ of -1.842 volts in $3 \mathrm{M}$ acid and -1.850 volts in $4 \mathrm{M}$ acid. 
There has been considerable dispute concerning the authenticity of an oxide of tripositive nickel. The weight of the evidence, however, appears to be in favor of the existence of such a substance. The conclusions drawn from the most thorough investigation of this subject ${ }^{22}$ will be discussed here. Bromine water reacts with a suspension of nickel(II) hydroxide in potassium hydroxide solution at $25^{\circ}$ to give a product the analysis of which, after drying in vacuo, corresponds to the formula $\mathrm{Ni}_{2} \mathrm{O}_{3}$. ${ }_{2} \mathrm{H}_{2} \mathrm{O}$. Heating this material with water in a Pyrex bomb at $130-150^{\circ}$ results in the loss of oxygen and the formation of the hydroxide of dipositive nickel. If the oxidation of the nickel(II) hydroxide is carried out initially at $100^{\circ}$ and followed by continued reaction at $25^{\circ}$, the monohydrate $\mathrm{Ni}_{2} \mathrm{O}_{3}: \mathrm{H}_{2} \mathrm{O}$ is formed. The X-ray diffraction pattern of this substance differs from that of the dihydrate. Thermal decomposition of the monohydrate is accompanied by the loss of oxygen and the formation of nickel(II) oxide. The compounds $\mathrm{Ni}_{2} \mathrm{O}_{3} \cdot 2 \mathrm{H}_{2} \mathrm{O}$ and $\mathrm{Ni}_{2} \mathrm{O}_{3}$. $\mathrm{H}_{2} \mathrm{O}$ are not true hydrates, however, since neither the transition from di- to monohydrate nor the reverse process can be made to take place. Moreover, all efforts to prepare the anhydrous oxide from these substances have been unsuccessful; in attempts at dehydration, loss of water is always accompanied by loss of oxygen. The following structures are assumed to be the correct ones for the "hydrates":

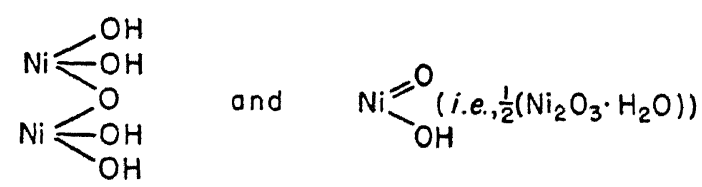

The acidic nature of $\mathrm{Ni}_{2} \mathrm{O}_{3} \cdot \mathrm{H}_{2} \mathrm{O}$ is indicated by its relatively slow rate of peptization. 
A few complex compounds containing tripositive nickel bound to oxime compounds have been prepared. Nickel formoxime in alkaline solutions absorbs oxygen from the air, giving a deep brown solution; the oxygen uptake corresponds to one equivalent per atom of dipositive nickel. ${ }^{23}$ A compound of tripositive nickel may be crystallized from the oxidized solution. The assertion that benzamide oxime forms a nickel(III) complex of the formula

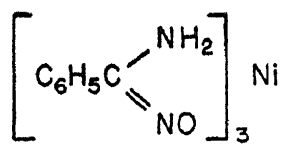

has been disputed. ${ }^{24,25} a$-Benzildioximonickel(III) bromide and iodide may be obtained by the action of the appropriate halogen on $a$-benzildioximonickel(II) ${ }^{26}$ Analysis shows that these compounds may be formulated in the following manner:

$$
\left.\left[\begin{array}{ccc}
\mathrm{C}_{6} \mathrm{H}_{5}-\mathrm{C} & -\mathrm{C}-\mathrm{C}_{6} \mathrm{H}_{5} \\
\mathrm{HO}-\mathrm{N}^{\mathrm{N}} & \mathbb{N}=0 \\
\mathrm{O}=\mathrm{N}_{6} \mathrm{H}_{5}-\mathrm{N}-\mathrm{N}-\mathrm{OH}-\mathrm{C}_{6} \mathrm{H}_{5}
\end{array}\right]^{+}\right]^{-}
$$

These substances are insoluble in water and most organic solvents with the exception of pyridine. In the latter they form red-violet solutions. Alkaline reagents convert the tripositive nickel complexes to a dark-red compound which reverts to $a$-benzildioximonickel(II). Decomposition at $100^{\circ}$ always gives the original dipositive nickel compound. 


\section{Tetrapositive Cobalt and Nickel}

Although neither has been obtained in the pure condition, there appears to be no doubt of the existence of both cobalt (IV) and nickel(IV) oxides. The oxidation of cobalt(II) solutions by iodine dissolved in strong alkali yields a black precipitate in which, according to oxidation studies, the metal is tetrapositive. ${ }^{27}$ Similarly, the action of a variety of oxidizing agents on dipositive nickel in alkaline medium gives preparations containing as much as 1.9 atoms of oxygen per atom of nickel, ${ }^{28}$ although the ratio of 2 to 1 is never attained. Tetrapositive nickel is a powerful oxidizing agent; $\mathrm{NiO}_{2}$ in acid medium converts dipositive manganese to permanganate. ${ }^{29}$

One study on the action of sodium hydroxide and hypochlorite on solutions of nickel(II) sulfate indicates that nickel(II) hydroxide is oxidized simultaneously to the nickel(III) and the nickel(IV) oxide, and that the former is not an intermediate in the formation of the latter. ${ }^{30}$ Moreover, nickel(IV) oxide decomposes directly to the dipositive hydroxide, the tripositive oxide, in this case also, not being formed as an intermediate. When just sufficient sodium hydroxide is used for precipitation of the nickel(II), the oxidizing action of the hypochlorite first produces the tetrapositive oxide and then the tripositive oxide. With the use of increasing amounts of alkali for precipitation, the fraction of nickel(IV) oxide in the mixture increases.

The mixture resulting from the oxidation of nickel (II) hydroxide is used as the oxidizing agent in the Edison storage battery. The standard potential for the reaction

$$
\mathrm{NiO}_{2}+2 \mathrm{H}_{2} \mathrm{O}+2 \mathrm{e}^{-}=\mathrm{Ni}(\mathrm{OH})_{2}+{ }_{2} \mathrm{OH}^{-}
$$

has been given as +0.49 volt. $^{31}$ 
Dipositive nickel and cobalt may be oxidized by ammonium persulfate in the presence of ammonium molybdate to give complex heteropolymolybdates of the tetrapositive metals. ${ }^{32}$ The compounds that have been isolated are: $3 \mathrm{BaO}_{2} \mathrm{NiO}_{2} .9 \mathrm{MoO}_{3} .12 \mathrm{H}_{2} \mathrm{O}$ and ${ }_{3} \mathrm{~K}_{2} \mathrm{O} . \mathrm{CoO}_{2}$. ${ }_{9} \mathrm{MoO}_{3} \cdot 6 \frac{1}{2} \mathrm{H}_{2} \mathrm{O}$. The nickel compound is diamagnetic, indicating that the tetrapositive nickel acts as a center of a covalent complex with octahedral $\mathrm{d}^{2} s \mathrm{p}^{3}$ bonds. ${ }^{33}$ As has already been pointed out, tripositive cobalt, which possesses the same number of electrons as tetrapositive nickel, forms similar complexes.

Dark purple, insoluble crystals of a complex periodate containing tetrapositive nickel are said to be formed when nickel(II) sulfate is oxidized by a hot solution of sodium or potassium persulfate in the presence of the periodate ion. ${ }^{33}$ The composition of these crystals is represented by the formula $\mathrm{Na}(\mathrm{K}) \mathrm{NiIO}_{6} \cdot \mathrm{XH}_{2} \mathrm{O}$. The compounds have a paramagnetic moment of approximately 1.2 Bohr magnetons. The measured moment is said to favor the hypothesis of an octahedral configuration for the complex, a partial dissociation being assumed, due to temperature instability, into $\mathrm{K}^{+}, \mathrm{IO}_{4}^{-}$(or $\mathrm{Na}^{+}, \mathrm{IO}_{4}^{-}$), and $\mathrm{NiO}_{2}$. Such an assumption is necessary to account for the low paramagnetic moment of the complex; octahedral $\mathrm{d}^{2} s \mathrm{P}^{3}$ binding without dissociation would give a diamagnetic complex.

When dipositive nickel is heated with strong oxidizing agents in alkaline medium in the presence of dimethylglyoxime, red solutions are formed. By careful neutralization of these solutions, a dark red complex, presumably containing tetrapositive nickel, may be isolated. $^{34}$ Elemental analysis supports the following formula for the complex:

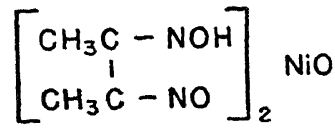


Solutions of the complex, when acidified in the presence of potassium iodide, liberate approximately two equivalents of iodine per gram atom of nickel. The dry complex decomposes explosively on heating. It is insoluble in water and in the usual organic solvents; acids decompose it into the dipositive nickel ion and dimethylglyoxime. However, the complex dissolves readily in alkaline media, giving blue-red solutions.

The conclusions drawn in the report just described have been contradicted in their entircty. ${ }^{35}$ It is stated that the red precipitate formed by the careful neutralization of the oxidized solutions is obtained only when lead dioxide has been used as the oxidizing agent, and that lead is an essential constituent of this precipitate. Moreover, it is claimed that the precipitatc contains no tetrapositive nickel, but that rather, it is the oxime group of dimethylglyoxime which is oxidized.

Many polynuclear cobalt ammines have been prepared in which the cobalt atoms are bridged by the $\mathrm{O}_{2}$ group. ${ }^{36}$ It has been proposed that some of these ammines may contain both tri- and tetrapositive cobalt, which are bridged by the peroxo group. Examples of such complexes and their postulated structures are

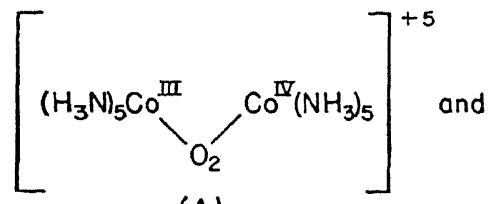

(A)

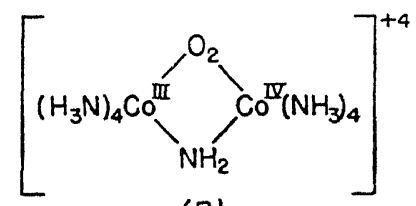

(B)

Complex ion A has been prepared in two ways: (1) by atmospheric oxidation of dipositive cobalt in a strongly ammoniacal medium, ${ }^{37}$ and $(2)$ by oxidation in a similar medium with hydrogen peroxide and ammonium persul- 
fate. ${ }^{38}$ All analytical data would appear to support the postulate of $\mathrm{Co}$ (III) and $\mathrm{Co}(\mathrm{IV})$. Magnetic susceptibility measurements give effective moments for these compounds of 1.7 Bohr magnetons, showing the presence of an unpaired electron; ${ }^{38,39}$ this is in line with the assumption of the presence of the two higher oxidation states of cobalt. Oxidation studies also appear to be in agreement with this postulate. ${ }^{36,38}$ It has been pointed out, however, that the magnetic data may also be explained on the assumption that the compounds contain tripositive cobalt and the superoxide ion, ${ }^{40}$

$$
\text { :Ọ ... O.:- }
$$

A close inspection of the analytical studies shows that, with one exception, all the data may also be explained on the hypothesis of the presence of superoxide ion and tripositive cobalt. Examination of the exceptional case reveals an interesting point. Upon being warmed with concentrated sulfuric acid, the ion

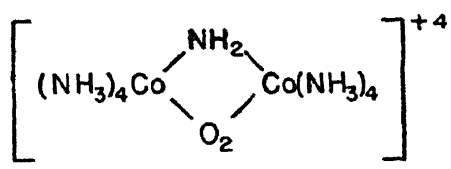

is decomposed with the liberation of oxygen. ${ }^{36}$ Three equivalents of oxygen are set free per formula weight of the ion. Calculations show that this can be cxplained only on the basis of the presence of $\mathrm{Co}$ (III), $\mathrm{Co}$ (IV) and peroxide ion. On further heating, however, nitrogen is liberated from solution, indicating, perhaps, that the oxidizing power of the compound cannot, in this case, be determined solely from the quantity of oxygen evolved. The question of the exact structure of these polynuclear ammines would appear to be an open one. 


\section{VIII}

\section{The "Rare-Earths"}

TOR AN ADEQUATE discussion of the transition elements of general interest, one additional class

1 of substances which falls within the scope of this project must be examined; this is the so-called "rareearth" series of elements. The study of the chemistry of the individual members of this series has long been hampered by the difficulty of obtaining most of them in a reasonably pure condition. However, by the use of ionexchange methods the individual members of the "rareearth" series may now be rapidly separated in a high state of purity. This development will undoubtedly stimulate research in "rare-earth" chemistry, and a period of rapid progress in this field may now be expected.

\section{TABLE XVI}

Electronic Configurations of the "Rare-Earths"

\begin{tabular}{|c|c|c|}
\hline Atomic No. & Element & Configuration \\
\hline 58 & $\mathrm{Ce}$ & $\left(4 f^{2} 6 s^{2}\right)$ \\
\hline 59 & $\operatorname{Pr}$ & $\left(4 f^{3} \quad 6 s^{2}\right)$ \\
\hline 60 & $\mathrm{Nd}$ & $4 f^{4} \quad 6 s^{2}$ \\
\hline 61 & $\mathrm{Pm}$ & $\left(\begin{array}{ll}4 f^{5} & 6 s^{2}\end{array}\right)$ \\
\hline 62 & $\mathrm{Sm}$ & $4 f^{6} \quad 6 s^{2}$ \\
\hline 63 & $\mathrm{Eu}$ & $4 f^{7} \quad 6 s^{2}$ \\
\hline 64 & $\overline{G d}$ & $4 f^{f^{\top}} 5 d^{1} \quad 6 s^{2}$ \\
\hline 65 & $\mathrm{~Tb}$ & $\left(4 f^{9} 6 s^{2}\right)$ \\
\hline 66 & Dy & $\left(4 f^{10} 6 s^{2}\right)$ \\
\hline 67 & Ho & $\left(4 f^{11} 6 s^{2}\right)$ \\
\hline 68 & Er & $\left(4^{f^{12}} 6 s^{2}\right)$ \\
\hline 69 & $\operatorname{Tm}$ & $4^{f^{13}} 6 s^{2}$ \\
\hline 70 & $\mathrm{Yb}$ & $4 f^{14} 6 s^{2}$ \\
\hline 71 & $\mathrm{Lu}$ & $4^{f^{14}} 5 d^{1} 6 s^{2}$ \\
\hline
\end{tabular}


The electronic configurations of elements 58-71, the "rare-earths," are shown in Table XVI. All subshells up to $4 \mathrm{f}$ are filled, and are therefore omitted from the table. The symbols in parentheses represent extrapolations or predictions based on the analysis of neighboring spectra. ${ }^{1}$

The common oxidation state of the elements of this group is +3 . Several of the "rare-earths," however, exhibit also so-called "anomalous" oxidation states. These "anomalous" states have, in the past, been useful in the separation of some of the "rare-earths." With rapid means now at our disposal for the isolation, in the pure state, of the individual members of the series, much attention will undoubtedly be directed toward the "anomalous" or unfamiliar oxidation states.

The unfamiliar oxidation states of these elements are best explained in terms of their electronic configurations. In successive elements of the "rare-earth" series, the $4 f$ subshell is being filled. Quantum mechanical considerations, as well as chemical observations, show that subshells in an atom are most stable when they are halffilled, completely filled or empty of electrons. The $4^{f}$ subshell is, accordingly, most stable when it contains $O$, 7 or 14 electrons. ${ }^{2}$ The stability of the unfamiliar oxidation states is thus readily understandable. $\mathrm{Ce}^{+4}$ possesses no $4^{f}$ electrons.* In dipositive europium and tetrapositive terbium the $4 f$ subshell is half completed, whereas in +2 ytterbium this subshell is filled. The existence of $\mathrm{Sm}^{+2}$, containing 6 ff electrons, is comprehensible in the light of its near attainment of a half-filled subshell; however, its lesser stability as compared to dipositive europium is likewise to be expected. Similar considerations

* The chemistry of ${ }^{+} 4$ cerium is too well known to be included in this discussion. 
apply to a discussion of +4 and +5 praseodymium. It is also not surprising that no rcal cvidence has been uncovcred for an oxidation state other than +3 for gadolinium and lutetium, the seventh and fourteenth members, respectively, of the series.

\section{The Dipositive State}

Compounds containing "rare-earths" in the dipositive state have been made chiefly by (1) the high temperature reduction of anhydrous halides of the tripositive state with hydrogen, aluminum, or ammonia, (2) the cathodic reduction of the tripositive ion in aqueous solution in the presence of sulfate ion with the formation of the insoluble sulfate, (3) reduction of the tripositive ion in the Jones reductor, and (4) the thermal decomposition of the anhydrous trihalides.

Samarium dichloride, $\mathrm{SmCl}_{2}$, has been prepared by the reduction with hydrogen of the tripositive halide at high temperatures in a boat of porcelain, platinum, or gold, the last giving the best results. ${ }^{3 b}$ Reduction for thirty hours at $600-650^{\circ}$ gives a maximum yield of $90-92$ per cent of the dichloride; ${ }^{3 c}$ a similar reaction yields the dibromide. The dichloride has been made from samarium trichloride, $\mathrm{SmCl}_{3}$, also by reduction with aluminum ${ }^{3 a}$ and with ammonia, ${ }^{3 a, 4}$ the latter giving a 98.5 per cent yield. The thermal clecomposition of anhydrous samarium (III) iodide at $800-900^{\circ}$ in a quartz tube at a pressure of $0.01 \mathrm{~mm}$. of mcrcury results in the formation of the dcep green, almost black, diiodide in go per cent yield. Most of the evolution of iodine takes place below $75^{\circ}$. The diiodide may be obtained also by the hydrogen reduction of the triiodide in a gold boat at $750^{\circ}$.

Samarium dichloride, $\mathrm{SmCl}_{2}$, is a red-brown substance melting at $740^{\circ}$. With water it gives a deep brown 
solution which evolves hydrogen, the dipositive samarium ion being converted to the tripositive oxide and oxychloride. The dichloride is insoluble in the usual organic solvents. When heated to $1000^{\circ}$, it disproportionates according to the equation:

$$
{ }_{3} \mathrm{SmCl}_{2}=\mathrm{Sm}+2 \mathrm{SmCl}_{3} .
$$

With ammonia it forms the ammoniates $\mathrm{SmCl}_{2} \cdot 2 \mathrm{NH}_{3}$, and $\mathrm{SmCl}_{2} .8 \mathrm{NH}_{3}$. It is readily oxidized in air to the tripositive state. The dibromide, which melts at approximately $700^{\circ}$, has properties similar to those of the dichloride. The diiodide disproportionates at $680^{\circ}$ in a manner analogous to that described for the dichloride. It dissolves in water to give a deep Bordeaux-red solution which decomposes with the liberation of hydrogen and the conversion of the samarium to the tripositive basic iodide. Treatment of an ice-cold solution of the diiodide in air-free water with sodium sulfate results in the precipitation of the orange-red $\mathrm{SmSO}_{4}$; the dipositive phosphate and chromate may be formed similarly. The sulfate is slowly oxidized by water or dilute acids, with the evolution of hydrogen. Solutions of tripositive samarium chloride and sulfate have been studied polarographically, with and without supporting electrolytes. ${ }^{6}$ For $0.001 \mathrm{M} \mathrm{Sm}^{+3}$ ion in a medium $0.001 \mathrm{~N}$ in sulfuric acid, $0.1 \mathrm{M}$ in tetramethylammonium iodide, and containing also 0.01 per cent of gelatin, a two-step polarogram is obtained (Fig. 6). The half-wave potentials are -1.80 and -1.96 volts against the saturated calomel electrode. This result would indicate a probable normal potential of +2.05 volts for the reaction

$$
\mathrm{Sm}^{+2}=\mathrm{Sm}^{+3}+\mathrm{e}^{-}
$$


and of 2.21 volts for the reaction

$$
\mathrm{Sm}=\mathrm{Sm}^{+2}+2 \mathrm{e}^{-} \text {. }
$$

In $0.004 \mathrm{M}$ solution, however, the polarographic bchavior of samarium is anomalous.

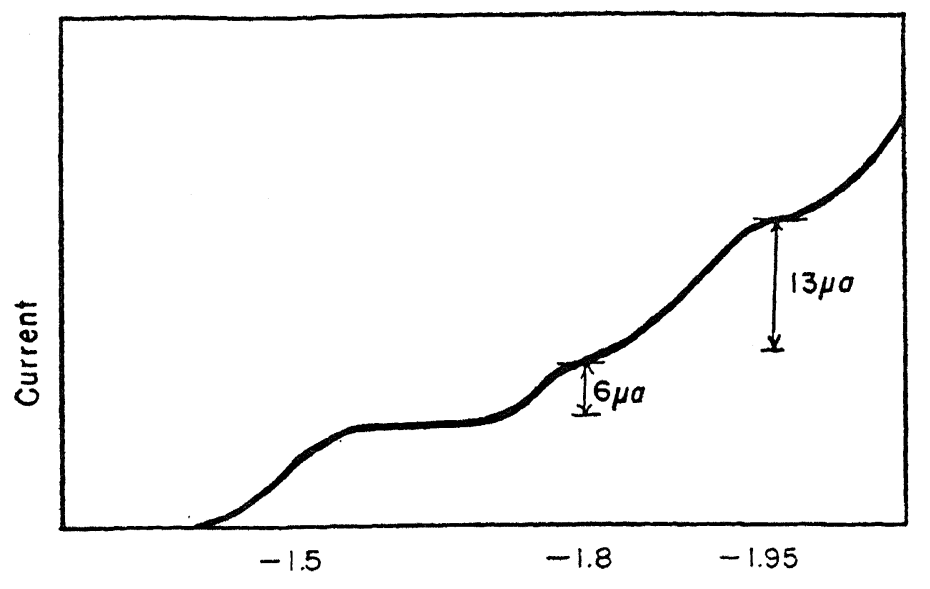

$E_{\text {de }}$ vs. S.C.E.

Frg. 6.- $\mathrm{Sm}^{+3}$, I Millimolar, in $0.001 \mathrm{~N} \mathrm{H}_{2} \mathrm{SO}_{4}$, $0.1 \mathrm{M}\left(\mathrm{CH}_{3}\right)_{4} \mathrm{NI} .0 .01 \%$ Gelatin Medium.

Europium(III) chloride is reduced by hydrogen to give the white dichloride according to the equation:

$$
2 \mathrm{EuCl}_{3}+\mathrm{H}_{2}=2 \mathrm{EuCl}_{2}+2 \mathrm{HCl} \text {. }
$$

The reaction begins at approximately $270^{\circ}$ and is extremely rapid at 400-450 $0^{\circ}$. Chocolate-brown europium dibromide, $\mathrm{EuBr}_{2}$, of 90 per cent purity has been made by heating the tribromide with hydrogen bromide to $350^{\circ} .8$ The diiodide may be made by treatment of europium(III) iodide hydrate with a hydrogen-hydrogen iodide mixture. ${ }^{9}$ The reduction of the trifluoride by hy- 
drogen in a platinum boat results in the formation of the yellow difluoride, contaninated with a film of silicon formed from the walls of the quartz reaction vessel. ${ }^{10}$ The difluoride has a face-centered cubic structure with a cube edge of $5.796 \pm 0.006 \AA$.

Whereas samarium(II) is too unstable in aqueous medium to be produced and isolated in the pure state by the electrolytic reduction of the tripositive ion, this method has been of great utility for the preparation of dipositive europium. The cell consists of a mercury or lead amalgam cathode, a platinum anode and an electrolyte of tripositive europium. ${ }^{11}$ The europium(II) is usually isolated as the colorless insoluble sulfate by carrying out the reduction with sulfate ion present in the electrolyte. Tripositive europium may also be quantitatively reduced by zinc in a Jones reductor. ${ }^{12}$

When europium(III) sulfate is heated in an atmosphere of hydrogen sulfide the brown-violet sulfide EuS is formed. ${ }^{10}$ this substance is pyrophoric at high temperatures. It is insoluble in water, but readily soluble in dilute acids; the dipositive oxide cannot be precipitated from these solutions. The dipositive sulfide has a crystal structure of the sodium chloride type, its cube edge being $5.957 \pm 0.002 \AA$.

The selenide and telluride, as well as the sulfide, of europium(II) have been made by the reaction in a quartz apparatus of the dichloride, $\mathrm{EuCl}_{2}$, with the appropriatc nonmetal. ${ }^{13}$ The mixture is heated in hydrogen to $600^{\circ}$ for several hours, and the excess of the selenium, tellurium, or sulfur is then removed in hydrogen at $800^{\circ}$. The selenide, EuSe, is dark brown and the telluride EuTe is black. Both the selenide and the telluride have the same 
crystal structure as the sulfide, namely of the sodium chloride type; the cube edge for the selenide is

$$
6.173 \pm 0.001 \AA \text {, }
$$

and for the telluride $6.572 \pm 0.001 \AA$.

The ease with which europium(III) is reduced to the dipositive state has been of use in separating europium from other "rare-earths." Europium has been removed almost quantitatively from aqueous solutions containing also samarium and a little gadolinium, ${ }^{11 a}$ or gadolinium alone $^{11 \mathrm{~b}}$ by electrolytic reduction and precipitation as $\mathrm{EuSO}_{4}$. Europium, present in a terbium mixture in a quantity too small to give a direct precipitate of $\mathrm{EuSO}_{4}$, has been removed quantitatively by reduction followed by coprecipitation with barium sulfate. ${ }^{1+}$

The compounds of dipositive europium are of much greater stability than those of the corresponding oxidation state of samarium. Solutions of europium(II) salts are fairly stable in the absence of air, decomposing only slowly with the evolution of hydrogen. In the presence of air, however, the europium is rapidly oxidized to the tripositive state. The salt most inert toward atmospheric oxidation is the sulfate; its stability in this respect is undoubtedly due to its insolubility. The sulfate exists in two crystalline forms: the $\alpha$ form, which is usually made by the passage of $\mathrm{Eu}$ (II) from a Jones reductor into a solution of sulfuric acid, and consists of tufts of small feathery needles; and the more stable $\beta$ modification, which occurs as still smaller and more compact crystals. Dipositive europium is oxidized readily by the usual reagents. Measurements on the cell $\mathrm{Pt}, \mathrm{Eu}(\mathrm{OOCH})_{3}$, $\mathrm{Eu}(\mathrm{OOCH})_{2}, \mathrm{HCOOH}$ (very dilute),

${ }_{1} \mathrm{~N} \mathrm{KCl} / 1 \mathrm{~N} \mathrm{KCl} / 1 \mathrm{~N} \mathrm{KCl}_{1} \mathrm{Hg}_{2} \mathrm{Cl}_{2}, \mathrm{Hg}$ 
give an $\mathrm{E}^{\circ}$ value of +0.43 volt for the reaction

$$
\mathrm{Eu}^{+2}=\mathrm{Eu}^{+3}+\mathrm{e}^{-11 \mathrm{c}}
$$

Ytterbium dichloride, $\mathrm{YbCl}_{2}$, has been made by reduction of the anhydrous trichloride with hydrogen. Reaction for 9 hours in a quartz boat at $600-630^{\circ}$ gives a practically colorless product of 98 per cent purity..$^{15}$ A similar reduction of ytterbium(III) telluride at $95^{\circ}$ gives the telluride YbTe in 97 per cent yield. The selenide can be prepared by an analogous reaction at $125^{\circ}$. Attempts to prepare the dipositive sulfide in this manner proved unsuccessful. ${ }^{16}$ Both the telluride and the selenide have the sodium chloride type of structure with a cube edge of $6.34 \pm 0.002 \AA$ and $5.867 \pm 0.002 \AA$ respectively. $\mathrm{Yb}^{+2}$ ion is of the same size as calcium ion. The chloride, bromide, and iodide of dipositive ytterbium may each be made by the thermal decomposition of the corresponding trihalide in a vacuum. Halogen begins to be split off at approximately $870^{\circ}, 700^{\circ}$, and $250^{\circ}$, for the trichloride, tribromide, and triiodide, respectively. ${ }^{17}$

The cathodic reduction of $\mathrm{Yb}$ (III) in a cell of a type similar to that used for the production of dipositive europium results in the formation of $\mathrm{Yb}$ (II). If the electrolysis is carried out in a dilute sulfuric acid medium, green ytterbium(II) sulfate, $\mathrm{YbSO}_{4}$, is precipitated. ${ }^{18}$ In this manner, ytterbium of 98 per cent purity has been separated in one operation from a mixed yttrium group material containing only 2 per cent of ytterbium. ${ }^{18 a}$ Since ytterbium(II) sulfate is somewhat soluble, and is also slowly oxidized by the sulfuric acid in the medium, electrolytic precipitation is never complete.

$\mathrm{Yb}$ (II) gives fairly stable yellow-green aqueous solutions which decompose slowly with the evolution of hy- 
drogen. In dilute hydrochloric or sulfuric acid solutions such decomposition is much more rapid. Dipositive ytterbium reduces nitric acid, liberating oxides of nitrogen. The dichloride reacts with ammonia to form the ammoniate $\mathrm{YbCl}_{2} .2 \mathrm{NH}_{3}$ at $100^{\circ}$, and $\mathrm{YbCl}_{2} \cdot \mathrm{NH}_{3}$ and $\mathrm{YbCl}_{2} .8 \mathrm{NH}_{3}$ at $0^{\circ}$; all of these ammoniates are yellow. ${ }^{15}$

The standard potential for the $\mathrm{Yb}$ (II)-Yb(III) couple, as measured by means of an ytterbium amalgam dropping into a solution of the tripositive ion, is +1.15 volts. ${ }^{19}$ This value appears to be more nearly correct than that of +0.578 volt previously recorded for $\mathrm{I} \mathrm{N}$ acetic acid solution. ${ }^{20}$ The lower value is open to the following criticisms: ${ }^{19}$

(1) It would lead to the prediction that $\mathrm{Yb}^{+3}$ ions should be reducible by zinc. This is not the case.

(2) The determinations of the potentials were made by means of a platinum electrode in solutions containing $\mathrm{Yb}^{+3}$ and $\mathrm{Yb}^{+2}$ ions in a $1 \mathrm{~N}$ potassium chloride, I $\mathrm{N}$ acetic acid medium. The platinum electrode in such a medium can act in part as a hydrogen electrode.

Magnetochemical investigations indicate that dipositive samarium is isoelectronic with tripositive europium, and dipositive europium with tripositive gadolinium. The data of Table XVII show that the values for the

\section{TABLE XVII}

Molar Susceptibilities of $\mathrm{Sm}^{+2}$ and $\mathrm{Eu}^{+3}$ Ions

\begin{tabular}{lcc}
\hline${ }^{\circ} \mathrm{K}$ & $x \mathrm{Sm}^{+2} \times 10^{6}$ & $x \mathrm{Eu}^{+3} \times 10^{6}$ \\
\hline 373 & 4800 & $4630\left(343^{\circ}\right)$ \\
293 & 5420 & 4940 \\
223 & 6170 & 5480 \\
153 & 7190 & 6060 \\
83 & $77^{20}$ & 6370 \\
\hline
\end{tabular}


molar paramagnetic susceptibilities of $\mathrm{Sm}^{+2}$ and $\mathrm{Eu}^{+3}$ ions are of the same order of magnitude. ${ }^{21}$

A plot of effective Bohr magneton numbers for $\mathrm{Sm}^{+3}$, $\mathrm{Eu}^{+3}$, and $\mathrm{Sm}^{+2}$ ions against temperature (Fig. 7) shows that the experimental points for dipositive samarium are almost identical with those for tripositive europium at all temperatures. In view of this correspondence, it is concluded that the electronic configurations of the two ions are identical. Similarly, it has been shown that over a wide temperature range the effective moments of dipositive europium and tripositive gadolinium are practically the same. ${ }^{22}$ Dipositive ytterbium, having 14 if electrons, is diamagnetic. Measurements made on a sample of ytterbium(II) chloride showed it to be slightly paramagnetic; ${ }^{18}$ undoubtedly, this was due to the presence of a small amount of tripositive ytterbium.

The statement that both tripositive neodymium and tripositive gadolinium are reduced polarographically in two steps ${ }^{23}$ has been disputed. ${ }^{24}$ The results of the later investigations ${ }^{24}$ indicate that both of these cations are reduced directly to the metallic state at the dropping mercury electrode. The contention that strontium amalgam is capable of reducing tripositive cerium, praseodymium, neodymium, and gadolinium sulfates, in concentrated solution, to the dipositive condition ${ }^{25 a}$ has not been substantiated. Attempts to reduce tripositive neoclymium in this manner have failed. ${ }^{25 b}$

\section{Higher Oxidation States}

There is no question that the ignition of praseodymium sesquioxide, $\mathrm{Pr}_{2} \mathrm{O}_{3}$, in air gives oxides in which the praseodymium has an oxidation state higher than +3 . Whether this higher oxidation state is +4 or +5 , 
or, indeed, whether or not both are possible of attainment, is a question which still remains to be settled conclusively. There appears to be no doubt that a black compound of empirical formula $\mathrm{Pr}_{6} \mathrm{O}_{11}$ is obtained by ignition of the sesquioxide in air under a wide variety of conditions. ${ }^{26}$ The structure of this material has been represented by the formulas ${ }_{2} \mathrm{Pr}_{2} \mathrm{O}_{3} \cdot \mathrm{Pr}_{2} \mathrm{O}_{5}{ }_{3}^{27}$ and $\mathrm{Pr}_{2} \mathrm{O}_{3}$. ${ }_{4} \mathrm{PrO}_{2} \cdot{ }^{26 \mathrm{c}} \mathrm{Pr}_{6} \mathrm{O}_{11}$ has a crystal structure belonging to the fluorite type, with a cell edge of $5.41 \AA .26 \mathrm{a}$

Evidence that +5 praseodymium may exist comes from studies on the heating of mixtures of the sesqui-

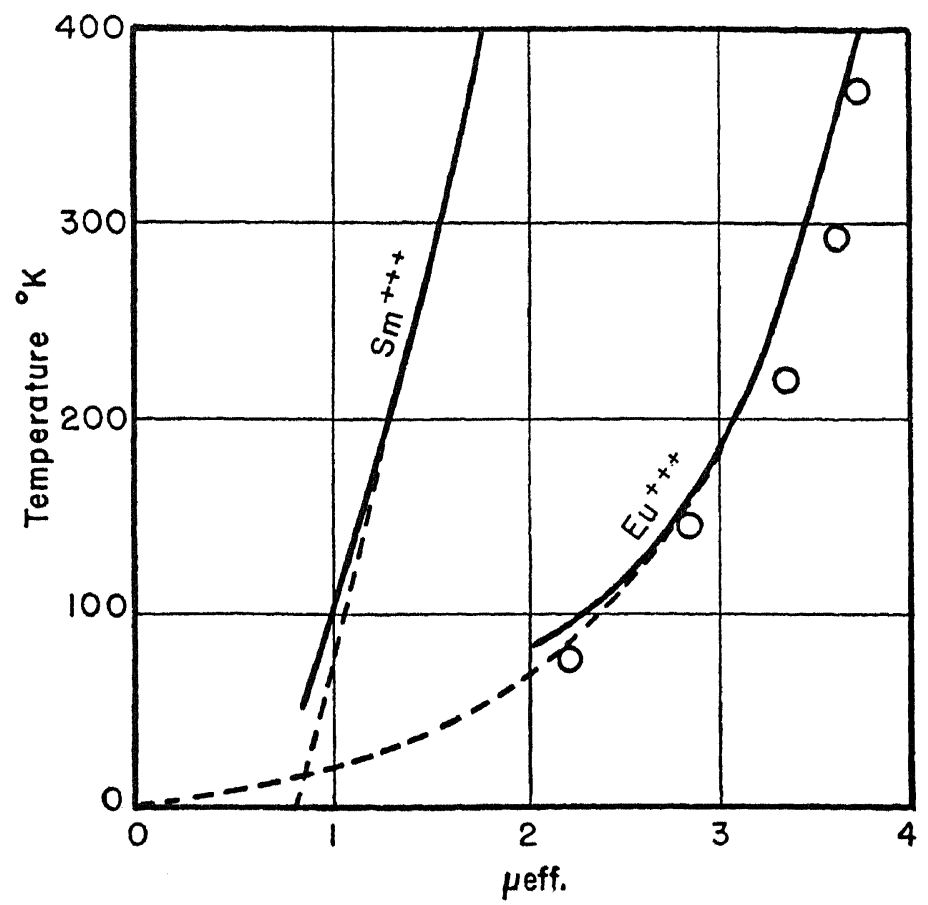

FIg. 7.-Effective Bohr Magneton Numbers for the Ions $\mathrm{Sm}^{+3}$, $\mathrm{Eu}^{+3}$, and $\mathrm{Sm}^{+2}$ : Experimental Points $\mathrm{O}$ for $\mathrm{Sm}^{+2}$. 
oxides of praseodymium and yttrium in oxygen under various conditions. ${ }^{27}$ The extent of oxidation was determined by weighing the resulting products and then reducing them with hydrogen and reweighing. Since yttrium exists in the $+_{3}$ state only, any gain in weight of the mixture must be attributed to the oxidation of tripositive praseodymium. The greatest $\mathrm{O}: \mathrm{Pr}_{2} \mathrm{O}_{3}$ ratio in the ignition products was obtained with an oxide mixture of the molar ratio ${ }_{1} \mathrm{Pr}_{2} \mathrm{O}_{3}: 9 \mathrm{Y}_{2} \mathrm{O}_{3}$, at $350^{\circ}$ and 15 atmospheres of oxygen pressure. This ratio had a value of 1.80 ; the theoretical value for $\mathrm{Pr}_{2} \mathrm{O}_{5}$ is 2.00 and that for $\mathrm{PrO}_{2}$ is 1.00 .

The validity of the work just described has been questioned, ${ }^{26 c}$ since repetition of similar experiments gave 1.00 as the highest $\mathrm{O}: \mathrm{Pr}_{2} \mathrm{O}_{3}$ ratio obtainable, a value corresponding to the formation of $\mathrm{PrO}_{2}$ alone. It is claimed that abnormal hygroscopicity of yttrium sesquioxide after ignition in hydrogen may have caused an analytical error in the previous work. It should be pointed out, however, that the $\mathrm{O}: \mathrm{Pr}_{2} \mathrm{O}_{3}$ ratio of 1.00 was obtained in work performed at a maximum oxygen pressure of only 3 atmospheres, whereas the value 1.80 was found in experiments carried out at an oxygen pressure of 15 atmospheres. In other experimental work involving the ignition of lower oxides of praseodymium in the absence of supporting oxide, $\mathrm{PrO}_{2}$ of 99.2 mole per cent purity has been obtained at $37^{8} \pm 3^{\circ}$ and approximately 15 atmospheres of oxygen pressure. ${ }^{26 \mathrm{~b}}$

A black substance of empirical formula $\mathrm{PrO}_{2}$ is formed also when $\mathrm{Pr}_{6} \mathrm{O}_{11}$ is fused with sodium chlorate. Its crystal structure, as revealed by $\mathrm{X}$-ray studies, is again of the fluorite type. ${ }^{26 a, 28}$ It is of course conceivable that $\mathrm{PrO}_{2}$ may contain praseodymium in two different oxida- 
tion states, e.g., $\mathrm{Pr}_{2} \mathrm{O}_{3} . \mathrm{Pr}_{2} \mathrm{O}_{5}$. On the basis of magnetic measurements, it is claimed that $\mathrm{PrO}_{2}$ contains tetrapositive praseodymium, ${ }^{29}$ but, as has been pointed out, the magnetic criterion cannot differentiate between +4 and a mixture of +3 and +5 praseodymium.*

Treatment of the higher oxides of praseodymium with nonreducing acids results in the reduction of praseodymium to the tripositive state, with evolution of oxygen. The elementary halogens are liberated from hydrohalic acids. ${ }^{26 a}$ No evidence has been found for an oxidation state greater than ${ }_{3} 3$ for praseodymium in solution.

When mixtures of $\mathrm{Y}_{2} \mathrm{O}_{3}$ and $\mathrm{Tb}_{2} \mathrm{O}_{3}$ are heated in air, the maximum oxygen absorption corresponds to the conversion of the terbium sesquioxide to $\mathrm{TbO}_{2}{ }^{27}$ In view of the electronic configuration of terbium, there can be little doubt that the product of this reaction is an oxide of the tetrapositive state. Evidence for the existence of $\mathrm{Tb}_{6} \mathrm{O}_{11}$ and $\mathrm{Tb}_{4} \mathrm{O}_{7}$, both brown, has also been obtained in these studies. Presumably, these compositions correspond to $\mathrm{Tb}_{2} \mathrm{O}_{3} .4 \mathrm{TbO}_{2}$ and $\mathrm{Tb}_{2} \mathrm{O}_{3} .2 \mathrm{TbO}_{2}$, respectively. Above $350^{\circ}, \mathrm{Tb}_{4} \mathrm{O}_{7}$ begins to dissociate into the sesquioxide and oxygen; at $700^{\circ}$ this dissociation is complete.

Conversion of praseodymium and terbium sesquioxides to higher oxides by heating in oxygen may frequently be promoted by the addition of other oxides. For example, the formation of higher oxides of praseodymium in high concentrations of oxygen is markedly catalyzed by cerium dioxide, $\mathrm{CeO}_{2}$. A comprehensive investigation of the role played by other sesquioxides, and particularly by "rare-earth" oxides, in the direct oxidation of praseodymium and terbium sesquioxides to di-

* Yost, Russell, and Garner, The Rare Earth Elements and Their Compounds, p. 9 . 
oxides, has led to the following conclusions. ${ }^{20 c}$ Dioxides of the fluorite type of structure, and sesquioxides which have the C-type lattice, * can form solid solutions with one another. Dioxide formation by praseodymium and terbium is promoted by admixture with sesquioxides of metals with larger apparent ionic radii, provided C-type sesquioxide structure is maintained. If, however, A type sesquioxides are added as promoters, or if there is conversion from the C-type to the A-type lattice, dioxide formation is inhibited. A-type sesquioxides, being unable to accommodate the dioxides, are, therefore, unable to form solid solutions with them.

* A C-type sesquioxide lattice is a fluorite type cubic lattice. It is stable over an ionic radius ratio range of $0.53-0.86$. The upper limit is reached at about $\mathrm{Sm}_{2} \mathrm{O}_{3}$ in the "rare-earth" series. For larger ratios $(0.86-0.92)$ found in $\mathrm{La}_{2} \mathrm{O}_{3}$ and other members of the series, a hexagonal layer A-type of lattice is formed. 


\section{IX}

\section{Miscellaneous}

HERE are several interesting isolated instances of research on unfamiliar oxidation states which,

1 while they do not fit into any general pattern, are nevertheless worthy of discussion. The polarographic evidence discussed below for the existence of lower states of antimony and bismuth in solution suggests the problem of the isolation of compounds containing these elements in such states. The discovery of uninegative rhenium offers the chemist a challenge to elucidate its structure, and also opens the question of the possibility of the existence of other transition elements in the same oxidation state. The isolation of complex cyanides of palladium $(\mathrm{O})$ and platinum $(\mathrm{O})$ supplements the discussion in a previous section of a similar complex for nickel.

Polarographic Reduction of Antimony(III) and Bismuth(III) in Citrate Media

The polarographic reduction of tripositive antimony in a citrate medium is irreversible over a wide range of $\mathrm{pH}$ and citrate ion concentration. ${ }^{1}$ Moreover, no linear rclationship exists between the diffusion current and the antimony concentration at any of the $\mathrm{pH}$ valucs used. At $\mathrm{pH}$ values between 7 and 14 antimony(III) is reduced in two steps (Fig. 8), the diffusion current for the first wave being approximately one-half of that for a second wave. This observation appears to indicate that the first step in the reduction is the formation of dipositive antimony, stabilized in a citrate complex. 
The reduction of tripositive bismuth in a citrate medium is likewise irreversible, although reversibility appears to be approached at high $\mathrm{pH}$ values. In alkaline citrate medium the reduction of bismuth also proceeds in two stages; in this case, however, the first step apparently involves reduction to the unipositive state (Fig. 8).

\section{Uninegative Rhenium}

An extraordinarily interesting example of an unusual oxidation state is furnished by uninegative rhenium. At low temperatures dilute solutions of potassium perrhenate, acidified with sulfuric acid, are reduced in a Jones reductor with the formation of uninegative rhenium. ${ }^{2}$ The postulated reaction is

$$
\mathrm{ReO}_{4}^{-}+8 \mathrm{H}^{+}+8 \mathrm{e}^{-}=\mathrm{Re}^{-}+{ }_{4} \mathrm{H}_{2} \mathrm{O} .
$$

The evidence for the existence of the rhenide ion is derived from measurements of the reducing power of the solution formed.

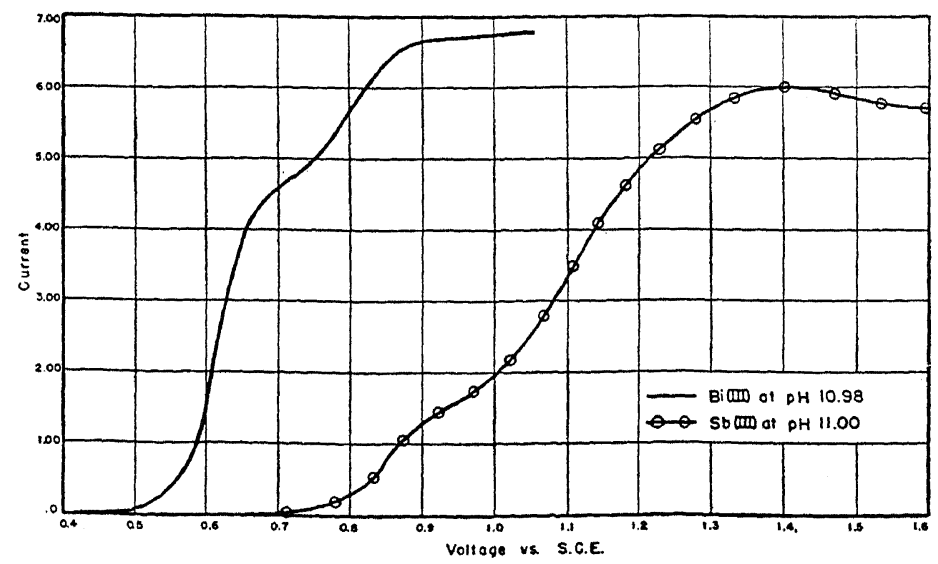

Frg. 8.-Polarograms of $\mathrm{Sb}(\mathrm{III})$ and $\mathrm{Bi}(\mathrm{III})$ in Citrate Media. 
Additional information concerning uninegative rhenium has been obtained from polarographic studies. ${ }^{3}$ In neutral unbuffered potassium chloride solutions, the perrhenate ion is irreversibly reduced at the dropping mercury electrode..$^{3 a}$ A double wave is obtained, the first part of which $\left(E^{1 / 2}\right.$ vs. the saturated calomel electrode = $\mathbf{- 1 . 4 1}$ volts) corresponds to reduction to uninegative rhenium. The second part of the wave is believed to be attributable to the catalytic discharge of hydrogen. The oxidation of uninegative rhenium at the dropping mercury electrode in $1-2 \mathrm{~N}$ sulfuric acid at $0^{\circ}$ shows three waves at potentials of $-0.54,-0.34$ and --0.07 volts, respectively, against the saturated calomel electrode, ${ }^{3 b}$ The polarogram obtained in I $\mathrm{N}$ perchloric acid, is similar, except that the second wave described above is resolved into two separate waves $\left(\mathrm{E}_{1 / 2}=-0.42\right.$ volts and $\mathrm{E}_{1 / 2}=$ -0.26 volts). The data obtained indicate that uninegative rhenium is oxidized in the following stages:

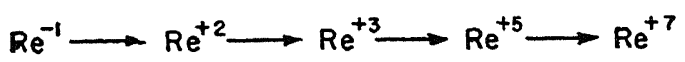

Confirmation of these changes was obtained by amperometric titration of uninegative rhenium with ceric ion.

Rhenium in the -1 state is a powerful reducing agent, reacting with copper or silver salts to give the element, and with titanium (IV) sulfate to produce compounds of lower oxidation state. Under certain conditions uninegative rhenium is capable also of reducing sulfuric acid.

An explanation has recently been offered for the existence of -1 rhenium. ${ }^{4}$ Rhenide ion is isoelectronic with dipositive platinum, which exists only in covalent complexes with four groups arranged in coplanar fashion in a square around the platinum. It seems likely, therefore, 
that uninegative rhenium exists in a similar complex, and it is possible that four water molecules may be coordinated about the rhenium atom at the corners of a square.

\section{Palladium of Zero Oxidation State}

The reduction of an aqueous solution of potassium tetracyanopalladate(II), $\mathrm{K}_{2}\left[\mathrm{Pd}(\mathrm{CN})_{4}\right]$, by potassium amalgam yields a clear, colorless solution, free from colloidal metal, which exhibits strong reducing powers. ${ }^{5}$ When the reduction is carried out by means of potassium in liquid ammonia at $-33^{\circ}$, yellow crystals are formed in the solution. When an amount of potassium slightly in excess of two equivalents per formula weight of $\mathrm{K}_{2}\left[\mathrm{Pd}(\mathrm{CN})_{4}\right]$ has been added, the solution turns bluishgreen, and metallic palladium begins to be deposited. Practically no hydrogen is liberated during the course of the reaction. Similar reactions carried out at $0^{\circ}$ permit the isolation and antysis of the reduction product; the results correspond to the formula $\mathrm{K}_{4}\left[\mathrm{Pd}(\mathrm{CN})_{4}\right] .^{6}$

Potassium tetracyanopalladate $(\mathrm{O}), \mathrm{K}_{4}\left[\mathrm{Pd}(\mathrm{CN})_{4}\right]$, is stable for at least six hours when left in liquid ammonia at $0^{\circ}$, and for twelve hours at $-33^{\circ}$. It dissolves readily in water, momentarily forming a clear solution, after which hydrogen and hydrogen cyanide gases are evolved and palladium is deposited. It reduces silver iodide quantitatively to free silver, with the formation of much free palladium. Azobenzene is converted by the palladium compound to $\mathrm{N}, \mathrm{N}^{\prime}$-diphenylbenzhydrazide.

Observations on the Reduction of Potassium TetraCYANOPLATINATE(II)

Potassium tetracyanoplatinate(II), $\mathrm{K}_{2}\left[\mathrm{Pt}(\mathrm{CN})_{4}\right]$, is reduced also by potassium in liquid ammonia. ${ }^{6} \mathrm{Com}-$ 
plete characterization of the reduction product is, however, made difficult by the relative insolubility of the dipositive platinum complex, and by the evolution of much hydrogen. At $-33^{\circ}$ the reacting ratios of $\mathrm{K}: \mathrm{K}_{2}\left[\mathrm{Pt}(\mathrm{CN})_{4}\right]$ cven after correction for hydrogen evolution, are always greater than two. When potassium is added to a solution containing the dipositive platinum complex and potassium amide in the ratio 1:5, very little hydrogen is evolved, and the reacting ratio of $\mathrm{K}: \mathrm{K}_{2}\left[\mathrm{Pt}(\mathrm{CN})_{t}\right]$ becomes approximately two. At $\mathrm{O}^{\circ}$ a white precipitate is formed, the analysis of which corresponds roughly to the formula $\mathrm{K}_{4}\left[\mathrm{Pt}(\mathrm{CN})_{4}\right]$.

Reduction of a dilute aqueous solution of $\mathrm{K}_{2} \mathrm{Pt}(\mathrm{CN})_{4}$. ${ }_{3} \mathrm{H}_{2} \mathrm{O}$ with sodium amalgam yields a solution possessing marked reducing properties. ${ }^{7}$ The reducing solution formed has been presumed to contain unipositive platinum. 


\section{References}

I

1. Brukl and Ortner, Z. anorg. allgem. Chem., 203, 23 (1931); Klemm and Schnick, ibid., 226, 353 (1936); Brukl and Ortner, Monatsh., 56, $35^{8}$ (1930); Nilson and Petterson, Z. physik. Chem., 2, 657 (1888); Thiel and Koelsch, Z. anorg. Chem. 66, 288 (1910).

2. Emeléus and Anderson, Modern Aspects of Inorganic Chemistry, D. Van Nostrand Company, Inc., New York 1939, pp. 144-5.

3. Wöhler and Buff, Ann., 103, 218 (1857); Turrentine, J. Phys. Chem., 12, 448 (1908); Sborgi and Marchetti, Nuovo cimento, 22, 151 (1921); del Boca, Helv. Chim. Acta, 16, 565 (1933).

4. Davidson and Jirik, J. Am. Chem. Soc. (in press).

5. Corson, MacKenzie and Segré, Phys. Rev., 57, 459 (1940); 58, 672 (1940); Segré, MacKenzie and Corson, ibid., 57, 1087 (1940).

6. Copley, Foster and, Bailar, Chem. Revs., 30, 227 (1942).

7. Poggendorff, Pogg. Ann., 54, 161 (1841); Rose, ibid., 59, 314 (1843); Haber, Z. Elektrochem., 7, 215 (1900); Pick, ibid., 7, 713 (1900); Grube and Gmelin, ibid., 26, 153 (1920); 26, 459 (1920).

8. Buntin and Vlasov, Acta Univ. Voronegiensis, 8, No. 4, 6 (1935).

9. Luther and Pokorny, Z. anorg. Chem., 57, 290 (1908).

10. Hall, J. Am. Chem. Soc., 29, 692 (1907).

11. Malatesta, Gazz. chim. ital., 71, 467 (1941); 580 (1941).

12. Rây and Sarma, Nature, 157, 627 (1946); J. Indian Chem. Soc., 25, $205(1948)$. (1937).

13. Noyes, DeVault, Coryell, and Deahl, J. Am. Chem. Soc., 59, 1326

14. Trauble and Passarge, Ber., 46, 1505 (1913).

15. Eastes and Burgess, J. Am. Chem. Soc., 64, 2715 (1942).

16. Burbage and Fernelius, J. Am. Chem. Soc., 65, 1484 (1943).

17. Deasy, J. Am. Chem. Soc., 67, 152 (1945).

18. Yost, Russell, and Gamer, The Rare Earth Elements and Their Compounds, John Wiley \& Sons, Inc., New York, 1947, pp. 4-6.

19. Meggers, Science, 105, 514 (1947).

20. Pagel and Brinton, J. Am. Chem. Soc., 51, 42 (1929).

21. Selwood, Abstracts of Papers, Division of Physical and Inorganic Chemistry, American Chemical Society, Chicago, April 1948, p. 20-0; Selwood, J. Am. Chem. Soc., 70, 883 (1948).

22. Bailar and Callis, paper presented before the Physical and Inorganic Division of the American Chemical Society at the San Francisco meeting, March 27-April 1, 1949.

23. De Boer and van Ormondt, British patent 579,817 (1946); Chem. Abstracts, 41, 1401 (1947).

24. Barbieri, Atti accad. Lincei, 13, 882 (1931).

25. Marshall, Proc. Roy. Soc. Edinburgh, 14, 203 (1886-7).

26. Rây and Chakravarty, J. Indian Chem. Soc., 21, 47 (1944).

27. Selwood, J. Am. Chem. Soc., 55, 4869 (1933).

28. Neuman, J. Chem. Phys., 2, 31 (1934); Helms and Klemm, Z. anorg. allgem. Chem., 241, 97 (1939).

29. Kassatochkin and Kotov, J. Chem. Phys., 4, 458 (1936). 
30. Pauling, The Nature of the Chemical Bond, and Edition, Cornell University Press, Ithaca, New York, 1940, p. 272.

31. Gleu and Rehm, Z. anorg. allgem. Chem., 237, 79 (1938).

32. Swann and Xanthakos, J. Am. Chem. Soc., 53, 400 (1931).

33. Sulc, Z. anorg. Chem., 12, 89 (1896); Watson, J. Chem. Soc., 89, $57^{3}$ (1906); Barbieri, Atti accad. Lincei, [5], 16, II, 72 (1907); Baborovsky and Kuzma, Z. physik. Chem., 67, 48 (1909); Noyes, DeVault, Coryell and Deahl, J. Am. Chem. Soc., 59, 1326 (1937).

34. Tubandt and Riedel, Z. anorg. Chem. 72, 219 (1911).

35. Noyes, Hoard and Pitzer, J. Am. Chem. Soc. 57, 1221 (1935); Noyes, Pitzer and Dunn, ibid., 57, 1229 (1935); Noyes and Kossiakoff, ibid., 57, 1238 (1935); Noyes, Coryell, Stitt and Kossiakoff, ibid., 57, 1316 (1937).

36. Jirsa and Jelinek, Z. anorg. allgem. Chem., 158, 61 (1926).

37. Ruff and Ascher, Z. anorg. allgem. Chem., 183, 193 (1929).

38. Ebert, Rodowskas and Frazer, J. Am. Chem. Soc., 55, 3056 (1933); Ruff and Giese, Angew. Chem., 47, 480 (1934).

39. Moberg, J. prakt. Chem., [1], 29, 175 (1843); Peligot, Ann. chim. phys., [3], 12, 528 (1844).

40. Matignon and Cazes, Compt. rend., 142, 83 (1906); Prandtl and Kögl, Z. anorg. allgem. Chem., 172, 265 (1928); Klemm and Rockstroh, ibid., 176, 181 (1928); Urbain and Bourion, Compt. rend., 153, 1155 (1911); Jantsch, Alber and Grubitsch, Monatsh., 53-54, 305 (1929); Beck and Nowacki, Naturwissenschaften, 26, 495 (1938); Klemm and Schuth, Z., anorg. allgem. Chem., 184, 352 (1929); Senff and Klemm, ibid., 242, 92 (1939).

41. Yntema, J. Am. Chem. Soc., 52, 2782 (1930); Marsh, J. Chem. Soc., 1934, 1972; McCoy, J. Am. Chem. Soc., 58, 1577 (1936); Ball and Yntema, ibid., 52, 4264 (1930); Pearce, Naesar and Hopkins, Trans. Electrochem. Soc., 69,557 (1936); Marsh, J. Chem. Soc., 1937, 1367.

42. Lundell and Knowles, J. Research Nat. Bur. Standards, 18, 629 (1937).

43. Jantsch and Skalla, Z. anorg. allgem. Chem., 193, 391 (1930).

44. Jantsch, Skalla and Jawurek, Z. anorg. allgem. Chem. 201, 207 (1931).

\section{II}

1. (a) Nilson and Petterson, Z. physik. Chem. 2, 657 (2888); (b) Klemm and Tilk, Z. anorg. Chem., 207, I75 (1932); (c) Laubengayer and Schirmer, J. Am. Chem. Soc., 62, $157^{8}$ (1940).

2. Hannebohn and Klemm, Z. anorg. allgem. Chem., 229, 337 (1936).

3. Klemm, Z. anorg. allgem. Chem., 152, 252 (1926).

4. Thiel and Koelsch, Z. anorg. Chem., 66, 288 (1910).

5. Klemm and Tilk, Z. anorg. Chem., 207, I75 (1932).

6. Emeléus and Anderson, Modern Aspects of Inorganic Chemistry, D. Van Nostrand Company, Inc., New York, 1939, pp. 144-5.

7. Brukl and Ortner, Z. anorg. allgem. Chem., 203, 23 (1932).

8. Klemm and Schnick, Z. anorg. allgem. Chem., 226, 353 (1936).

9. Brukl and Ortner, Monatsh., 56, $35^{8}$ (1930).

10. Del Boca, Helv. Chim. Acta, 16, 565 (1933).

11. (a) Wöhler and Buff, Ann., 103, 218 (1857); (b) Turrentine, J. Phys. Chem., 12, 448 (1908).

12. Sborgi and Marchetti, Nuovo cimento, 22, 151 (1921).

13. Davidson and Jirik, J. Am. Chem. Soc. (in press); Jirik, Ph.D. Thesis, University of Kansas, 1948.

14. Davidson, Kleinberg, Bennett, and McElroy, J. Am. Chem. Soc., 71, 377 (1949). 


\section{III}

1. Latimer and Hildebrand, Reference Book of Inorganic Chemistry, Macmillan Company, New York, 1940, p. 34.

2. (a) Harcourt, J. Chem. Soc., 14, 267 (1862); (b) Holt and Sims, ibid., 65, 432 (1894); (c) Rengade, Ann. chim. phys., (8), 11, 348 (1907).

3. (a) Joannis, Compt. rend., 116, 1370 (1893); (b) Kraus and Whyte, J. Am. Chem. Soc., 48, 1781 (1926); (c) Kraus and Parmenter, ibid., 56, 2384 (1934).

4. Schechter, Sisler and Kleinberg, J. Am. Chem. Soc., 70, 267 (1948).

5. Schechter, Thompson and Kleinberg, J. Am. Chem. Soc., 71, 1816 (1949).

6. Stephanou, Schechter, Argersinger, and Kleinberg, J. Am. Chem. Soc., 71, 1819 (1949).

7. Traube and Schulze, Ber., 54, 1626 (1921).

8. Pauling, J. Am. Chem. Soc., 53, 3225 (1931).

9. Neuman, J. Chem. Phys., 2, 31 (1934).

10. Ehrlich, Z. anorg. Chem., 255, 370 (1944).

11. Kassatochkin and Ko'ov, J. Chem. Phys., 4, $45^{8}$ (1936).

12. Helms and Klemm, Z. anorg. allgem. Chem., 241, 97 (1939).

13. Pauling, The Nature of the Chemical Bond, and Edition, Cornell University Press, Ithaca, New York, 1940, p. 272.

14. Kazarnovskii and Raikhstein, J. Phys. Chem. (U.S.S.R.), 21, 245 (1947).

15. Helms and Klemm, Z. anorg. allgem. Chem., 242, 201 (1939).

\section{IV}

1. (a) Sinonini, Monatsh., 14, 81 (1893); (b) Wieland and Fischer, Ann., 446, 49 (1926); (c) Prévost, Compt. rend., 196, 1129 (1933).

2. Goodrich, Master's Thesis, University of Kansas, 1948.

3. Cofman, J. Chem. Soc., 115, 1040 (1919).

4. Carlsohn, Uber eine Neue Klasse von Verbindungen des Positiv Einwertigen Iods, Verlag Hirzel, Leipzig, 1932.

5. Zingaro, Master's Thesis, University of Kansas, 1948.

6. Finkelstein, Z. physik. Chem., 124, 285 (1926).

7. Carlsohn, Angew. Chem., 46, 747 (1933).

8. Uschakov and Tchistov, Ber., 68, 824 (1935).

9. Carlsohn, Ber., 68, 2209 (1935).

10. Partingtor and Bahl, J. Chem. Soc., 1935, 1258.

11. Fichter and Stern, Helv. Chim. Acta, 11, 1256 (1928).

12. Fouque, Chem. Ztg., 38, 680 (1914).

13. (a) Corson, Mackenzie and Segrè, Phys. Rev., 57, 459 (1940); (b)

Segre, MacKenzie and Corson, ibid., 57, 1087 (1940); (c) Corson, MacKenzie and Segrè, ibid., 58, 672 (1940).

14. Johnson, Leininger and Segrè, J. Chem. Phys., 17, 1 (1949).

15. Hamilton and Soley, Proc. Nat. Acad. Sci., 26, 483 (1940).

16. Birckenbach and Goubeau, Ber., 65, 395 (1932).

17. (a) Gomberg, J. Am. Chem. Soc., 45, 398 (1923); (b) Gomberg and Gamrath, Trans. Faraday Soc., 30, 24 (1934).

\section{$\mathrm{V}$}

1. Rice, Electronic Structure and Chemical Binding, McGraw-Hill Book Company, New York, 1940, pp. 334-335.

2. Randles, J. Chem. Soc., 802 (1941). 
3. Copley, Foster and Bailar, Chem. Revs., 30, 227 (1942).

4. Morgan, J. Chem. Soc., 123, 2901 (1923).

5. (a) Kohlschütter, Ber., 36, 1151 (1903); (b) Kohlschütter and Brittlebank, Ann., 349, 232 (1906).

6. Rosenheim and Loewenstamm, Z. anorg. Chem., 34, 62 (1903).

7. Morgan and Burstall, J. Chem. Soc., 143 (1928).

8. Spacu and Murgulescu, Kolloid Z., 91, 294 (1940); Chem. Abstracts, 35,4700 (2941).

9. Latimer and Hildebrand, Reference Book of Inorganic Chemistry, Rev. Ed., Macmillan Company, New York, 1940, p. 206.

10. Grossman and von der Forst, Z. anorg. Chem., 43, 94 (1905).

11. Cox, Wardlaw, and Webster, J. Chem. Soc., 775 (1936).

12. Morgan and Burstall, J. Chem. Soc., 2018 (1926).

13. Mann, Purdie and Wells, J. Chem. Soc., 1503 (1936).

14. Tartarini, Gazz. chim. ital., 63, 597 (1933).

15. (a) Krüger, Pogg. Ann. Phys., 62, 447 (1844); (b) Frémy, Ann. chim. phys., (3), 12, 457 (1844); (c) Crum, Ann., 55, 213 (1845).

16. Müller and Spitzer, Z. Elektrochem., 13, 25 (1907).

17. Buntin and Vlasov, Acta Univ. Vorongiensis, 8, No. 4, 6 (1935).

18. Virtis, Rec. trav. chim., 44, 425 (1925).

19. (a) Brauner and Kuzma, Ber., 40, 3362 (1907); (b) Malatesta, Gazz. chim. ital., 71, 580 (1941).

20. Malatesta, Gazz. chim. ital., 71, 467 (1941).

21. (a) Mulder, Rec. trav. chim., 17, 129 (1898); (b) Watson, J. Chem. Soc., 89, 578 (1906); (c) Jirsa, Z. anorg. allgem. Chem., 148, 130 (1925); (d) Noyes, DeVault, Coryell and Deahl, J. Am. Chem. Soc., 59, 1326 (1937) 22. (a) Barbieri, Ber., 6oB, 2427 (1927); (b) de Boer and Van Ormondt, British Patent 579,817 (1946); Chem. Abstracts, 41, 1401 (1947).

23. Luther and Pokorny, Z. anorg. Chem., 57, 290 (1908).

24. (a) Ebert, Rodowskas and Frazer, J. Am. Chem. Soc., 55, 3056 (1933);

(b) Ruff and Giese, Angew. Chem., 47, 480 (1934).

25. Gruner and Klemm, Naturwissenschaften, 25, 59 (1937).

26. (a) Noyes, Hoard and Pitzer, J. Am. Chem. Soc., 57, 1221 (1935);

(b) Noyes, Pitzer and Dunn, ibid., 57, 1229 (1935); (c) Noyes, Coryell, Stitt and Kossiakoff, ibid., 59, 1316 (1937).

27. Noyes and Kossiakoff, J. Am. Chem. Soc., 57, 1238 (1935).

28. Weber, Trans. Amer. Electrochem. Soc., 32, 391 (1917).

29. (a) Barbieri, Gazz. chim. ital., 42, II, 7 (1912); (b) Atti accad. Lincei, 21, I, 560 (1912).

30. Barbieri, Atti accad. Lincei, 13, 882 (1931).

31. Barbieri, Ber., 6oB, 2424 (1927).

32. Morgan and Burstall, J. Chem. Soc., 1930, 2594.

33. Barbieri, Atti accad. Lincei, 16, 44 (1932).

34. Hieber and Mühlbauer, Ber., 61B, 2149 (1928).

35. Morgan and Burstall, J. Chem. Soc., 1937, 1649.

36. (a) Barbieri, Atti accad. Lincei, 17, 1078 (1933); (b) Cox, Wardlaw and Webster, J. Chem. Soc., 1936, 775 .

37. Burada, Ann. sci. univ. Jassy, 20, 71 (1935).

38. Nakatsuka, Bull. Chem. Soc. Japan, 11, 45 (1936).

39. Private communication from Professor John C. Bailar, Jr.; Block, Ph.D. Thesis, University of Illinois (1949).

40. (a) Morgan and Sugden, Nature, 128, 31 (1931); (b) Klemm, Z. anorg. allgem. Chem., 201, $3^{2}$ (1931); (c) Sugden, J. Chem. Soc., 1932, 161. 
41. (a) Sulc, Z. anorg. Chem., 12, 89 (1896); (b) Mulder and Heringa, Rec. trav. chim., 15, 236 (1896); (c) Barbieri, Atti accad. Lincei, [5], 16, II, 72 (1907); (d) Brown, J. Phys. Chem., 20,680 (1916).

42. Fichter and Goldbach, Helv. Chim. Acta, 13, 99 (1930).

43. Braekken, Kgl. Norske Videnskab. Selskab. Forh., 7, 143 (1935); Chem. Abstracts, 29, 4647 (1935).

44. Jirsa and Jelinek, Z. anorg. allgem. Chem., 158, 61 (1926).

45. (a) Yost, J. Am. Chem. Soc., 48, 152 (1926); (b) Yost and Claussen, ibid., 53, 3349 (1931); Dekker, Lévy and Yost, ibid., 59, 2129 (1937).

46. Carman, Trans. Faraday Soc., 30, 566 (1934).

47. Malaprade, Compt. rend., 210, 504 (1940).

48. Rây and Chakravarty, J. Indian Chem. Soc.. 21, 47 (1944).

\section{VI}

1. (a) Moberg, J. prakt. Chem., [1], 29, 175 (1843); (b) Peligot, Ann. chim. phys., [3], 12, 528 (1844).

2. (a) Traube and Goodson, Ber., 49, 1679 (1916); (b) Asmanov, Z. anorg. allgem. Chem., 160, 209 (1927).

3. Sand and Burger, Ber., 39, 1771 (1906).

4. (a) Peligot, Ann. chim. phys., [3], 12, 528 (1844); (b) Recoura, ibid., [6], 10, 5 (1887); (c) Inorganic Syntheses, Vol. I, McGraw-Hill Book Company, New York, 1939, p. 122.

5. (a) Knight and Rich, J. Chem. Soc., 99, 87 (1911); (b) Inorganic Syntheses, Vol. I, p. 125.

6. Traube, Burmeister and Stahn, Z. anorg. allgem. Chem., 247, 50 (1925).

7. Traube and Lange, Ber., 58, 2773 (1925).

8. Kohlschütter, Ber., 37, 3053 (1904).

9. Berthelot, Ann., [4], 9, 401 (1866).

10. Traube and Passarge, Ber., 49, 1692 (1916).

11. (a) Peters, Ber., 42, 4826 (1910); (b) Ephraim and Millman, Ber., 50, 529 (1917); (c) Schlesinger and Hammond, J. Am. Chem. Soc., 55, 3971 (1933); (d) Chatelet, Compt. rend., 199, 290 (1934).

12. Chatelet and Chatelet, Compt. rend., 198, 833 (1934).

13. Traube and Passarge, Ber., 46, 1505 (1913).

14. Hume and Stone, J. Am. Chem. Soc., $6_{3}, 1200$ (1941).

15. Balthis and Bailar, J. Am. Chem. Soc., 58, 1474 (1936).

16. Barbieri and Tettamanzi, Atti Accad. Lincei, 15, 877 (1932).

17. Hammett, Walden and Edmonds, J. Am. Chem. Soc., 56, 1092 (1934).

18. Christensen, J. prakt. Chem., 31, 163 (1885).

19. Koppel, Z. anorg. Chem., 45, 359 (1905).

20. Lips, Helv. Phys. Acta, 7,537 (1934).

21. (a) Manchot and Gall, Ber., 60B, 191 (1927); (b) ibid., 61B, 1135 (1928).

22. Grube and Brause, Ber., 6oB, 2273 (1927).

23. Treadwell, Gübeli and Huber, Helv. Chim. Acta, 24, 152 (1941).

24. (a) Bhatnagar, Prakash and Maheswari, Proc. Indian Acad. Sci., 10A, 150 (1939); (b) Goldenberg, Trans. Faraday Soc., 36, 1847 (1940). Ward.

25. Private communication of unpublished work from Professor Roland

26. Lux, Z. Naturforsch., 1, 281 (1946); Chem. Abstracts, 41, 3008 (1947).

27. Miller and Rogers, Science, 109, 62 (1949). 


\section{VII}

1 Moser and Borch, Ber., 42, 4279 (1909).

2. (a) Ward and Struthers, J. Am. Chem. Soc., 59, 1849 (1937); (b) Erchak, Fankuchen and Ward, ibid., 68, 2085 (1946); (c) Erchak and Ward, ibid., 68, 2093 (1946).

3. Bray and Gorin, J. Am. Chem. Soc., 54, 2124 (1932).

4. (a) Fremy, Compt. rend., 14, 442 (1843); (b) Losana, Gazz. chim. ital., 55,468 (1925).

5. (a) Fremy, Compt. rend., 12, 23 (184x); (b) Rosell, J. Am. Chem. Soc., 17,760 (1895).

6. Traube, Burmeister and Stahn, Z. anorg. allgem. Chem., 147, 50 (1925). (1843); (c) Haber, Z. Elektrochem., 7, 21.5 (1910); (d) Pick, ibid., 7, 713 (1900); (e) Grube and Gmelin, ibid., 26, 153 (1920); 26, 459 (1920); (f) Petrov and Ormont, J. Gen. Chem. (U.S.S.R.), 7, 1690 (1937).

7. Eidmann and Moeser, Ber., 36, 2290 (1903).

8. Eastes and Burgess, J. Am. Chem. Soc., 64, 1187 (1942).

9. Deasy, J. Am. Chem. Soc., 67, 152 (1945).

10. (a) Papasogli, Gazz. chim. ital., 9, 509 (1879); (b) Moore, Chem. News, 68, 295 (1893); 71, 81 (1895); (c) Reitzenstein, Ann., 282, 267 (1894); (d) Bellucci and Correlli, Z. anorg. Chem., 86, 88 (1914); (e) Bellucci, Gazz. chim. ital., 6o, 946 (1930); (g) Mellor and Craig, J. Proc. Roy. Soc., N.S. Wales, 76, 281 (1942).

11. (a) Job and Samuel, Compt. rend., 177, 188 (1923); (b) Manchot and Gall, Ber., 59B, 1060 (1926).

12. Tedeschi, Atti accad. Lincei, Classe di. sci. fis. mat. e nat., 23, 894 (1935).

13. Grube, Z. Elektrochem., 32, 561 (1926).

14. Pauling, The Nature of the Chemical Bond, and Edition, Cornell University Press, Ithaca, New York, 1940, pp. 95-97.

15 (a) Schall and Markgraf, Trans. Amer. Electrochem., Soc. 45, 161 (1924); (b) Schall and Thieme-Wiedtmurckter, Z. Elektrochem., 35, 337 (1929).

16. Schall, Z. Elektrochem., 38, 37 (1932).

17. Swann and Xanthakos, J. Am. Chem. Soc., 53, 400 (1931).

18. Marshall, Proc. Roy. Soc. Edinburgh, 14, 203 (1886-7).

19. Ruff and Ascher, Z. anorg. allgem. Chem., 183, 193 (1929).

20. Liévin and Herman, Compt. rend., 200, 1474 (1935).

21. Noyes and Deahl, J. Am. Chem. Soc., 59, 1337 (1937).

22. Cairns and Ott, J. Am. Chem. Soc., 55, 534 (1933).

23. Hofmann and Ehrhardt, Ber., 46, 1457 (1913).

24. Dubsky and Kuras, Spisy vydávané prirodovedeckou Fakultou Masarykovy. Univ., 1929, No. 114; Chem. Abstracts, 24, 4733 (1930).

25. Malatesta and Monti, Gazz. chim. ital., 70, 842 (1940).

26. Edelman, paper read at the New York meeting of the American Chemical Society, September, 1947.

27. Metzl, Z. anorg. Chem. 86, 358 (1914).

28. Bellucci and Clavari, Atti accad. Lincei, [5], 14, II, 234 (1905); Gazz. chim. ital., $36,1,58$ (1906).

29. Tubandt and Riedel, Z. anorg. Chem., 72, 219 (1911).

30. Howell, J. Chem. Soc., 123,1772 (1923).

31. Latimer, The Oxidation States of the Elements and their Potentials in Aqueous Solutions, Prentice-Hall, Inc., New York, 1938, p. 190.

32. Hall, J. Am. Chem. Soc., 29, 692 (1907). 
33. (a) Rầy and Sarma, Nature, 157,627 (1946); (b) J. Indian Chem. Soc., 25, 205 (1948).

34. Feigl, Ber., 57 B, 758 (1924).

35. Okac and Polster, Collection Czechoslov. Chem. Communs., 13, 561, 572 (1948).

36. Werner, Ann., 375, 1 (1910).

37. Werner and Mylius, Z. anorg. Chem., 16, 245 (1898).

38. Gleu and Rehm, Z. anorg. allgem. Chem., 237, 79 (1938).

39. Malatesta, Gazz. chim. ital., 72, 287 (1942).

40. Private communication from Dr. Eugene Brimm to Professor John C. Bailar, Jr., June 21, 1946.

\section{VIII}

1. Meggers, Science, 105, 514 (1947).

2. Yost, Russell, and Garner, The Rare Earth Elements and Their Compounds, John Wiley and Sons, Inc., New York, 1947, pp. 4-6.

3. (a) Matignon and Cazes, Compt. rend., 142, 83 (1906); (b) Prandtl and Kögl, Z. anorg. allgem. Chem., 172, 265 (1928); (c) Klemm and Rockstroh, ibid., 176, 181 (1928).

4. Jantsch, Rüping and Kunze, Z. anorg. allgem. Chem., 161, 210 (1927).

5. Jantsch and Skalla, Z. anorg. allgem. Chem., 193, 391 (1930).

6. Timnick and Glockler, J. Am. Chem. Soc., 70, 1347 (1948).

7. Urbain and Bourion, Compt. rend., 153, 1155 (1911).

8. Klemm and Döll, Z. anorg. allgem. Chem., 241, 233 (1939).

9. Jantsch, Alber and Grubitsch, Monatsh., 53-54, 305 (1929).

10. Beck and Nowacki, Naturwissenschaften, 26,495 (1938).

11. (a) Yntema, J. Am. Chem. Soc., 52, 2782 (1930); (b) Marsh, J. Chem. Soc., 1934, 1972; (c) McCoy, J. Am. Chem. Soc., 58, 1577 (1936).

12. McCoy, J. Am. Chem. Soc., 57, 1756 (1935).

13. Klemm and Senf, Z. anorg. allgem. Chem., 241, 259 (1939).

14. Selwood, J. Am. Chem. Soc., 57, 1145 (1935).

15. Klemm and Schuth, Z. anorg. allgem. Chem., 184, 352 (1929).

16. Senff and Klemm, Z. anorg. allgem. Chem., 242, 92 (1939).

17. Jantsch, Skalla and Jawurek, Z. anorg. allgem. Chem., 201, 207 (1931). 18. (a) Ball and Yntema, J. Am. Chem. Soc., 52, 4264 (1939); (b) Pearce, Naesar and Hopkins, Trans. Electrochem. Soc., 69, 557 (1936); (c) Marsh, J. Chem. Soc., 1937, 1367.

19. Laitinen, J. Am. Chem. Soc., 64, 1133 (1942).

20. Walters and Pearce, J. Am. Chem. Soc., 62, 3330 (1940).

21. Selwood, J. Am. Chem. Soc., 56, 2392 (2934).

22. Selwood, J. Am. Chem. Soc., 55, 4869 (1933).

23. Noddack and Brukl, Angew. Chem., 50, 362 (1937).

24. (a) Estes and Glockler, J. Am. Chem. Soc., 70, 1344 (1948); (b) Rabideau and Glockler, ibid., 70, 1342 (1948).

25. (a) Holleck and Noddack, Angew. Chem., 50, 819 (1937); (b)

Laitinen and Blodgett, J. Am. Chem. Soc., 71, 2260 (1949).

26. (a) Prandtl and Huttner, Z. anorg. allgem. Chem., 149, 235 (1925);

(b) Pagel and Brinton, J. Am. Chem. Soc., 51, 42 (1929); (c) Marsh, J.

Chem. Soc., $2946,15$.

27. Frandtl and Rieder, Z. anorg. allgem. Chem., 238, 225 (1938).

28. Scherrer and Palacios, Anales soc. españ. fis. quím., 26, 309 (1928).

29. Klemm, Z. angew. Chem., 44, 250 (1931). 


\section{IX}

1. Reynolds, Lowen and Stoenner, unpublished work.

2. (a) Lundell and Knowles, J. Research Nat. Bur. Standards, 18, 629 (1937); (b) Tomicek and Tomicek, Coll. Czech. Chem. Commun., 11, 626 (1939).

3. (a) Lingane, J. Am. Chem. Soc., 64, 1001 (1942); (b) Lingane, ibid., 64,2182 (1942).

4. Pauling, Chem. Eng. News, 25, 2970 (1947).

5. Manchot and Schnid, Ber., $63 B, 2782$ (1930); $64 B, 2672$ (1931).

6 . Burbage and Fernelius, J. Am. Chem. Soc., 65, 1484 (1943).

7. Manchot and Lehmann, Ber., 63B, 2775 (1930). 


\section{Index}

Aluminum

anodic oxidation in nonaqueous solvents, 20-22

metallic aluminum in liquid ammonia, 21, 22

Aluminum group, oxidation states of, $3,14,16-24$

Americium, tripositive, 7

Antimony, dipositive, 115

Astatine, 4, 46-48

Bismuth, unipositive, 116

Bromine, unipositive, 44

Cerium, tetrapsitive, 7

Characterization of unfamiliar states by analytical data and chemical properties, 9

by magnetic susceptibility measurements, is

by X-ray studies, 11

isomorphism and the, 9

Chlorine, the perchlorate radical, $4^{8-49}$

Chromium (II)

acetate, 75

ammine complexes, $77^{-82}$ chloride, $14,74,75,76$

formate, 75

glycollate, 75

malonate, 76

simple and double salts, 74-76

sulfate, 75,76

Cobalt(I), cyanide complex, 92

Cobalt (III)

acetate, 93

ammonium alum, 10, 93

fluoride, 13, 93, 94

oxide, 94

sulfate, 13, 93

Cobalt (IV)

complex molybdate, $5,12,98$ oxide, 97

polynuclear ammines, 99-100

Copper(I)

acetonitrile complexes of, 54

alkyl-substituted phosphine and

arsine complexes of, 57-59

ammine complexes of, 53

ethylenethiourea complexes of, $55-56$ simple salts of, 51-53

thiosulfate complexes of, 56-57

thiourea complexes of, 55

Copper(III)

complexes with periodate and tellurate, $5,12,60-61$

oxide, $5,7,59-60$

Copper group, oxidation states of, 3

Curium, tripositive, 7

Europium(II)

halides, 14, 105, 106

magnetic susceptibility of, 109, 110

potential of $\mathrm{Eu}^{+2}-\mathrm{Eu}^{+3}$ couple, $107^{\circ}$ 108

selenide, 106, 107

sulfate, $7,106,107$

sulfide, 106

telluride, 106, 107

Gallium

anodic oxidation in anhydrous acetic acid, 22-23

$\mathrm{GaCl}_{2}, 17$

$\mathrm{GaS}, 19$

Gallium(I)

oxide, 19

sulfide, 19

Halogens

astatine, $46-48$

the perchlorate radical, $48-49$

tripositive iodine, $45-46$

unipositive iodine and bromine, $37-44$

Indium

anodic oxidation in anhydrous acetic acid, 23-24

$\mathrm{InCl}_{2}, 17$

$\operatorname{InF}_{2}, 17$

Indium(I)

chloride, 18

iodide, 18

Iodine

coördination compounds of iodine (I), 37-45

tripositive, $45-46$

Iron

unipositive, $4,37-45$

hexapositive iron, the ferrates, 12 , $87-88$ 
tetrapositive iron, the ferryl ion, 87

tetrapositive iron, the perferrites, $85,86-87$

Isomorphism, and characterization of unfamiliar states, 10

Magnetic susceptibility and the characterization of unfamiliar oxidation states, 11 of complex molybdate of nickel (IV), 98

of complex periodate of nickel (IV), 98

of complex tellurates and periodates of copper(III), 61

of complex tellurates and periodates of silver(III), 72

of dihalides of gallium and indium, 19

of dipositive chromium compounds, $81-82$

of dipositive europium, 109, 110 of dipositive samarium, 109, 110 of dipositive ytterbium, 110 of $\mathrm{PrO}_{2}, 112-113$

of manganese(I)-cyanide complex, 83

of nickel(I)-cyanide complex, 92 of dispositive silver complexes, 69 of silver(III) complexes with ethylenedibiguanide, 73

of silver(II) fluoride, $6_{3}$

of silver(II)-nitrate complex, 64

of sodium superoxide-sodium peroxide mixtures, 30

of superoxides, $30,32,33$

\section{Manganese}

pentapositive, 84

unipositive, $82-83$

$\operatorname{Nickel}(0)$, complex cyanide of, 6 , $14,88-89$

Nickel(I), complex cyanide of, 6,

$14,90-92$

Nickel(III)

oxide, 95,97

oxime complexes of, 96

Nickel(IV)

complex molybdate of, $5,12,98$

complex periodate of, 98

dimethylglyoxime complex of, 98-99

oxide, 13,97
Oxidation state, concept of, 2

Oxidation states, definition of stabilization of, 4-5

Palladium(O), complex cyanide of, $6,14,118$

Platinum $(\mathrm{O})$, cyanide complex of, 119

Praseodymium, higher oxides of, 110-114

Preparation of unfamiliar oxidation states

by anodic oxidation, 12, 13, 14

by oxidation with fluorine, 13

by oxidation with ozone, 13

by oxidation with persulfate ion, 12 by reduction of higher states, 14 , 15

"Rare-earths"

"anomalous" oxidation states of, 6-7

electronic configurations of, 101 . 102

electronic configurations and "anomalous" oxidation states of, 102-103

higher oxidation states of, 110-114 the dipositive state of, $103-110$

Rhenium, uninegative, 14, 116-118

Samarium(II)

halides, 14, 103-104

magnetic susceptibility of, 109 , 110

sulfate, 104

Samarium(III), polarographic reduction of, 104-105

Silver(II)

complexes with amines, 10, 66-69

fluoride, $13,6_{3}$

nitrate complex, 63-66

oxide, $5,10,12,61-63,70$

Silver(III)

catalytic effect of, 70-71

complexes with ethylenedibiguanide, 11, 72-73

complexes with periodate and tel-

lurate, $5,12,71-72$

oxide, $70,7^{1}$

oxynitrate complex of, $69-70$

Stabilization of oxidation states by periodate and tellurate groups, 5 definition of, 4-5 
effect of chelation on, 8-9

higher states, 5

influence of solubility on, 7

lower states, 6

role of crystal structure, $7^{-8}$

stabilizing influence of certain electronic configurations, 6-7

Superoxides

cesium superoxide, $26,33,34,35$, $3^{6}$

general properties, 33-35

magnetic susceptibility of sodium superoxide-sodium peroxide mixtures, 30

potassium superoxide, 26-27, 32 , $33,34,35,36$ preparation of, 26-32

rubidium superoxide, $26,33,34$, 35,36

"scsquioxides" of the alkali metals, $35-36$

sodium superoxide, $27-31$

structure of the superoxide ion, 11, 32-33

Terbium, tetrapositive, $7,113,114$

Valence inductivity, 8

Ytterbium(II)

halides, 14, 15, 108, 109

sulfate, 108

magnetic susceptibility of, 110

potential of $\mathrm{Yb}^{+2}-\mathrm{Yb}^{+3}$ couple, 109 